\title{
Nuclear Data Performance Assessment for Advanced Reactors
}

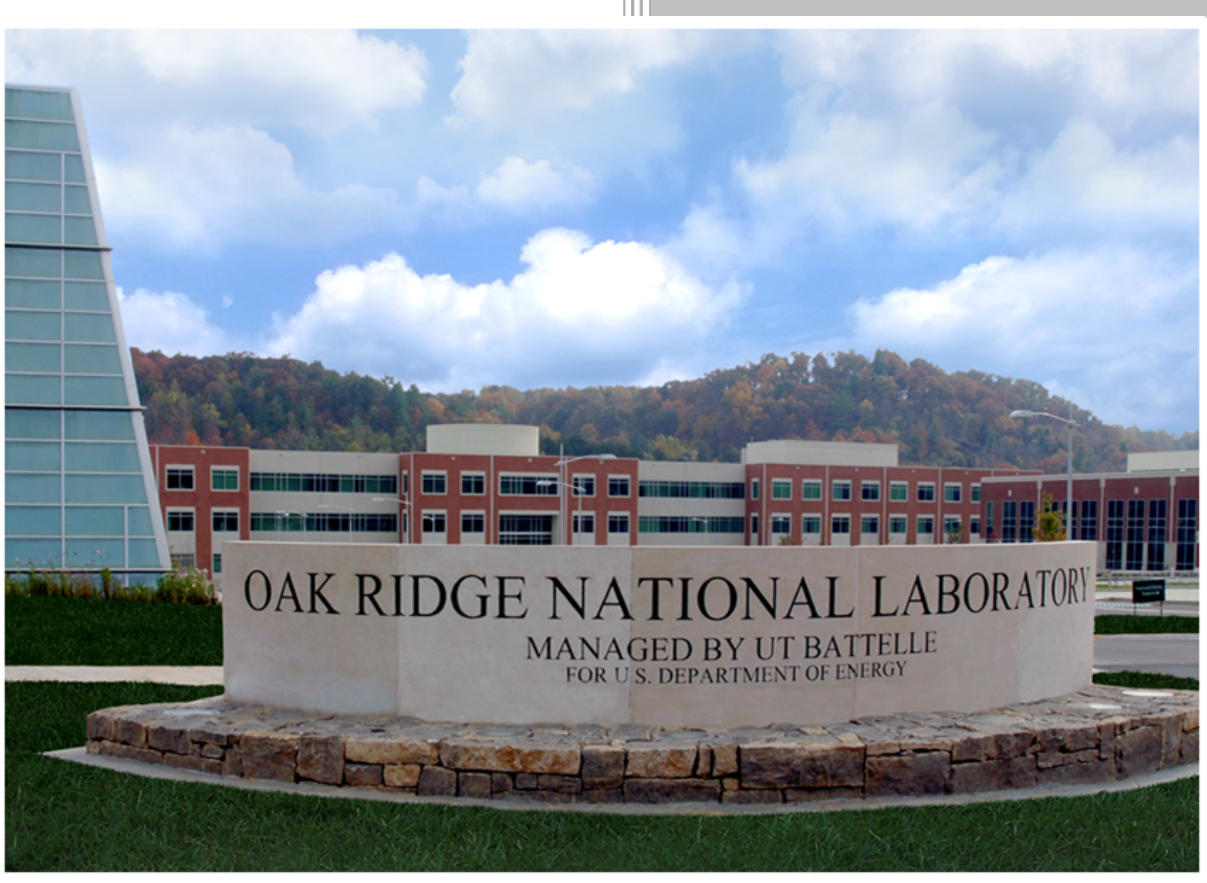

Approved for public release.

Distribution is unlimited.

Friederike Bostelmann

Andrew M. Holcomb Justin B. Clarity

William J. Marshall

Vladimir Sobes

Bradley T. Rearden

March 2019 


\title{
DOCUMENT AVAILABILITY
}

Reports produced after January 1, 1996, are generally available free via US Department of Energy (DOE) SciTech Connect.

Website www.osti.gov

Reports produced before January 1, 1996, may be purchased by members of the public from the following source:

\author{
National Technical Information Service \\ 5285 Port Royal Road \\ Springfield, VA 22161 \\ Telephone 703-605-6000 (1-800-553-6847) \\ TDD 703-487-4639 \\ Fax 703-605-6900 \\ E-mail info@ntis.gov \\ Website http://classic.ntis.gov/
}

Reports are available to DOE employees, DOE contractors, Energy Technology Data Exchange representatives, and International Nuclear Information System representatives from the following source:

Office of Scientific and Technical Information

PO Box 62

Oak Ridge, TN 37831

Telephone 865-576-8401

Fax 865-576-5728

E-mail reports@osti.gov

Website http://www.osti.gov/contact.html

This report was prepared as an account of work sponsored by an agency of the United States Government. Neither the United States Government nor any agency thereof, nor any of their employees, makes any warranty, express or implied, or assumes any legal liability or responsibility for the accuracy, completeness, or usefulness of any information, apparatus, product, or process disclosed, or represents that its use would not infringe privately owned rights. Reference herein to any specific commercial product, process, or service by trade name, trademark, manufacturer, or otherwise, does not necessarily constitute or imply its endorsement, recommendation, or favoring by the United States Government or any agency thereof. The views and opinions of authors expressed herein do not necessarily state or reflect those of the United States Government or any agency thereof. 
Reactor and Nuclear Systems Division

\section{NUCLEAR DATA PERFORMANCE ASSESSMENT FOR ADVANCED REACTORS}

Friederike Bostelmann, Andrew M. Holcomb, Justin B. Clarity, William J. Marshall, Vladimir Sobes, Bradley T. Rearden

Date Published: March 2019

Prepared by

OAK RIDGE NATIONAL LABORATORY

Oak Ridge, TN 37831-6283

managed by

UT-BATTELLE, LLC

for the

US DEPARTMENT OF ENERGY

under contract DE-AC05-00OR22725 



\section{CONTENTS}

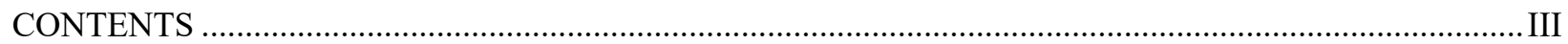

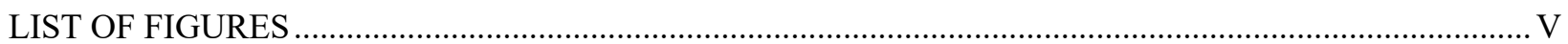

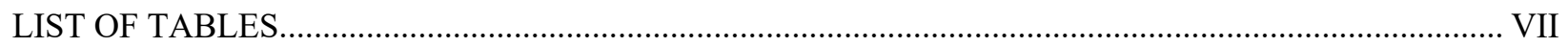

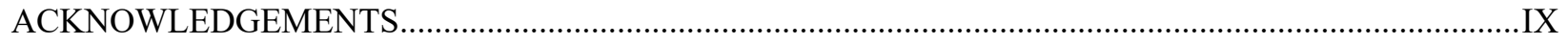

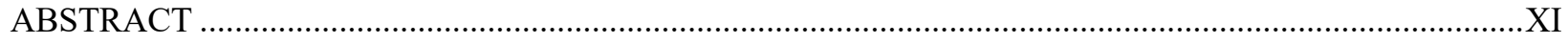

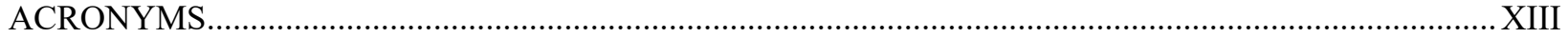

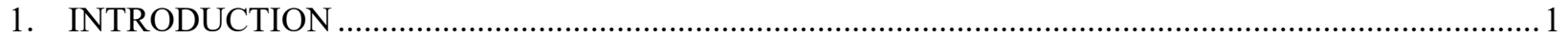

1.1 NUCLEAR DATA NEEDS FOR ADVANCED REACTOR APPLICATIONS ...................................... 1

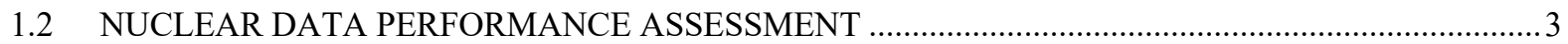

2. IMPACT OF TUNING CROSS SECTION DATA INTEGRAL BENCHMARKS …...............................5

3. NUCLEAR DATA PERFORMANCE ASSESSMENT ON ADVANCED REACTOR SYSTEMS .......... 12

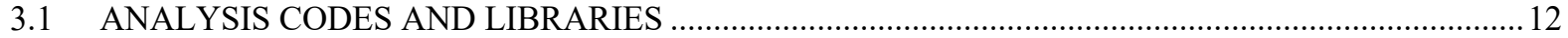

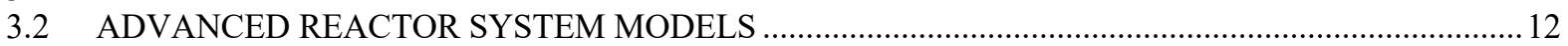

3.2.1 OECD/NEA UAM SFR Benchmark: MET1000 Fuel Assembly.......................................................12

3.2.2 OECD/NEA UAM SFR Benchmark: MOX3600 Fuel Assembly ................................................... 14

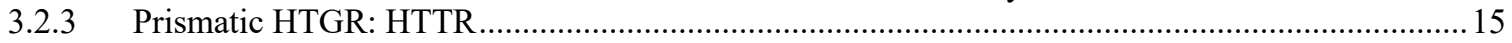

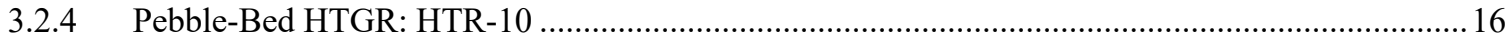

3.2.5 Graphite-Moderated MSR Unit Cell …………....................................................................... 18

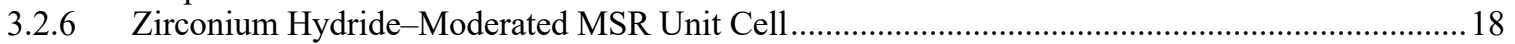

3.2.7 Fast Spectrum MSR Mixture ……………...................................................................... 19

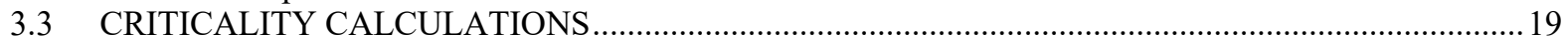

3.3.1 OECD/NEA UAM SFR Benchmark: MET1000 Fuel Assembly...................................................19

3.3.2 OECD/NEA UAM SFR Benchmark: MOX3600 Fuel Assembly.................................................22

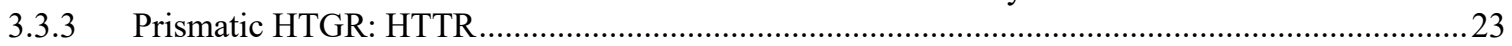

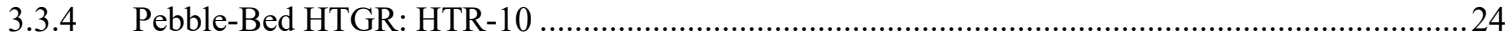

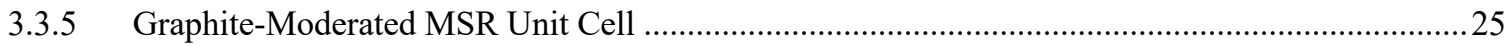

3.3.6 Zirconium Hydride-Moderated MSR Unit Cell ..........................................................................2. 26

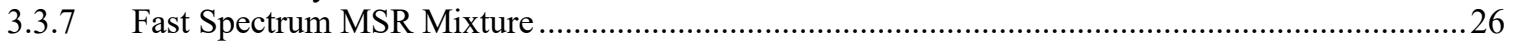

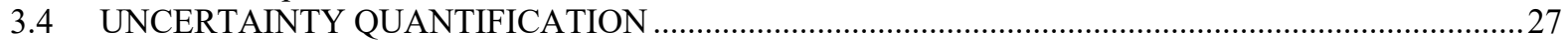

3.4.1 OECD/NEA UAM SFR Benchmark: MET1000 Fuel Assembly .................................................2

3.4.2 OECD/NEA UAM SFR Benchmark: MOX3600 Fuel Assembly .................................................2

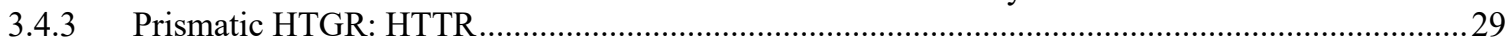

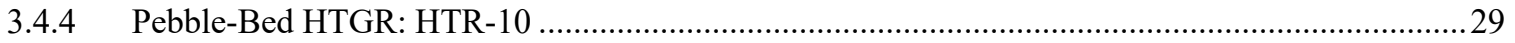

3.4.5 Graphite-Moderated MSR Unit Cell ......................................................................................29

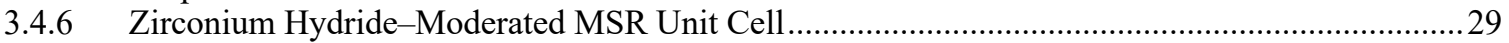

3.4.7 Fast-Spectrum MSR Mixture _............................................................................................. 30

4. IMPACT OF CROSS SECTION LIBRARIES ON PIN POWER DISTRIBUTIONS ............................31

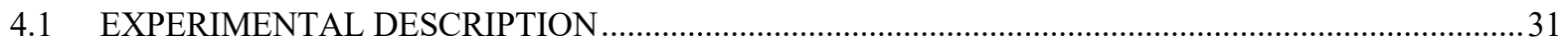

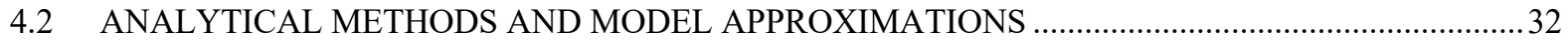

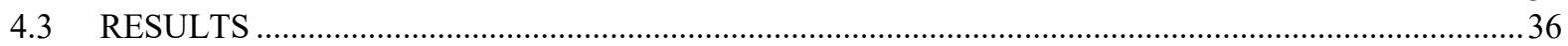

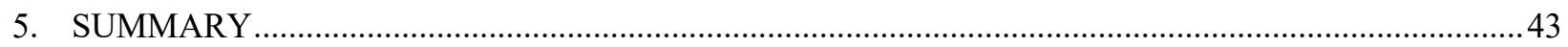

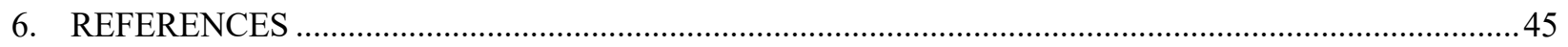

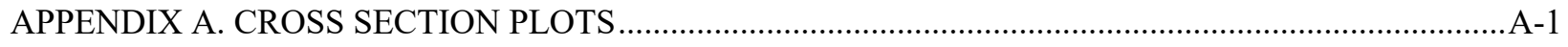

APPENDIX B. CROSS SECTION UNCERTAINTY PLOTS ...................................................................... B-1 



\section{LIST OF FIGURES}

Figure 1. Calculated flux spectra for several reactor concepts............................................................. 1

Figure 2. Neutron capture cross section of ${ }^{235} \mathrm{U}$ (left axis) and the relative uncertainty (right axis)............2 Figure 3. Demonstration of compensating errors between isotopes in ENDF/B-VII.1 and ENDF/B-

VIII.0: The uppermost eigenvalue is obtained when using only ENDF/B-VII.1 data................... 6

Figure 4. Demonstration of compensating errors between isotopes in ENDF/B-VIII.0 and ENDF/B-

VII.1: The uppermost eigenvalue is obtained when using only ENDF/B-VIII.0 data................... 7

Figure 5. Relative differences between ENDF/B-VII.1 and ENDF/B-VIII.0 for ${ }^{1} \mathrm{H}$ cross sections. ............ 8

Figure 6. Relative differences between ENDF/B-VII.1 and ENDF/B-VIII.0 for ${ }^{16} \mathrm{O}$ cross sections............ 8

Figure 7. Relative differences between ENDF/B-VII.1 and ENDF/B-VIII.0 for ${ }^{56} \mathrm{Fe}$ cross sections.

Figure 8. Relative differences between ENDF/B-VII.1 and ENDF/B-VIII.0 for ${ }^{235} \mathrm{U}$ cross sections.

Figure 9. Relative differences between ENDF/B-VII.1 and ENDF/B-VIII.0 for ${ }^{238} \mathrm{U}$ cross sections.

10

Figure 10. Relative differences between ENDF/B-VII.1 and ENDF/B-VIII.0 for ${ }^{239} \mathrm{Pu}$ cross

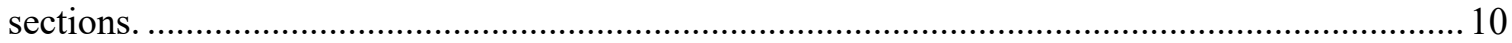

Figure 11. Relative differences of the ${ }^{235} \mathrm{U},{ }^{238} \mathrm{U}$ and ${ }^{239} \mathrm{Pu}$ neutron multiplicities between ENDF/B-

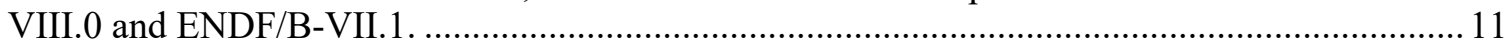

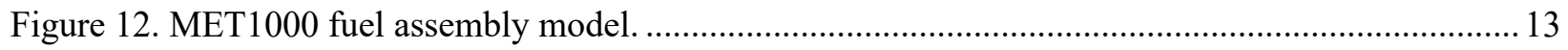

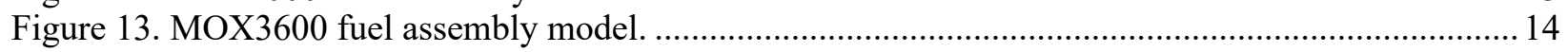

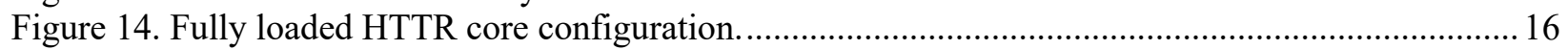

Figure 15. HTR-10: horizontal cross sectional view of SCALE model. ................................................. 17

Figure 16. HTR-10: vertical view of SCALE model...................................................................... 17

Figure 17. HTR-10 fuel pebble model including TRISO particles in a square lattice without particle

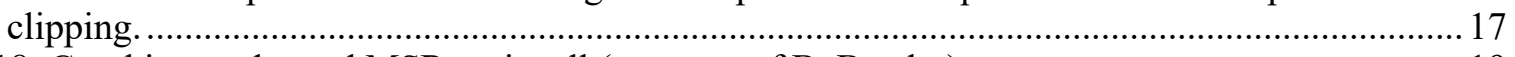

Figure 18. Graphite-moderated MSR unit cell (courtesy of B. Betzler).............................................. 19

Figure 19. MSR unit cell with fuel salt moderated by ZrH rods (courtesy of B. Betzler)....................... 19

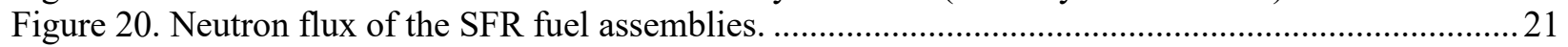

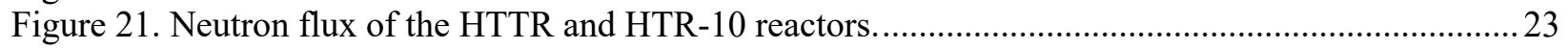

Figure 22. Neutron flux of the graphite-moderated MSR unit cell. ....................................................25

Figure 23. Neutron flux of the ZrH-moderated MSR unit cell ..............................................................26

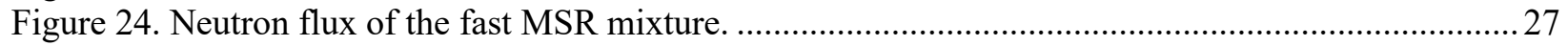

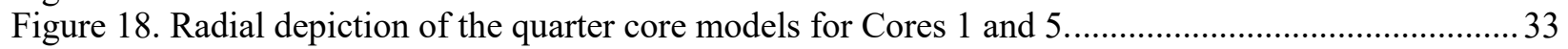

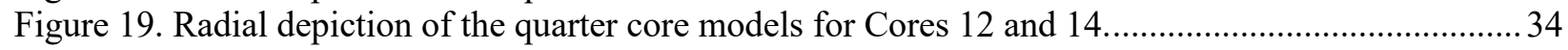

Figure 20. Radial depiction of the quarter core models for Cores 18 and 20...................................... 35

Figure 21. Left two columns: Differences of the calculated central pin powers to the BAW-1810 experimental results with ENDF/B-VII.1 and ENDF/B-VIII.0 nuclear data, respectively. Right column: Differences between the ENDF/B-VII.1 and ENDF/B-VIII pin powers............... 38

Figure 22. Relative difference of calculated central pin powers using ENDF/B-VII.1 data to the experimental values along the diagonal of BAW-1810 calculated. ................................................ 39

Figure 23. Relative difference of calculated central pin powers using ENDF/B-VIII.0 data to the experimental values along the diagonal of BAW-1810 calculated............................................. 39

Figure 24. Differences of calculated central pin powers for the BAW-1810 experiments between ENDF/B-VII.1 and ENDF/B-VIII.0 nuclear data for the case with depleted fuel isotopic compositions.

Figure 25. Differences between ENDF/B/VII.1 and ENDF/B-VIII.0 calculated pin powers for the case with depleted fuel isotopic compositions.

Figure A-1. Elastic scattering of ${ }^{1} \mathrm{H}$ compared between ENDF/B-VII.1 and ENDF/B-VIII.0 ................A-1

Figure A-2. Elastic scattering of ${ }^{16} \mathrm{O}$ compared between ENDF/B-VII.1 and ENDF/B-VIII.0...............A-1 
Figure A-3. Radiative capture of ${ }^{16} \mathrm{O}$ compared between ENDF/B-VII.1 and ENDF/B-VIII.0.

Figure A-4. Radiative capture of ${ }^{56} \mathrm{Fe}$ compared between ENDF/B-VII.1 and ENDF/B-VIII.0.

Figure A-5. Fission cross section of ${ }^{235} \mathrm{U}$ compared between ENDF/B-VII.1 and ENDF/B-VIII.0.

Figure A-6. Radiative capture cross section of ${ }^{235} \mathrm{U}$ compared between ENDF/B-VII.1 and ENDF/B-VIII.0.

Figure A-7. Neutron multiplicity of ${ }^{235} \mathrm{U}$ compared between ENDF/B-VII.1 and ENDF/B-VIII.0.........A-4

Figure A-8. Fission cross section of ${ }^{238} \mathrm{U}$ compared between ENDF/B-VII.1 and ENDF/B-VIII.0.........A-4

Figure A-9. Radiative capture cross section of ${ }^{238} \mathrm{U}$ compared between ENDF/B-VII.1 and ENDF/B-VIII.0.

Figure A-10. Neutron multiplicity of ${ }^{238} \mathrm{U}$ compared between ENDF/B-VII.1 and ENDF/B-VIII.0.......A-5

Figure A-11. Fission cross section of ${ }^{239} \mathrm{Pu}$ compared between ENDF/B-VII.1 and ENDF/B-VIII.0.

Figure A-12. Radiative capture cross section of ${ }^{239} \mathrm{Pu}$ compared between ENDF/B-VII.1 and ENDF/B-VIII.0.

Figure A-13. Neutron multiplicity of ${ }^{239} \mathrm{Pu}$ compared between ENDF/B-VII.1 and ENDF/B-VIII.0.

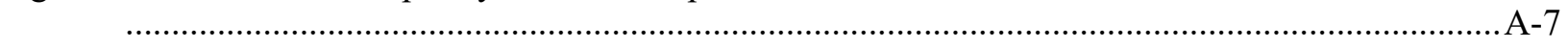

Figure A-14. Carbon capture cross section compared between the ENDF/B releases................................. A-7

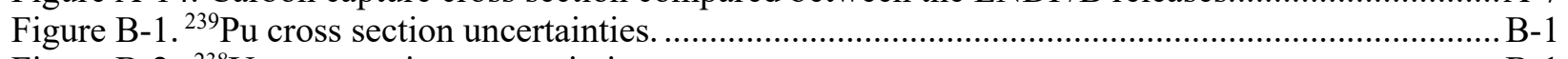

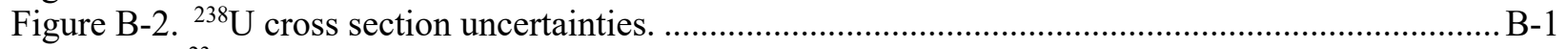

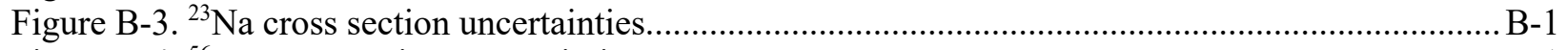

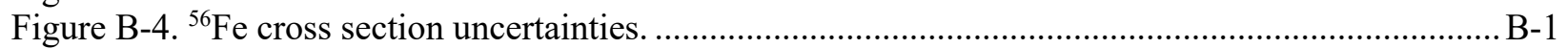

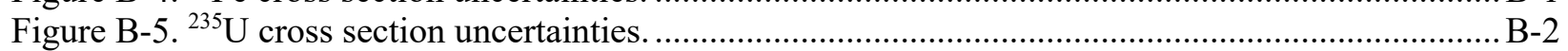

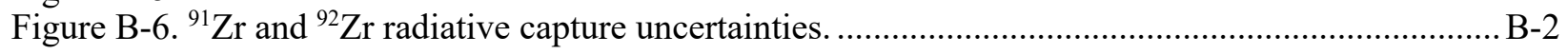

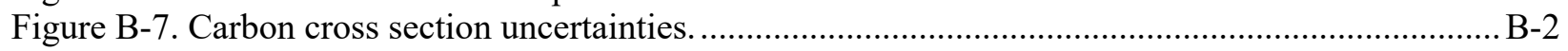




\section{LIST OF TABLES}

Table 1. Dimensions of the MET1000 fuel assembly ......................................................................... 13

Table 2. Material compositions of the MET1000 fuel assembly ......................................................... 13

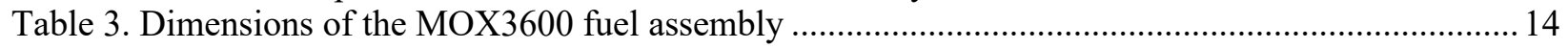

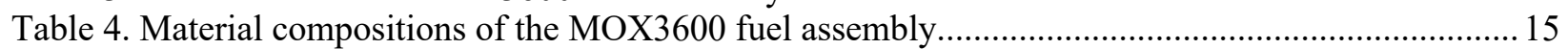

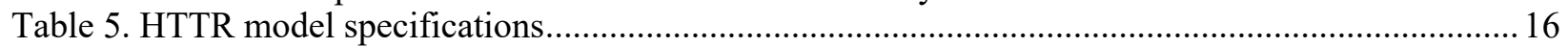

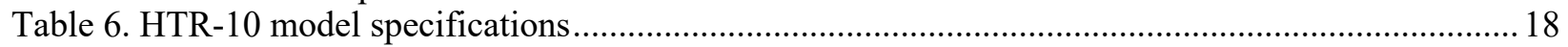

Table 7. Fresh graphite-moderated MSR unit cell compositions ........................................................ 18

Table 8. Fresh ZrH-moderated MSR unit cell compositions............................................................... 18

Table 9. Fresh fast-spectrum MSR mixture composition........................................................................ 19

Table 10. Calculated MET1000 fuel assembly eigenvalues with $1 \sigma$ statistical error ..............................20

Table 11. Calculated MET1000 fuel assembly Doppler constant with $1 \sigma$ statistical error.........................21

Table 12. Calculated MET1000 fuel assembly sodium void worth with $1 \sigma$ statistical error .....................21

Table 13. Calculated MOX3600 fuel assembly eigenvalues with $1 \sigma$ statistical error ..............................22

Table 14. Calculated MOX3600 fuel assembly Doppler coefficient with $1 \sigma$ statistical error ....................22

Table 15. Calculated MOX3600 fuel assembly sodium void worth with $1 \sigma$ statistical error .....................22

Table 16. Eigenvalue comparisons of the fully loaded HTTR core configuration (DH: double-het).........23

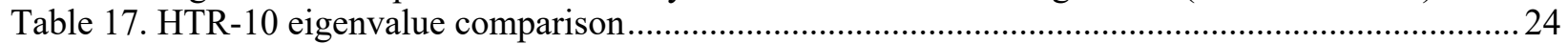

Table 18. Calculated HTR-10 KENO-VI CE results using different ENDF/B-VIII.0 graphite

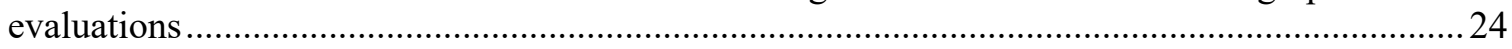

Table 19. Calculated eigenvalues of the graphite-moderated MSR unit cell ............................................25

Table 20. Calculated eigenvalues of the zirconium hydride-moderated MSR unit cell ..........................26

Table 21. Calculated eigenvalues of the fast-spectrum MSR mixture ..................................................2

Table 22. Nominal values and uncertainties due to nuclear data the MET1000 fuel assembly

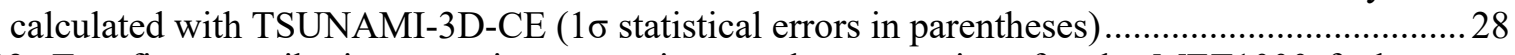

Table 23. Top five contributing covariance matrices to the uncertainty for the MET1000 fuel assembly calculated with TSUNAMI-3D-CE ( $1 \sigma$ statistical errors in parentheses $)$.......................28

Table 24. Nominal values and uncertainties due to nuclear data of the MOX3600 fuel assembly calculated with TSUNAMI-3D-CE ( $1 \sigma$ statistical errors in parentheses) ....................................28

Table 25. Top five contributing covariance matrices to the uncertainty for the MOX3600 fuel assembly calculated with TSUNAMI-3D-CE ( $1 \sigma$ statistical errors in parentheses) .....................28

Table 26. Top five contributing covariance matrices to the HTTR and HTR-10 eigenvalue uncertainty calculated with TSUNAMI-3D-CE ( $1 \sigma$ statistical errors in parentheses) ...................29

Table 27. Top five contributing covariance matrices to the graphite-moderated MSR eigenvalue uncertainties calculated with TSUNAMI-3D-CE ( $1 \sigma$ statistical errors in parentheses) ...............29

Table 28. Top five contributing covariance matrices to the $\mathrm{ZrH}$-moderated MSR eigenvalue uncertainties calculated with TSUNAMI-3D-CE ( $1 \sigma$ statistical errors in parentheses) ...............29

Table 29. Top five contributing covariance matrices to the fast-spectrum MSR eigenvalue uncertainties calculated with TSUNAMI-3D-CE ( $1 \sigma$ statistical errors in parentheses) .................30

Table 30. Characteristics of the analyzed BAW-1810 core ........................................................................ 32

Table 31. Calculated central pin power results for the BAW-1810 cores using the ENDF/B-VII.1 library

Table 32. Calculated central pin power results for the BAW-1810 cores using the ENDF/B-VIII.0 library 



\section{ACKNOWLEDGEMENTS}

The authors would like to thank Benjamin R. Betzler (ORNL) for providing the SCALE input files for the molten salt reactor models. Those input files were generated under the Fuel Cycle Options campaign and the GAIN initiative. This work was sponsored by the US Department of Energy, Office of Nuclear Energy. 



\begin{abstract}
Over the last several Evaluated Nuclear Data File (ENDF)/B releases, many updates have been introduced to the nuclear data libraries that can significantly change computational results. These changes can be particularly important for advanced reactor concepts, which are not as thoroughly investigated as those used in light water reactor (LWR) systems. Therefore, a performance assessment of the ENDF/B libraries using the SCALE 6.2.3 code package was conducted under the auspices of the U.S., Department of Energy Office of Nuclear Energy (DOE-NE). The following systems relevant to the advanced reactor community were chosen as subject for investigation in this report: sodium cooled fast reactor systems, graphite moderated high temperature gas-cooled reactors, and several molten salt reactor models.
\end{abstract}

At first, the similarity of the integral performance of the ENDF/B-VII.1 and ENDF/B-VIII.0 nuclear data libraries caused by compensating errors in important differential data was demonstrated. In calculations for a shipping container of high-assay low enriched uranium, the data of individual isotopes were systematically swapped between the two ENDF/B libraries. An eigenvalue difference of up to $450 \mathrm{pcm}$ was found due to the use of ${ }^{235} \mathrm{U}$ and ${ }^{238} \mathrm{U}$ from one library and ${ }^{1} \mathrm{H}$ and ${ }^{16} \mathrm{O}$ from the other library. This clearly demonstrates a cross-correlation between reaction data sets of different isotopes within a library that should be reported in the evaluations.

For sodium-cooled fast reactor (SFR) fuel assemblies, significant eigenvalue $\left(\mathrm{k}_{\mathrm{inf}}\right)$ differences $(200-$ $450 \mathrm{pcm}$ ) were found between calculations using the $2011 \mathrm{ENDF} / \mathrm{B}-\mathrm{VII} .1$ data and $2018 \mathrm{ENDF} / \mathrm{B}-\mathrm{VIII} .0$ data. These differences were mainly caused by updates of ${ }^{238} \mathrm{U}$ and ${ }^{239} \mathrm{Pu}$ neutron cross sections. Results from the multigroup (MG) calculations further revealed that the group structure of the applied MG library strongly influences the MG bias due to the importance of an appropriate energy resolution of the resonances in higher energy ranges. The application of previously used MG libraries requires new verification for advanced reactor simulation in comparisons with reference continuous-energy calculations.

Nuclear data uncertainty analyses of these SFR systems resulted in eigenvalue uncertainties between 1,400 and $1,800 \mathrm{pcm}$, which are three to four times higher than corresponding uncertainties in light water reactor (LWR) systems. The main contributor to this uncertainty was found to be inelastic scattering on ${ }^{238} \mathrm{U}$, which shows an uncertainty of up to $50 \%$ in the fast energy range. Other important contributors are the scattering reactions of ${ }^{56} \mathrm{Fe}$ and ${ }^{23} \mathrm{Na}$ which have so far not appeared in LWR analysis. Since the largest contribution to the eigenvalue uncertainty of SFR systems is coming from scattering reactions, it is expected that uncertainties in the angular scattering distributions also have a significant impact. Those uncertainties are, however, not available for the majority of nuclides, and the capabilities to determine sensitivities to this data are currently underdeveloped.

For two graphite moderated high temperature gas-cooled reactor (HTGR) benchmarks, only the ENDF/BVII.1 calculations resulted in consistent eigenvalues $\left(\mathrm{k}_{\mathrm{eff}}\right)$ with the corresponding experimental measurements. Eigenvalue differences of about $1,000 \mathrm{pcm}$ were found between the $2006 \mathrm{ENDF} / \mathrm{B}-\mathrm{VII} .0$ data and the $2011 \mathrm{ENDF} / \mathrm{B}-\mathrm{VII} .1$ data, primarily due to an updated carbon capture cross section in the thermal energy range in the later ENDF/B release. The ENDF/B-VIII.0 eigenvalue was larger than the ENDF/B-VII.1 eigenvalue by about 300 pcm mainly due to updates in multiple ${ }^{235} \mathrm{U}$ neutron cross sections, with offsetting updates in the ${ }^{238} \mathrm{U}$ cross sections.

With ENDF/B-VIII.0, graphite can be modeled as perfect crystal or with two different porosities. The choice of the graphite evaluation can have a significant influence of the eigenvalue. For a HTGR benchmark, maximum eigenvalue differences as high as $650 \mathrm{pcm}$ due to different porosities were observed. More detailed studies of the impact of the porosity are necessary while considering that the graphite porosity can vary between the used materials and changes as a function of neutron fluence. 
The uncertainty of the HTGR eigenvalues due to nuclear data uncertainties was found between 500 and $600 \mathrm{pcm}$, with the top contributor being the neutron multiplicity of ${ }^{235} \mathrm{U}$. A gap in the form of missing uncertainties in graphite thermal scattering data, that might have significant impact on HTGR reactors, was identified. This gap is being investigated by the DOE-NE Nuclear Data and Benchmarking Program, as documented in a separate report

The fast spectrum molten salt reactor calculations revealed similar comparisons as for the SFR assemblies. The eigenvalue uncertainties were significantly influenced by inelastic scattering on ${ }^{238} \mathrm{U}$, while the impact of angular scattering distributions is unknown. For the graphite and zirconium hydride moderated system, eigenvalue uncertainties of up to $700 \mathrm{pcm}$ were observed, requiring in depth analyses of the cross sections and corresponding uncertainties of the included materials. In general, it was observed that the flux spectra of the various molten salt reactor systems show significant differences, even between a fresh state and a depleted state. The choice of the energy group structure of MG calculations is therefore highly relevant; the applicability of previously used MG libraries needs to be verified.

Due the unavailability of pin power measurements of advanced reactor systems, pin power calculations with both ENDF/B-VII.1 and VIII.0 data were performed for a light water reactor and compared to corresponding measurements. Both calculations show good agreement with the measurements. A comparison between the ENDF/B-VII.1 and VIII.0 results revealed small differences, mostly in the range of about $0.2 \%$. 


\section{ACRONYMS}

\begin{tabular}{ll} 
1D & one-dimensional \\
2D & two-dimensional \\
CE & continuous energy \\
DoD & US Department of Defense \\
DOE & US Department of Energy \\
DOE-NE & DOE Office of Nuclear Energy \\
DOE-SC & DOE Office of Science \\
ENDF & Evaluated Nuclear Data Format \\
EOEC & end of equilibrium cycle \\
GRS & Global Research for Safety \\
HTGR & high-temperature gas-cooled reactor \\
HTTR & high-temperature engineering test reactor \\
ICSBEP & International Criticality Safety Benchmark Evaluation Project \\
IRPhEP & The International Reactor Physics Experiment Evaluation Project \\
LEU & low enriched uranium \\
LWR & light water reactor \\
MSR & molten salt reactor \\
MG & multigroup \\
NA-22 & Office of Defense Nuclear Nonproliferation \\
NCSP & Nuclear Criticality Safety Program \\
NEA & Nuclear Energy Agency \\
NEET & Nuclear Energy Enabling Technology \\
NEUP & Nuclear Energy University Program \\
NNSA & National Nuclear Security Administration \\
NRC & US Nuclear Regulatory Commission \\
OECD & Organisation for Economic Co-operation and Development \\
ORNL & Oak Ridge National Laboratory \\
RMS & root mean square \\
SFR & sodium-cooled fast reactor \\
UAM & Benchmark for Uncertainty Analysis in Modeling \\
XSUSA & Cross Section Uncertainty and Sensitivity Analysis \\
ZrH & zirconium hydride \\
\hline
\end{tabular}





\section{INTRODUCTION}

\subsection{Nuclear Data Needs for Advanced Reactor Applications}

Unlike light water reactors (LWRs), most advanced reactor concepts do not benefit of decades of operational experience and supporting infrastructure that lead to increased confidence in predictive results from modeling and simulation. Many advanced reactor concepts, including high-temperature gas reactors (HTGRs), fluoride salt-cooled high temperature reactors (FHRs), liquid fueled molten salt reactors (MSRs), sodium fast reactors (SFRs), and microreactors, implement unique materials and neutron spectra that do not realize the full benefit of decades of LWR operational experience. Advanced reactors push the envelope of very high burnup and high assay Low Enriched Uranium (LEU) fuel. Further nontraditional fuel forms and general lack of experienced analysts who understand design and safety aspects of these systems all present challenges for the advanced reactor community.

The current economic and regulatory environment does not allow rapid prototyping and construction of test and demonstration nuclear power plants for the proposed advanced reactors that was available for the LWR concepts at the dawn of the nuclear-power-age. Therefore, the advanced reactor concepts must now rely much more on advanced modeling and simulation tools to understand and predict the behavior of their reactor design. The accuracy of the predictions of modern modeling and simulation software, in particular for the neutronics analysis of nuclear reactors, is almost entirely dependent on the quality of the physics parameters implemented in the simulation. For the case of neutronics analysis, this input data is the fundamental nuclear data. Due to differences in neutron spectra and materials, many advanced reactor concepts rely on different aspects of nuclear data than traditional LWRs. Figure 1 presents a comparison of the representative flux profiles for a traditional LWR versus several advanced reactor concepts. Figure 2 presents the neutron capture cross section for ${ }^{235} \mathrm{U}$ and the associated evaluated uncertainty referenced to the right axis.

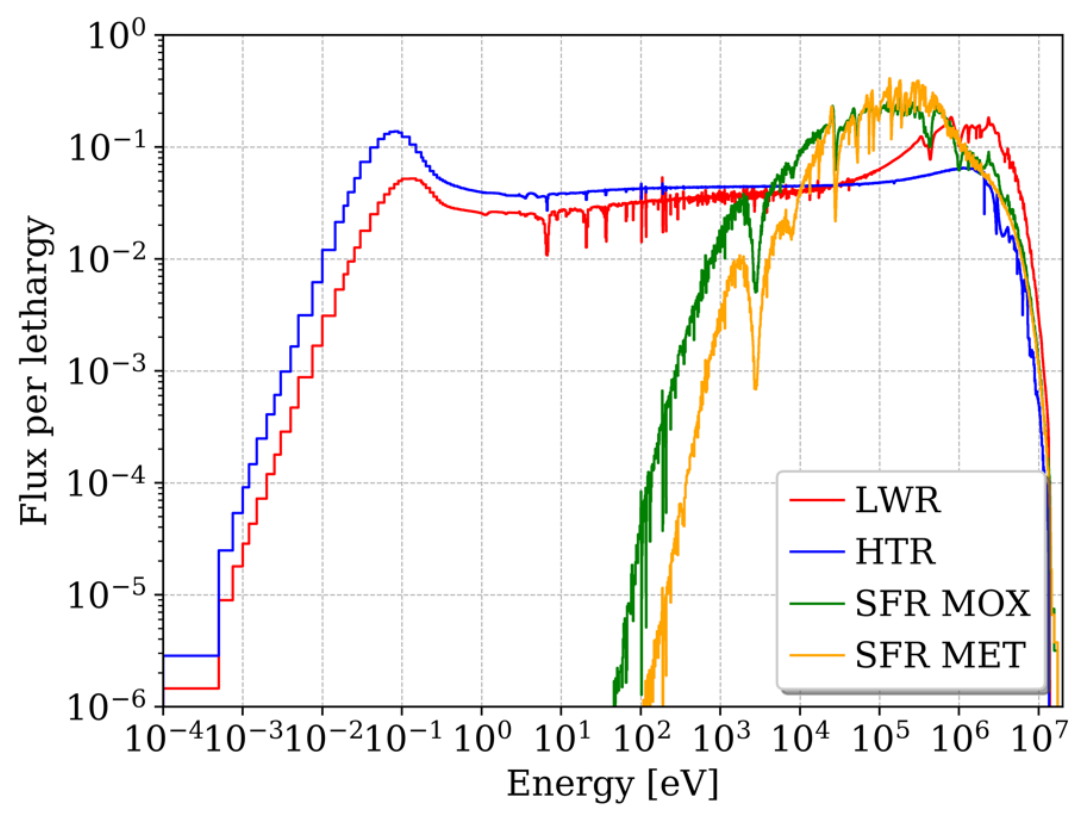

Figure 1. Calculated flux spectra for several reactor concepts. 


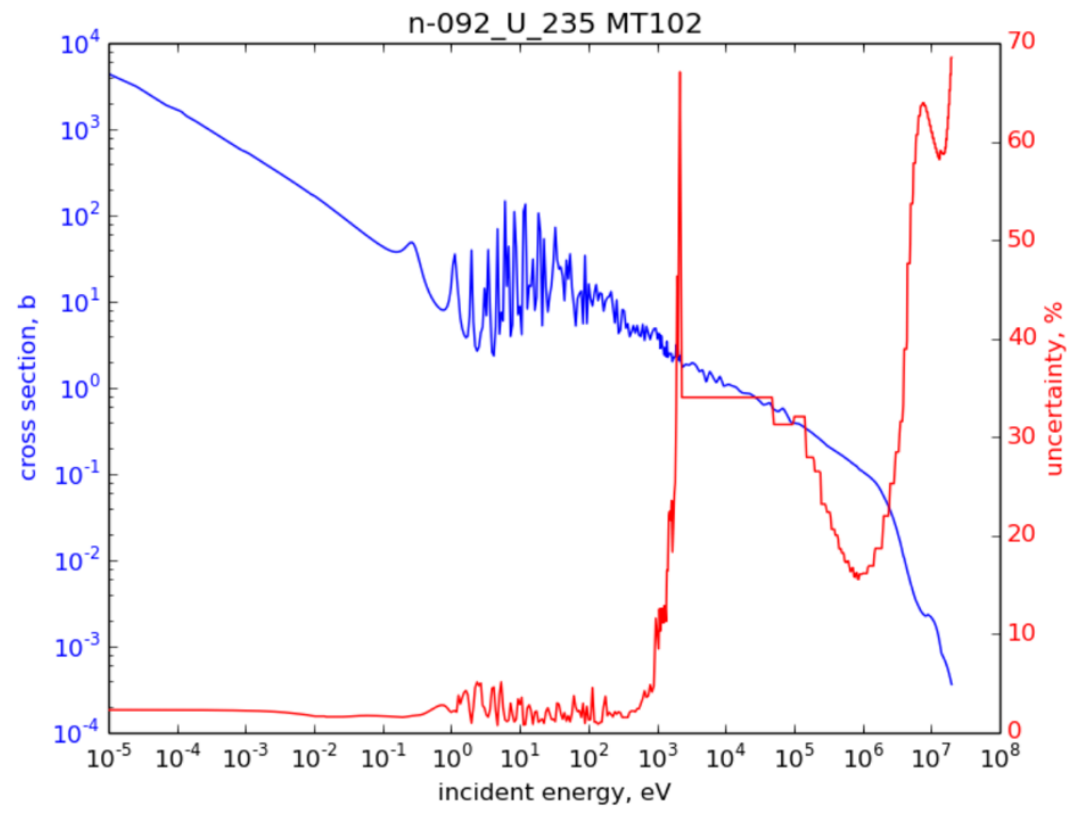

Figure 2. Neutron capture cross section of ${ }^{235} \mathrm{U}$ (left axis) and the relative uncertainty (right axis).

Notice that while the uncertainty on the capture cross section of ${ }^{235} \mathrm{U}$ is small, on the order of $5 \%$, in the energy region corresponding the peak in the LWR flux spectrum, the uncertainty spikes up to above $60 \%$ in the energy regions corresponding the calculate flux spectra for the SFR designs. This example demonstrates that even through nuclear data are well known for the important aspects for one reactor concept, that same nuclear data may not be well known in the important aspects of another reactor concept, even for perhaps the best studied nucleus of all, ${ }^{235} \mathrm{U}$.

In the recent decades nuclear data development has been supported by specific programs such as the US DOE Office of Nuclear Physics (DOE-NP), US DOE Nuclear Criticality Safety Program (NCSP), Office of Defense Nuclear Nonproliferation Research \& Development (DNN R\&D, NA-22), US DOE Office of Naval Reactors (DOE-NR), Defense Treat Reduction Agency (DTRA), as well as international organizations such as the International Atomic Energy Agency (IAEA). Activities supported by these programs have produced new differential physics experiments, data processing and comparison to and optimization with applications in their interest. One of the key issues is that when nuclear data research, seemingly a fundamental physical pursuit, is funded by specific programs with particular application interests, the evaluation of the updated nuclear data is biased to subjective to best meet the application needs of the sponsoring organization. Therefore, if the updated nuclear data benefit, or do not disrupt, applications of interest to these agencies, the new evaluation is approved and accepted into the National Nuclear Data Center for distribution with the next revision of ENDF. Notably absent from the list of agencies that sponsor nuclear data activities are the US DOE Office of Nuclear Energy (DOE-NE) and the US Nuclear Regulatory Commission (NRC).

The Nuclear Data and Benchmarking program was proposed in 2018 as a new Nuclear Energy Enabling Technology Crosscutting Program (NEET) supported DOE-NE. The goal of the program is to partner with industry, the NRC and other programs to improve nuclear data and benchmarking of modeling and simulation for the advanced reactors in the US. This program aims to achieve this by, 1) Identifying the priority needs for nuclear data and benchmarking 2) performing new data measurements and evaluations 3) supporting integral experiments and handbooks and 4) participating in application benchmark studies. 
In Fiscal Year 2018 (FY18) the DOE-NE Nuclear Data and Benchmarking Program was organized into 4 categories, 1) nuclear data and validation studies, 2) nuclear data generation, 3) international benchmarking activities 4) university projects. In the first of these categories, nuclear data and validation studies, a gap analysis of nuclear data was performed for non-LWR reactors and the validation basis, from the nuclear data perspective, for the transportation of high-assay LEU is investigated. The results of these studies are subject of this report.

In the second category, on the generation of new nuclear data, three tasks were performed. The first was investigation and generation of application driven covariance data, which is the topic of a companion report (Sobes, et al, 2018). The second was improvements of nuclear data for depletion, activation, and decay. Finally, a new nuclear data measurement for the ${ }^{238} \mathrm{U}(\mathrm{n}, \mathrm{n}$ ') reaction with the associated uncertainty estimated was awarded through competitive award issued under a Funding Opportunity Announcement issued under the auspices of the Nuclear Data Interagency Working Group (NDIWG), in collaboration with DOE-NP.

In the third category, the Nuclear Data and Benchmarking Program supported the international collaboration for Multi-Physics Experimental Data, Benchmark, and Validation as well as the International Physics Benchmark Programs: the International Criticality Safety Benchmark Evaluation Project (ICSBEP) and International Reactor Physics Experiment Evaluation Project (IRPhEP). Finally, the Nuclear Data and Benchmarking Program participated in the Nuclear Energy University Program (NEUP) funding opportunity announcement and is launching two NEUP University projects researching thermal scattering law development. Namely, the generation of thermal scattering data for graphite and the generation of thermal scattering sensitivity/uncertainty capabilities. (Sobes et al, 2018)

\subsection{Nuclear Data Performance Assessment}

The last several ENDF/B releases include many updates in the nuclear data that can result in significant changes to computational results. These changes can have a significant impact on advanced reactor concepts, which are distinctively different from the materials and nuclide reactions of the historically wellinvestigated LWR systems. This report describes the performance assessment of ENDF/B libraries for systems relevant to the advanced reactor community. Uncertainties in these systems due to uncertainties in the nuclear data are assessed where feasible. Additional gaps in nuclear data for advanced reactor systems that have unknown effects on reactor calculations have been identified.

In the first section of this report, the compensating errors between isotopes in an ENDF/B library evaluation are demonstrated by systematically replacing the applied nuclear data with data from another base set. This is followed by comparisons of Monte Carlo criticality and the nuclear data uncertainty calculations of various advanced systems using different ENDF/B evaluations. Lastly, comparisons of calculated pin power distribution of an LWR with the measurements between different ENDF/B libraries are presented. 



\section{IMPACT OF TUNING CROSS SECTION DATA INTEGRAL BENCHMARKS}

For files included in the ENDF library, nuclear data evaluations are produced by providing a best-fit representation of differential measurements (Brown et al. 2018). However, it is not the "goodness" of a particular fit to differential data that is used as a performance metric of the evaluation; the evaluation's performance is measured against integral quantities of interest. For example, the performance of a new $\mathrm{n}+{ }^{235} \mathrm{U}$ evaluation may be quantified by comparing the change in the ratio of computed-to-measured $k_{\text {eff }}$ values for a series of evaluated benchmark experiments such as those compiled and maintained for the ICSBEP (Briggs et al. 2017). If the new evaluation does not produce computed results consistent with measured values, then the evaluator may change one or more parts of the evaluation within the differential measurement uncertainties to provide better agreement with the measured integral quantities. For further explanations and discussions on the generation and evaluation of nuclear data including their covariance data, it is referred to the companion report (Sobes et al, 2018).

Unfortunately, this informed adjustment of the evaluated parameterization may lead to compensation of errors between reaction data sets for a particular isotope. In turn, this results in cross section data having cross correlations between isotopes. Previously, the error compensation between reaction data sets of a particular isotope has been demonstrated with ENDF/VII.1 and JEFF-3.2 (Bauge et al. 2012). Here, a CE KENO model of a small shipping container with $20 \mathrm{w} / \mathrm{o} \mathrm{UF} 6$, ES-4100, is used to demonstrate some of the compensating errors between isotopes of the ENDF/VII.1 and ENDF/B-VIII.0 libraries. For the analysis of this system, the impact of changes to the CIELO isotopes were reviewed. The CIELO isotopes include ${ }^{1} \mathrm{H}$, ${ }^{16} \mathrm{O},{ }^{56} \mathrm{Fe},{ }^{235} \mathrm{U},{ }^{238} \mathrm{U}$, and ${ }^{239} \mathrm{Pu}$ (Chadwick et al. 2018). Various cross sections of these nuclides are shown in Appendix A based on both ENDF/B-VII.1 and ENDF/B-VIII.0. To highlight the extent of some of the updates, relative differences of these cross sections are displayed in Figure 5 to Figure 11. Significant differences can, for example, be observed for fission and capture of ${ }^{235} \mathrm{U}$ and ${ }^{238} \mathrm{U}$, as well as the neutron multiplicities of ${ }^{235} \mathrm{U}$ and ${ }^{239} \mathrm{Pu}$.

The ES-4100 cask shipping configuration did not include ${ }^{239} \mathrm{Pu}$, and it proved to be insensitive to changes in the ${ }^{56} \mathrm{Fe}$ nuclear data, so it was ultimately excluded from the analysis. For the same ES-4100 KENO model, two base sets of CE nuclear data (ENDF/B-VII.1 and ENDF/B-VIII.0) were intermingled to perform the computations. Starting with a base set of data (either ENDF/B-VII.1 or ENDF/B-VIII.0), each CIELO isotope's data was systematically replaced with the data from the other base set. Once all CIELO isotopic data had been substituted from the other base set, the CIELO isotopes were returned to their original base evaluation in the same order of their removal. Figure 3 shows the change in $k_{\text {eff }}$ relative to the base result as CIELO ENDF/B-VII.1 isotopes are replaced with their ENDF/B-VIII.0 counterparts, and Figure 4 shows the change in $k_{e f f}$ relative to the base result as CIELO ENDF/B-VIII.0 isotopes are replaced with their ENDF/B-VII.1 counterparts. The isotopes next to the arrows report the isotopic evaluation being injected into the library at that step. The statistical uncertainty on the computed $k_{e f f}$ was less than $10 \mathrm{pcm}$ for all cases.

The base ENDF/B-VII.1 and ENDF/B-VIII.0 $k_{e f f}$ results differed by less than $100 \mathrm{pcm}$, indicating a good agreement between the integral performance of each base set of isotopic evaluations. However, there is up to a $450 \mathrm{pcm}$ change in the computed $k_{\text {eff }}$ due to the use of ${ }^{235} \mathrm{U}$ and ${ }^{238} \mathrm{U}$ from one base set with ${ }^{1} \mathrm{H}$ and ${ }^{16} \mathrm{O}$ from the other base set. Furthermore, complete replacement of the CIELO isotopes leads to a change of approximately $50 \mathrm{pcm}$ in the computed $k_{e f f}$ relative to the base result. These changes in the computed $k_{e f f}$ are similar, regardless of which starting base data set is used.

Both ENDF/B-VII.1 and ENDF/B-VIII.0 have similar integral performance due to the compensating errors of important differential data between the CIELO isotopic evaluations. However, when these artificial cancellations are removed, both libraries show a similar difference in the computed $k_{e f f}$. This clearly 
demonstrates a cross correlation between reaction data sets of different isotopes within a library that should be reported in the corresponding evaluations, and call into question the use of individual cross sections for predictions of reaction rates and power distributions of interest for nuclear energy applications.

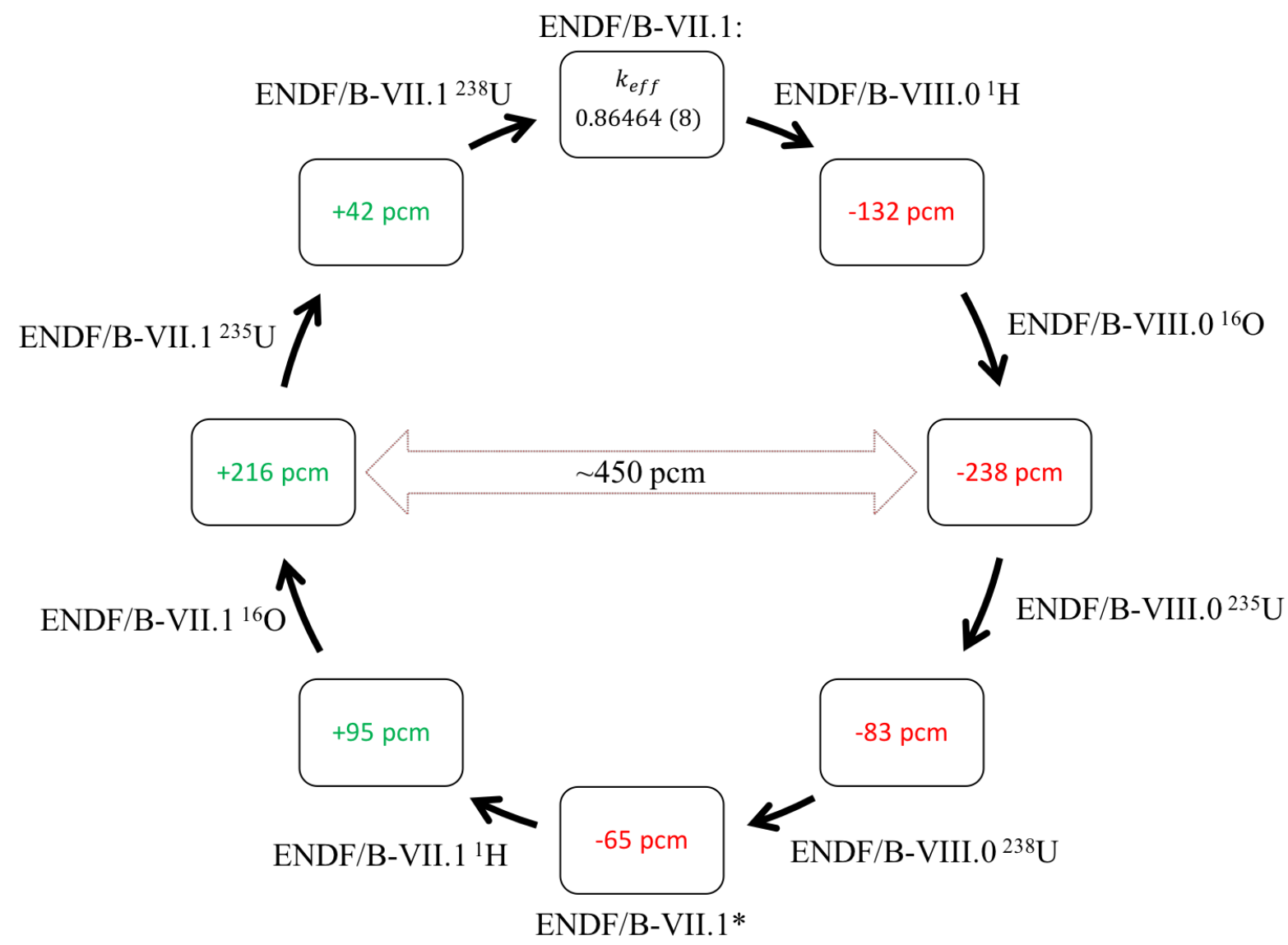

Figure 3. Demonstration of compensating errors between isotopes in ENDF/B-VII.1 and ENDF/B-VIII.0: The uppermost eigenvalue is obtained when using only ENDF/B-VII.1 data.

In clock-wise direction, the eigenvalue difference to this result is shown when gradually replacing data of individual nuclides by the corresponding different ENDF/B library evaluation. For the lowermost difference, the data for ${ }^{1} \mathrm{H}$,

${ }^{16} \mathrm{O},{ }^{235} \mathrm{U}$ and ${ }^{238} \mathrm{U}$ is taken from ENDF/B-VIII.0, but all other data from ENDF/B-VII.1. 
ENDF/B-VIII.0:

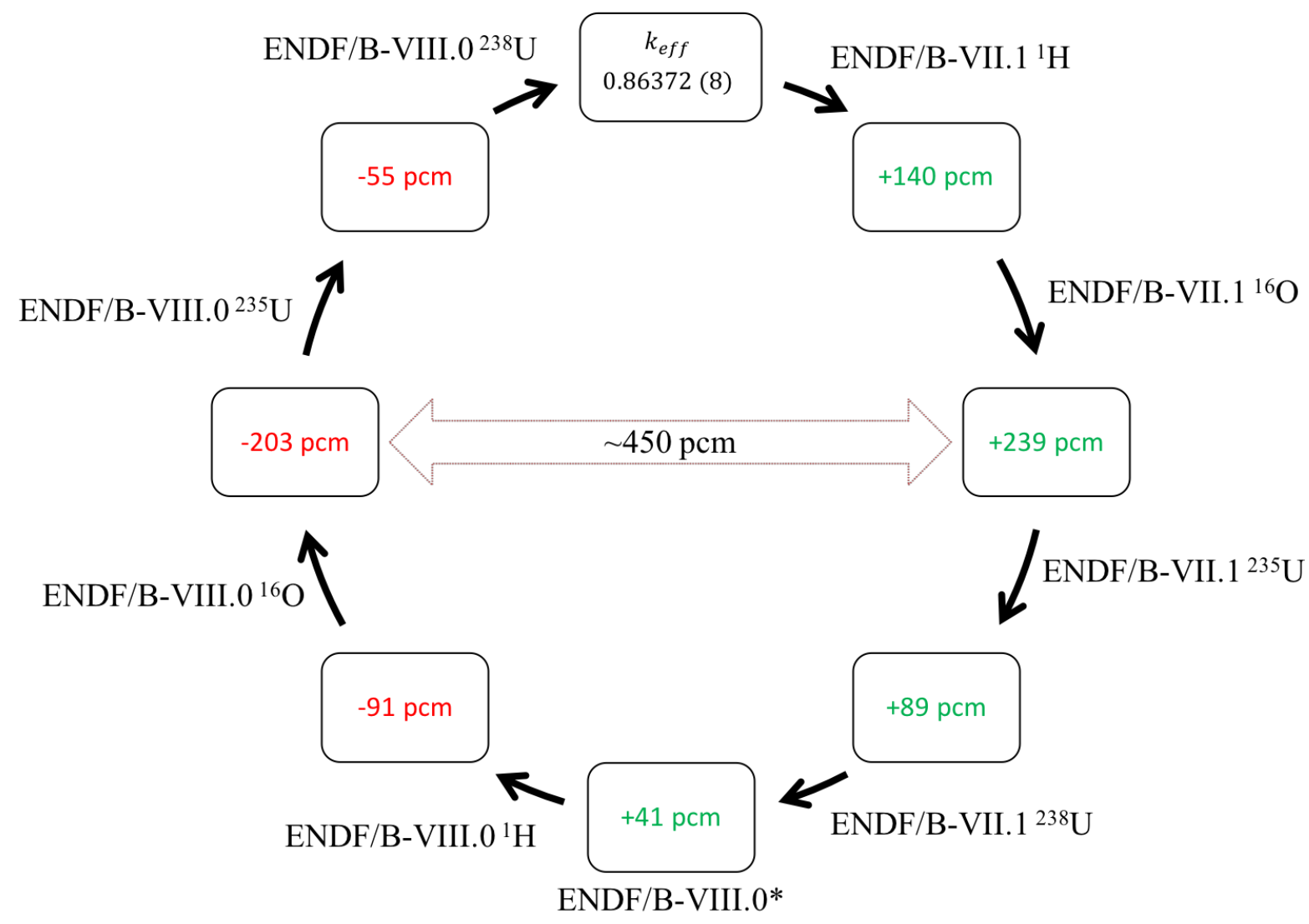

Figure 4. Demonstration of compensating errors between isotopes in ENDF/B-VIII.0 and ENDF/B-VII.1: The uppermost eigenvalue is obtained when using only ENDF/B-VIII.0 data.

In clock-wise direction, the eigenvalue difference to this result is shown when gradually replacing data of individual nuclides by the corresponding different ENDF/B library evaluation. For the lowermost difference, the data for ${ }^{1} \mathrm{H}$, ${ }^{16} \mathrm{O},{ }^{235} \mathrm{U}$ and ${ }^{238} \mathrm{U}$ is taken from ENDF/B-VII.1, but all other data from ENDF/B-VIII.0. 


\section{H1}

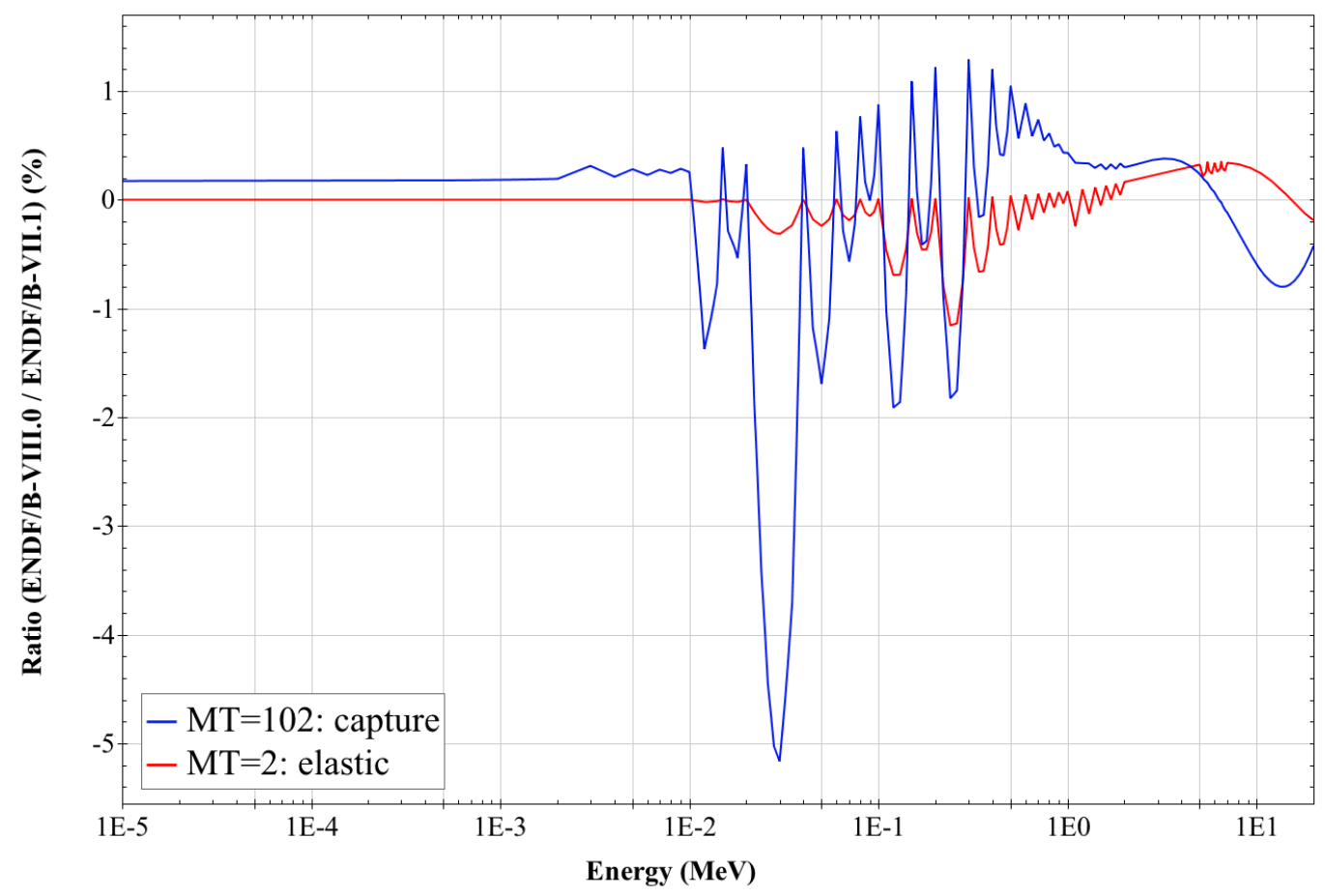

Figure 5. Relative differences between ENDF/B-VII.1 and ENDF/B-VIII.0 for ${ }^{1} \mathrm{H}$ cross sections.

\section{6}

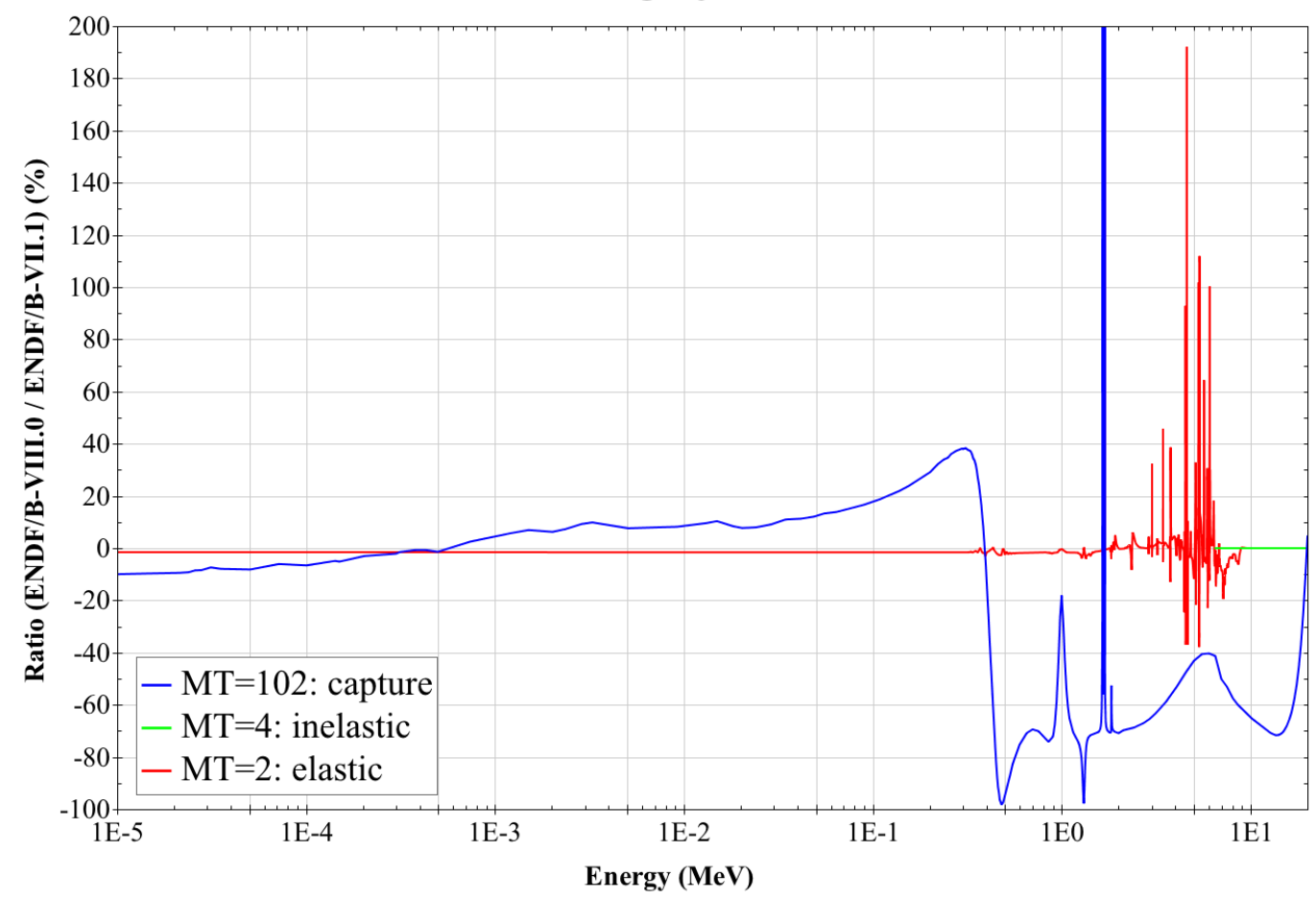

Figure 6. Relative differences between ENDF/B-VII.1 and ENDF/B-VIII.0 for ${ }^{16} \mathrm{O}$ cross sections. 


\section{Fe56}

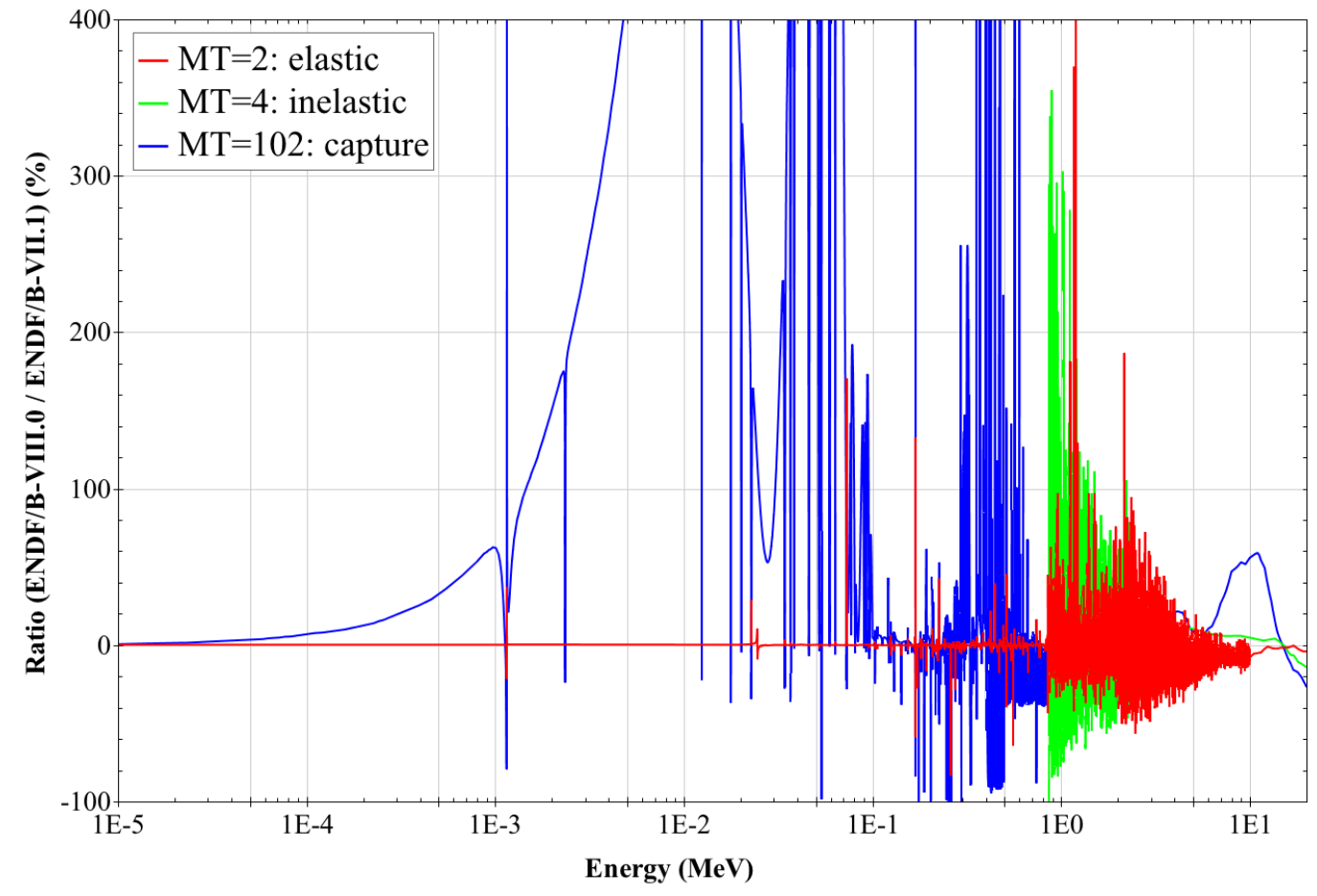

Figure 7. Relative differences between ENDF/B-VII.1 and ENDF/B-VIII.0 for ${ }^{56} \mathrm{Fe}$ cross sections.

\section{U235}

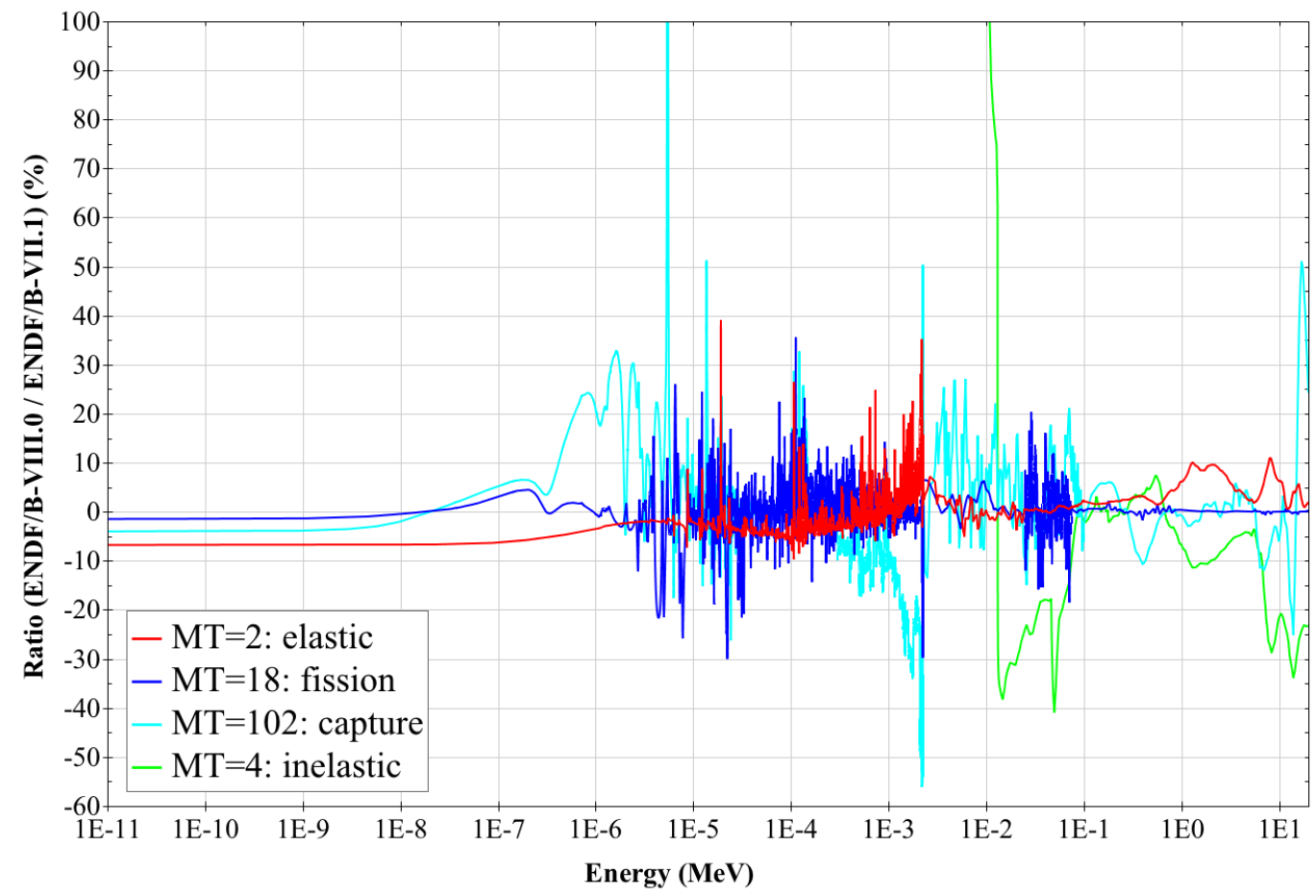

Figure 8. Relative differences between ENDF/B-VII.1 and ENDF/B-VIII.0 for ${ }^{235} \mathrm{U}$ cross sections. 


\section{U238}

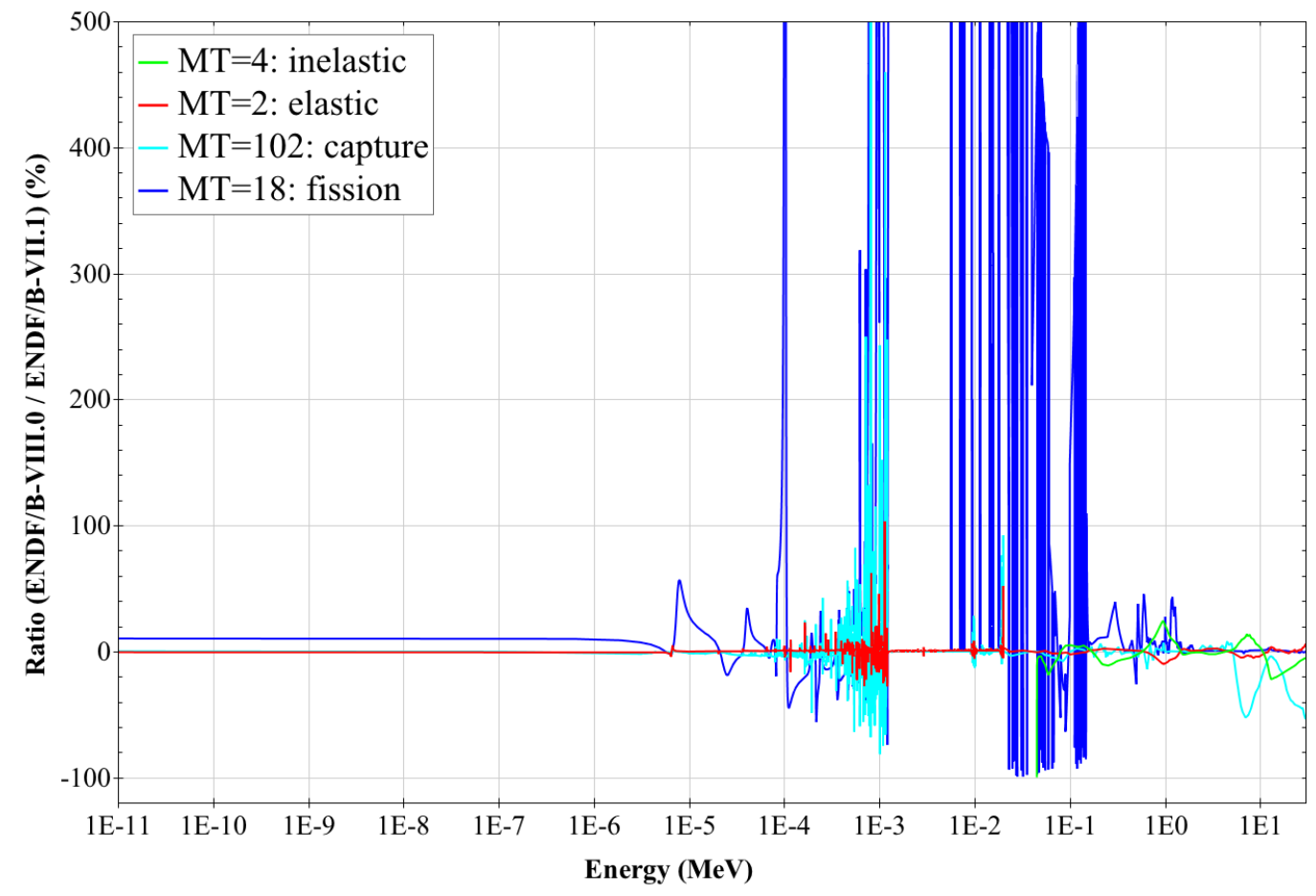

Figure 9. Relative differences between ENDF/B-VII.1 and ENDF/B-VIII.0 for ${ }^{238} \mathrm{U}$ cross sections.

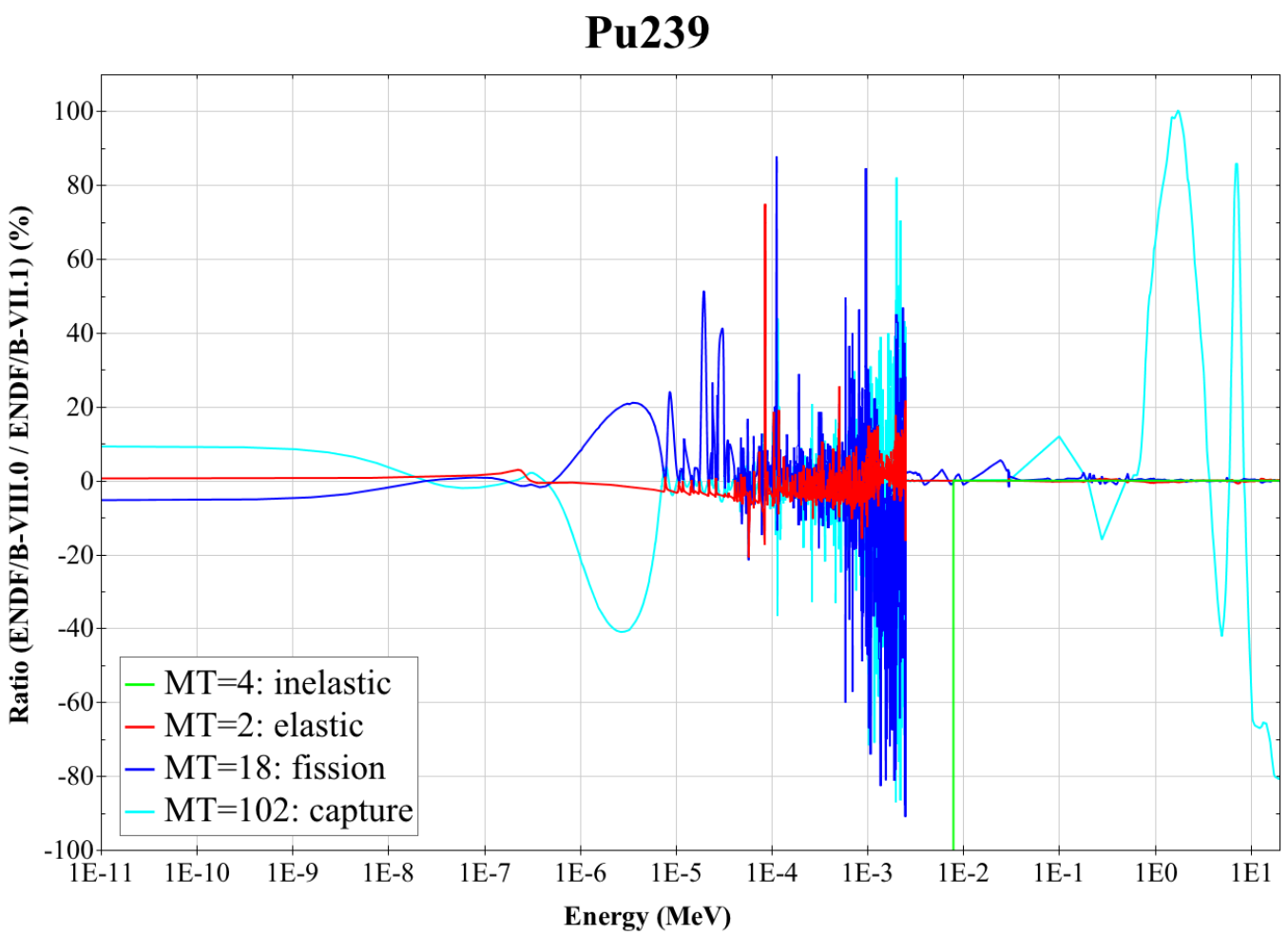

Figure 10. Relative differences between ENDF/B-VII.1 and ENDF/B-VIII.0 for ${ }^{239} \mathrm{Pu}$ cross sections. 


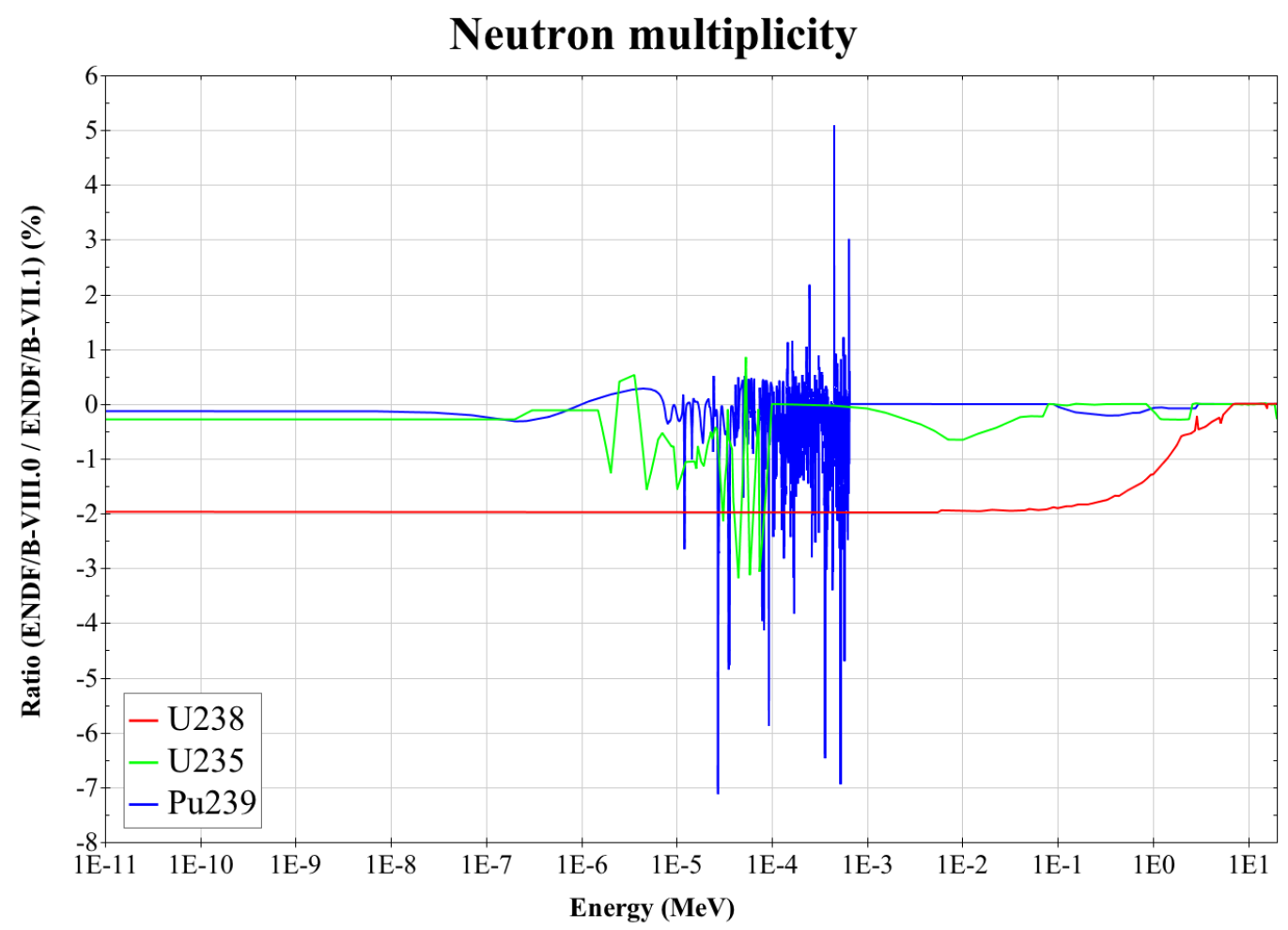

Figure 11. Relative differences of the ${ }^{235} \mathrm{U},{ }^{238} \mathrm{U}$ and ${ }^{239} \mathrm{Pu}$ neutron multiplicities between ENDF/B-VIII.0 and ENDF/B-VII.1. 


\section{NUCLEAR DATA PERFORMANCE ASSESSMENT ON ADVANCED REACTOR SYSTEMS}

This chapter provides descriptions of the applied analysis tools and libraries, the reactor models investigated, and the results of the criticality calculations and uncertainty analyses.

\subsection{Analysis Codes and Libraries}

The neutron transport calculations presented in this chapter were all performed with the Monte Carlo code KENO-VI of the SCALE 6.2.3 code package (Rearden and Jessee 2016). Results based on the last three ENDF/B nuclear data library releases were compared: ENDF/B-VII.0 (Chadwick et al. 2006), ENDF/BVII.1 (Chadwick et al. 2011), and ENDF/B-VIII.0 (Brown et al. 2018). In addition to continuous-energy (CE) calculations, several multigroup (MG) calculations were performed. In the case of ENDF/B-VII.0, a 238-group library that had already been shipped with the previous SCALE 6.1 release was used. In the case of ENDF/B-VIII.1, a 252-group library that shows various improvements compared to the 238-group library (Rearden et al. 2014) and a 302-group library optimized for sodium-cooled fast reactor systems was applied (Bostelmann et al. 2017).

The applied ENDF/B-VII.1 libraries are not identical to those provided with the official SCALE 6.2 release. The probability tables for the unresolved resonance range have recently been updated (Kim et al. 2018); this update required regeneration of the libraries. The updated libraries will be released with the first beta release of SCALE 6.3, including the 302-group library which includes a group structure that has not yet been released.

For uncertainty analyses, with respect to nuclear data, SCALE's perturbation theory-based TSUNAMI code was used, in particular the CE version of TSUNAMI with KENO-VI as the transport solver. These calculations were only performed based on ENDF/B-VII.1 cross section data and SCALE 6.2 covariance data, which are mainly based on ENDF/B-VII.1, as investigations of suitability of ENDF/B-VIII.0 data for use in applications is still under investigation (Sobes et al, 2018).

\subsection{Advanced Reactor System Models}

The advanced reactor concepts of the present study cover two sodium-cooled fast reactor (SFR) assemblies with metallic and oxide fuel, two high temperature gas-cooled reactor (HTGR) designs, and simple thermal and fast molten-salt reactor (MSR) models.

\subsubsection{OECD/NEA UAM SFR Benchmark: MET1000 Fuel Assembly}

The two-dimensional (2D) MET1000 assembly model was generated based on the sub-exercise definitions of the Organisation for Economic Co-operation and Development (OECD) / Nuclear Energy Agency (NEA) Benchmark for Uncertainty Analysis in Modelling for Design, Operation, and Safety Analysis of SFRs (UAM-SFR) (Buiron et al. 2017, Bostelmann et al. 2018). It is an assembly of the middle section of the inner core of a medium-sized metallic fuel core (Figure 12). The MET1000 pins contain cylindrical UTRU-Zr metal fuel at $807 \mathrm{~K}$. The fuel is end-of-equilibrium-cycle (EOEC) fuel in which the fission products are replaced by one representative isotope- $\mathrm{Mo}$ - with a density that accounts for equivalent absorption. The cladding and the hexagonal duct for the MET1000 assembly are made of HT-9 steel (706 K). Periodic boundary conditions are applied in all directions. Dimensions are provided in Table 1, and material compositions are given in Table 2. 


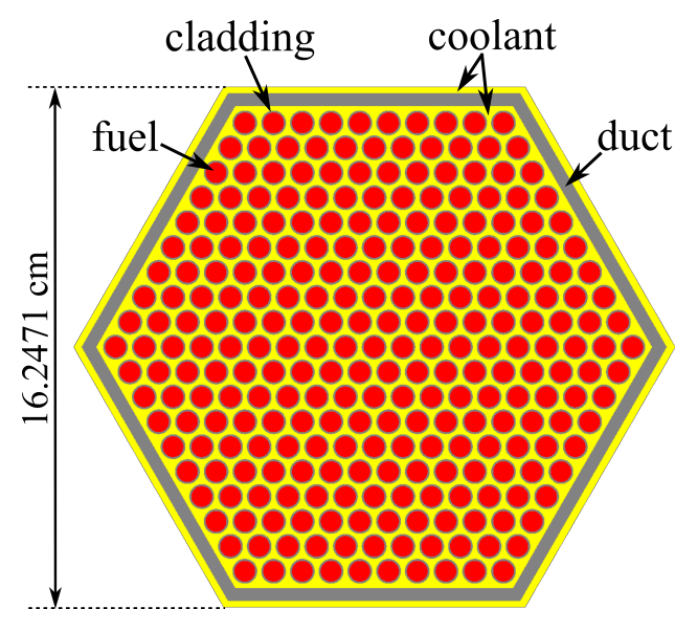

Figure 12. MET1000 fuel assembly model.

Table 1. Dimensions of the MET1000 fuel assembly

\begin{tabular}{lc}
\hline Description & Value \\
\hline Outer fuel radius & $0.3236 \mathrm{~cm}$ \\
Inner cladding radius & $0.3236 \mathrm{~cm}$ \\
Outer cladding radius & $0.3857 \mathrm{~cm}$ \\
Pin cell pitch & $0.8966 \mathrm{~cm}$ \\
\hline Number of fuel pins & 271 \\
\hline Inner subassembly duct flat-to-flat distance & $15.0191 \mathrm{~cm}$ \\
Outer subassembly duct flat-to-flat distance & $15.8123 \mathrm{~cm}$ \\
Subassembly pitch & $16.2471 \mathrm{~cm}$ \\
\hline
\end{tabular}

Table 2. Material compositions of the MET1000 fuel assembly

\begin{tabular}{lcccc}
\hline Material & Nuclide & Density (atoms/barn-cm) & Nuclide & Density (atoms/barn-cm) \\
\hline \multirow{6}{*}{} & ${ }^{234} \mathrm{U}$ & $1.7210 \mathrm{E}-06$ & ${ }^{241} \mathrm{Am}$ & $8.8828 \mathrm{E}-05$ \\
& ${ }^{235} \mathrm{U}$ & $2.2106 \mathrm{E}-05$ & ${ }^{242 \mathrm{~m}} \mathrm{Am}$ & $8.9023 \mathrm{E}-06$ \\
& ${ }^{236} \mathrm{U}$ & $3.8904 \mathrm{E}-06$ & ${ }^{243} \mathrm{Am}$ & $9.1054 \mathrm{E}-05$ \\
Fuel & ${ }^{238} \mathrm{U}$ & $1.8774 \mathrm{E}-02$ & ${ }^{242} \mathrm{Cm}$ & $7.4075 \mathrm{E}-06$ \\
& ${ }^{237} \mathrm{~Np}$ & $4.2264 \mathrm{E}-05$ & ${ }^{243} \mathrm{Cm}$ & $7.7307 \mathrm{E}-07$ \\
& ${ }^{236} \mathrm{Pu}$ & $7.3569 \mathrm{E}-10$ & ${ }^{244} \mathrm{Cm}$ & $7.1010 \mathrm{E}-05$ \\
& ${ }^{238} \mathrm{Pu}$ & $1.0560 \mathrm{E}-04$ & ${ }^{245} \mathrm{Cm}$ & $1.5116 \mathrm{E}-05$ \\
& ${ }^{239} \mathrm{Pu}$ & $2.1525 \mathrm{E}-03$ & ${ }^{246} \mathrm{Cm}$ & $9.1659 \mathrm{E}-06$ \\
& ${ }^{240} \mathrm{Pu}$ & $1.2570 \mathrm{E}-03$ & $\mathrm{Zr}$ & $7.2802 \mathrm{E}-03$ \\
& ${ }^{241} \mathrm{Pu}$ & $1.8043 \mathrm{E}-04$ & $\mathrm{Mo}$ & $2.7287 \mathrm{E}-03$ \\
\hline \multirow{2}{*}{ Cladding and } & ${ }^{242} \mathrm{Pu}$ & $2.7677 \mathrm{E}-04$ & & \\
duct (HT-9) & $\mathrm{Cr}$ & $1.0366 \mathrm{E}-02$ & $\mathrm{Mo}$ & $4.9007 \mathrm{E}-04$ \\
\hline Coolant & $\mathrm{Fe}$ & $6.9715 \mathrm{E}-02$ & $\mathrm{Mn}$ & $4.5921 \mathrm{E}-04$ \\
\hline \multicolumn{5}{c}{} \\
\hline
\end{tabular}




\subsubsection{OECD/NEA UAM SFR Benchmark: MOX3600 Fuel Assembly}

Similar to the MET1000 assembly, the 2D MOX3600 assembly model was generated based on the subexercise definitions of the UAM-SFR benchmark (Buiron et al. 2017, Bostelmann et al. 2018). It is an assembly of the middle section of the inner core of a large oxide core. The MOX3600 fuel pins contain annular uranium-transuranic (U-TRU) oxide at a temperature of 1,500 K (Figure 13). The fuel is EOEC fuel in which the fission products are replaced by one representative isotope-Mo-with a density that accounts for equivalent absorption. The cladding for the MOX3600 assembly is made of EM-10 like steel $(743 \mathrm{~K})$, and the hexagonal duct is made of oxide-strengthened steel $(743 \mathrm{~K})$. Periodic boundary conditions are applied in all directions. Dimensions are provided in Table 3, and material compositions are given in Table 4.

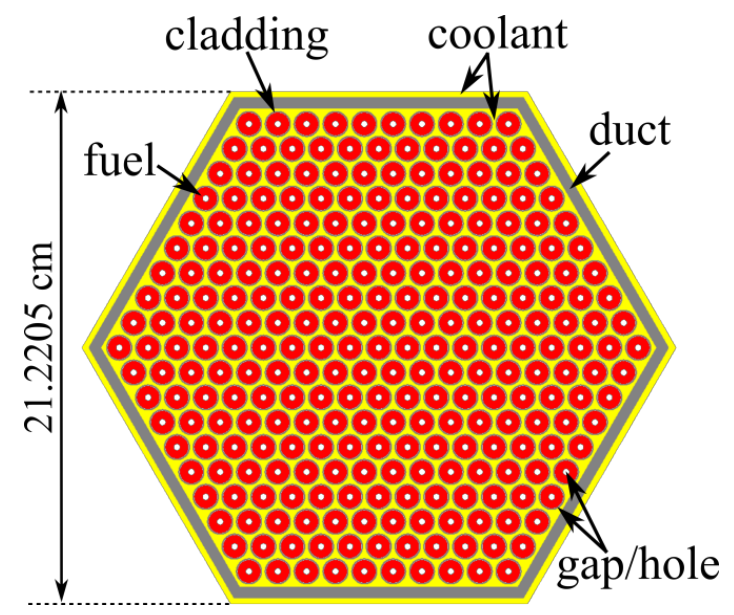

Figure 13. MOX3600 fuel assembly model.

Table 3. Dimensions of the MOX3600 fuel assembly

\begin{tabular}{lc}
\hline Description & Value \\
\hline Inner fuel radius & $0.1257 \mathrm{~cm}$ \\
Outer fuel radius & $0.4742 \mathrm{~cm}$ \\
Inner cladding radius & $0.4893 \mathrm{~cm}$ \\
Outer cladding radius & $0.5419 \mathrm{~cm}$ \\
Pin cell pitch & $1.1897 \mathrm{~cm}$ \\
\hline Number of fuel pins & 271 \\
\hline Inner subassembly duct flat-to-flat distance & $19.8418 \mathrm{~cm}$ \\
Outer subassembly duct flat-to-flat distance & $20.7468 \mathrm{~cm}$ \\
Subassembly pitch & $21.2205 \mathrm{~cm}$ \\
\hline
\end{tabular}


Table 4. Material compositions of the MOX3600 fuel assembly

\begin{tabular}{lcccc}
\hline Material & Nuclide & Density (atoms/barn-cm) & Nuclide & Density (atoms/barn-cm) \\
\hline \multirow{6}{*}{ Fuel } & ${ }^{16} \mathrm{O}$ & $4.2825 \mathrm{E}-02$ & ${ }^{241} \mathrm{Am}$ & $3.6901 \mathrm{E}-05$ \\
& ${ }^{234} \mathrm{U}$ & $2.1672 \mathrm{E}-06$ & ${ }^{242 \mathrm{Am}}$ & $1.7558 \mathrm{E}-08$ \\
& ${ }^{235} \mathrm{U}$ & $2.1336 \mathrm{E}-05$ & ${ }^{242 \mathrm{~m}} \mathrm{Am}$ & $1.9169 \mathrm{E}-06$ \\
& ${ }^{236} \mathrm{U}$ & $6.3334 \mathrm{E}-06$ & ${ }^{243} \mathrm{Am}$ & $4.0860 \mathrm{E}-05$ \\
& ${ }^{238} \mathrm{U}$ & $1.7571 \mathrm{E}-02$ & ${ }^{242} \mathrm{Cm}$ & $3.2303 \mathrm{E}-06$ \\
& ${ }^{237} \mathrm{~Np}$ & $7.5991 \mathrm{E}-06$ & ${ }^{243} \mathrm{Cm}$ & $2.4680 \mathrm{E}-07$ \\
& ${ }^{239} \mathrm{~Np}$ & $5.3141 \mathrm{E}-06$ & ${ }^{244} \mathrm{Cm}$ & $1.1034 \mathrm{E}-05$ \\
& ${ }^{238} \mathrm{Pu}$ & $7.4795 \mathrm{E}-05$ & ${ }^{245} \mathrm{Cm}$ & $9.4349 \mathrm{E}-07$ \\
& ${ }^{239} \mathrm{Pu}$ & $1.9750 \mathrm{E}-03$ & ${ }^{246} \mathrm{Cm}$ & $4.7941 \mathrm{E}-08$ \\
& ${ }^{240} \mathrm{Pu}$ & $1.0276 \mathrm{E}-03$ & ${ }^{247} \mathrm{Cm}$ & $1.6226 \mathrm{E}-09$ \\
& ${ }^{241} \mathrm{Pu}$ & $1.8497 \mathrm{E}-04$ & $\mathrm{Mo}$ & $4.5802 \mathrm{E}-03$ \\
& ${ }^{242} \mathrm{Pu}$ & $3.0146 \mathrm{E}-04$ & ${ }^{241} \mathrm{Am}$ & $3.6901 \mathrm{E}-05$ \\
\hline \multirow{5}{*}{ Cladding (ODS) } & $\mathrm{Cu}$ & $\mathrm{Mn}$ & $2.3441 \mathrm{E}-04$ \\
& $\mathrm{C}$ & $3.5740 \mathrm{E}-04$ & $\mathrm{P}$ & $2.7718 \mathrm{E}-05$ \\
& $\mathrm{O}$ & $3.9924 \mathrm{E}-04$ & $\mathrm{Al}$ & $9.1482 \mathrm{E}-03$ \\
& $\mathrm{Ti}$ & $5.3824 \mathrm{E}-04$ & $\mathrm{Co}$ & $2.1852 \mathrm{E}-04$ \\
& $\mathrm{Cr}$ & $1.7753 \mathrm{E}-02$ & $\mathrm{Cu}$ & $1.0135 \mathrm{E}-04$ \\
& $\mathrm{Fe}$ & $5.3872 \mathrm{E}-02$ & $\mathrm{Y}$ & $2.6616 \mathrm{E}-04$ \\
\hline \multirow{6}{*}{ Duct (EM10) } & $\mathrm{Ni}$ & $3.6588 \mathrm{E}-04$ & $\mathrm{Fe}$ & $7.3230 \mathrm{E}-02$ \\
& $\mathrm{C}$ & $3.8254 \mathrm{E}-04$ & $\mathrm{Ni}$ & $3.9162 \mathrm{E}-04$ \\
& $\mathrm{Si}$ & $4.9089 \mathrm{E}-04$ & $\mathrm{Mo}$ & $4.7925 \mathrm{E}-04$ \\
& $\mathrm{Ti}$ & $1.9203 \mathrm{E}-05$ & & \\
\hline Coolant & $\mathrm{Cr}$ & $7.5122 \mathrm{E}-03$ & $\mathrm{Mn}$ & \\
\hline
\end{tabular}

\subsubsection{Prismatic HTGR: HTTR}

The High Temperature Engineering Test Reactor (HTTR) is a graphite-moderated, helium-cooled $30 \mathrm{MW}_{\text {th }}$ prismatic reactor for which detailed specifications and benchmark results are provided in the International Handbook of Reactor Physics Experiments (2010). The core of the HTTR reactor consists of hexagonal graphite blocks $58 \mathrm{~cm}$ in height and $36 \mathrm{~cm}$ flat width (Figure 14). Five of these fuel blocks, control rod guide blocks, replaceable reflector blocks, or irradiation blocks are stacked vertically into columns. The fuel blocks contain fuel rods consisting of a stack of annular fuel compacts. The fuel compacts are composed of a graphite matrix in which Tristructural-isotropic (TRISO) fuel particles are dispersed with a volumetric packing fraction of $30 \%$. The TRISO particles contain a fuel kernel consisting of uranium dioxide with enrichments ranging between 3.4-9.9 wt.\%. The specifications for the fuel particles and components are summarized in Table 5.

The benchmark specifications contain descriptions of several critical and subcritical configurations with different loads. The fully loaded 30-fuel-column core is modeled for this study. Models generated for an earlier SCALE HTGR validation study could be updated and used for this study (Ilas et al. 2012). For the CE model, the TRISO particles in the fuel rods are modeled in square lattices with particles removed from the lattice cells at the outer cylindrical surface to avoid particle clipping.

Since the self-shielding treatment for MG calculations in SCALE 6.1 did not allow for annular double-het fuel pins, the HTTR fuel pins have been combined with the inner helium zone by mixing the helium into the graphite matrix composition and defining only an outer fuel radius. In addition to this model, a more realistic double-het MG model was developed that uses the new annular double-het pin capability provided in SCALE 6.2. For this mode, the graphite matrix composition was updated, and the inner helium zone was explicitly defined in the self-shielding and in the transport model. 


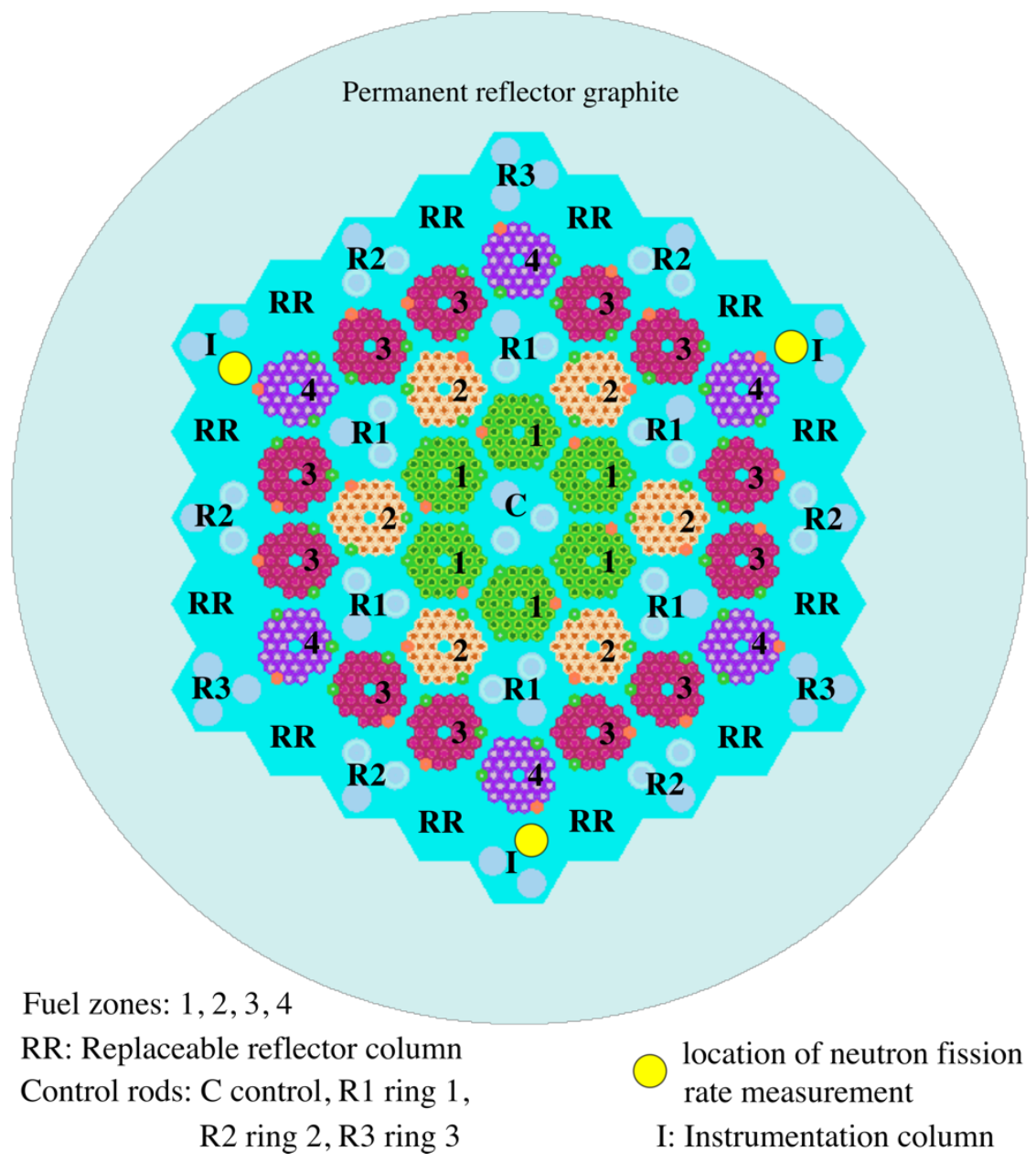

Figure 14. Fully loaded HTTR core configuration.

Table 5. HTTR model specifications

$\mathrm{UO}_{2}$ fuel density $\left(\mathrm{g} / \mathrm{cm}^{3}\right)$
Uranium enrichment
Fuel kernel radius $(\mathrm{mm})$
Fuel particle coating layer materials (starting from kernel)
Fuel particle coating layer thicknesses $(\mathrm{mm})$
Fuel particle coating layer densities $\left(\mathrm{g} / \mathrm{cm}^{3}\right)$
Packing fraction of TRISO particles
Graphite matrix density $\left(\mathrm{g} / \mathrm{cm}^{3}\right)$
Graphite $(\mathrm{IG}-110)$ density in fuel block $\left(\mathrm{g} / \mathrm{cm}^{3}\right)$
Fuel compact inner/outer diameter $(\mathrm{cm})$
Active height in fuel rod $(\mathrm{cm})$
Fuel pin pitch $(\mathrm{cm})$
Fuel block pitch $(\mathrm{cm})$

10.39
$3.4-9.9$ wt.\%
0.3

Buffer/PyC/SiC/PyC

$0.06 / 0.03 / 0.025 / 0.045$

$1.1 / 1.85 / 3.2 / 1.85$

$30 \%$

1.7

1.74

$1 / 2.6$

54.6

5.15

36

\subsubsection{Pebble-Bed HTGR: HTR-10}

The HTR-10 is a small $10 \mathrm{MW}_{\text {th }}$ prototype pebble-bed reactor at Tsinghua University in China. With a core diameter of $1.8 \mathrm{~m}$ and a mean height of $1.97 \mathrm{~m}$, it contains a number of fuel pebbles on the order of $10,000 \mathrm{~s}$ which are surrounded by graphite reflector structures. 
For this study, the initial critical configuration of the $10 \mathrm{MW}_{\text {th }}$ HTR-10 pebble-bed test reactor is modeled based on the high-fidelity specifications in the International Handbook of Reactor Physics Experiments (2007). For this configuration, the conus and discharge tube are filled with dummy pebbles (i.e., pure graphite pebbles). The cylindrical core consists of a mixture of 9,627 fuel pebbles and 7,263 dummy pebbles. The pebbles were modeled in various hexagonal prisms with different packing fractions to achieve an average packing fraction of $61 \%$. Criticality is achieved at room temperature while all control rods are withdrawn and void spaces are filled with ambient air (Figure 15 and Figure 16). KENO-VI models prepared for earlier studies (Sunny et al. 2010, Ilas et al. 2010) could be used for the present work. As in the HTTR, the particles in the fuel pebble are modeled in square lattices without particle clipping (Figure 17). The specifications for the fuel particles and pebbles are summarized in Table 6 .

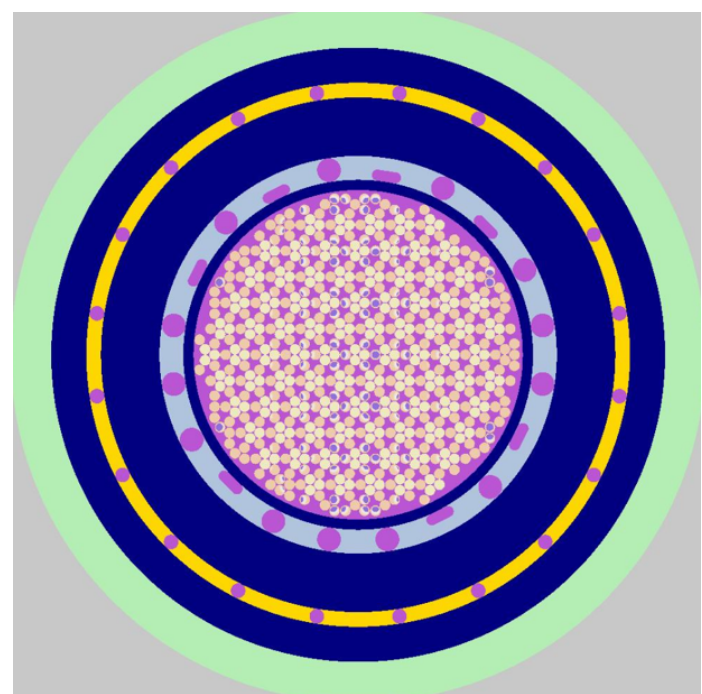

Figure 15. HTR-10: horizontal cross sectional view of SCALE model.

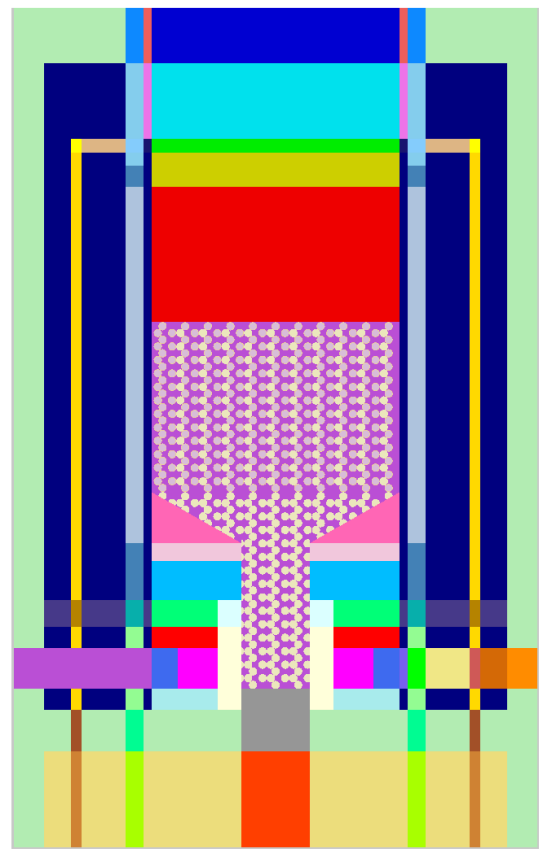

Figure 16. HTR-10: vertical view of SCALE model.

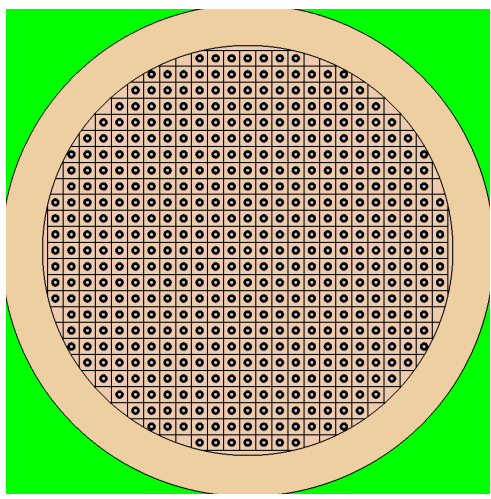

Figure 17. HTR-10 fuel pebble model including TRISO particles in a square lattice without particle clipping. 
Table 6. HTR-10 model specifications

\begin{tabular}{lc}
\hline $\mathrm{UO}_{2}$ fuel density $\left(\mathrm{g} / \mathrm{cm}^{3}\right)$ & 10.4 \\
Uranium enrichment & $17 \mathrm{wt} . \%$ \\
Fuel kernel radius $(\mathrm{mm})$ & 0.25 \\
Fuel particle coating layer materials (starting from kernel) & Buffer/PyC/SiC/PyC \\
Fuel particle coating layer thicknesses $(\mathrm{cm})$ & $0.009 / 0.004 / 0.0035 / 0.004$ \\
Fuel particle coating layer densities $\left(\mathrm{g} / \mathrm{cm}^{3}\right)$ & $1.1 / 1.9 / 3.18 / 1.9$ \\
Number of particles in pebble & 8,385 \\
Diameter of fuel pebble $(\mathrm{cm})$ & 3.0 \\
Diameter of fuel zone in pebble $(\mathrm{cm})$ & 2.5 \\
Graphite matrix and fuel pebble outer shell density $\left(\mathrm{g} / \mathrm{cm}^{3}\right)$ & 1.73 \\
\hline
\end{tabular}

\subsubsection{Graphite-Moderated MSR Unit Cell}

An infinite lattice of 2D MSR unit cells is modeled with a fuel salt channel surrounded by graphite moderator (Figure 18, Table 7). The fuel is $4 \%$ enriched uranium in a mixture of $\mathrm{LiF}_{2} \mathrm{BeF}_{2}$, and $\mathrm{UF}_{4}$. The fuel channel has a radius of $1.72417 \mathrm{~cm}$, and the square pitch of the unit cell is $10.16 \mathrm{~cm}$. The models are taken from earlier studies at ORNL (Betzler et al. 2017a).

Table 7. Fresh graphite-moderated MSR unit cell compositions

\begin{tabular}{lcccc}
\hline & Fuel & & \multicolumn{2}{c}{ Moderator } \\
\cline { 1 - 2 } \cline { 5 - 5 } Nuclide & Density (atoms/barn-cm) & & Nuclide & Density (atoms/barn-cm) \\
\hline${ }^{9} \mathrm{Be}$ & $7.41560 \mathrm{E}-02$ & & Graphite & $9.248159 \mathrm{e}-02$ \\
${ }^{19} \mathrm{~F}$ & $1.02089 \mathrm{E}+00$ & & & \\
${ }^{7} \mathrm{Li}$ & $2.58704 \mathrm{E}-01$ & & & \\
${ }^{235} \mathrm{U}$ & $7.25250 \mathrm{E}-02$ & & & \\
${ }^{238} \mathrm{U}$ & $1.74060 \mathrm{E}+00$ & & & \\
\hline
\end{tabular}

\subsubsection{Zirconium Hydride-Moderated MSR Unit Cell}

Another infinite lattice of 2D MSR unit cells is modeled with fuel salt surrounding a small-diameter zirconium hydride $(\mathrm{ZrH})$ rod moderator (Figure 19, Table 8 ). The rod radius is $1.15 \mathrm{~cm}$, and the square pitch of the unit cell is $6.8 \mathrm{~cm}$. The models are taken from earlier studies at ORNL (Betzler et al. 2017b, 2017c, 2018).

Table 8. Fresh ZrH-moderated MSR unit cell compositions

\begin{tabular}{lcccc}
\hline & Fuel & & \multicolumn{2}{c}{ Moderator } \\
\cline { 1 - 2 } \cline { 5 - 5 } Nuclide & Density (atoms/barn-cm) & & Nuclide & Density (atoms/barn-cm) \\
\hline${ }^{6} \mathrm{Li}$ & $1.140210 \mathrm{e}-06$ & & ${ }^{1} \mathrm{H}$ & $6.088629 \mathrm{e}-02$ \\
${ }^{7} \mathrm{Li}$ & $1.955016 \mathrm{e}-02$ & & ${ }^{2} \mathrm{H}$ & $7.002728 \mathrm{e}-06$ \\
${ }^{19} \mathrm{~F}$ & $4.921455 \mathrm{e}-02$ & & ${ }^{90} \mathrm{Zr}$ & $1.887790 \mathrm{e}-02$ \\
${ }^{235} \mathrm{U}$ & $3.753041 \mathrm{e}-04$ & & $91 \mathrm{Zr}$ & $4.116814 \mathrm{e}-03$ \\
${ }^{238} \mathrm{U}$ & $7.040709 \mathrm{e}-03$ & & ${ }^{92} \mathrm{Zr}$ & $6.292635 \mathrm{e}-03$ \\
& & & ${ }^{94} \mathrm{Zr}$ & $6.377026 \mathrm{e}-03$ \\
& & ${ }^{6} \mathrm{Zr}$ & $1.027369 \mathrm{e}-03$ \\
\hline
\end{tabular}




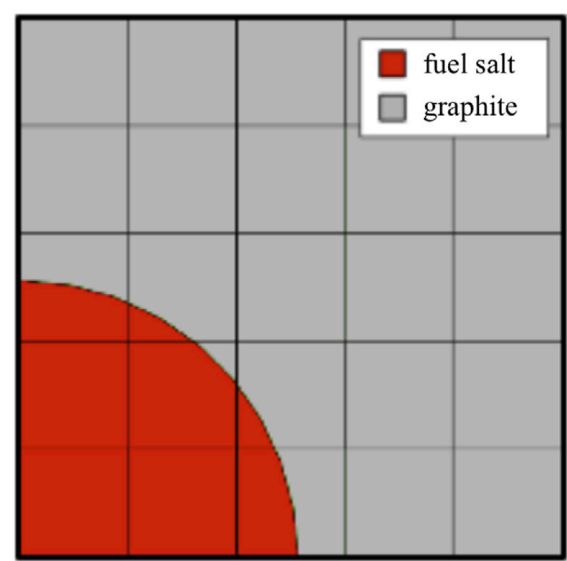

Figure 18. Graphite-moderated MSR unit cell (courtesy of B. Betzler).

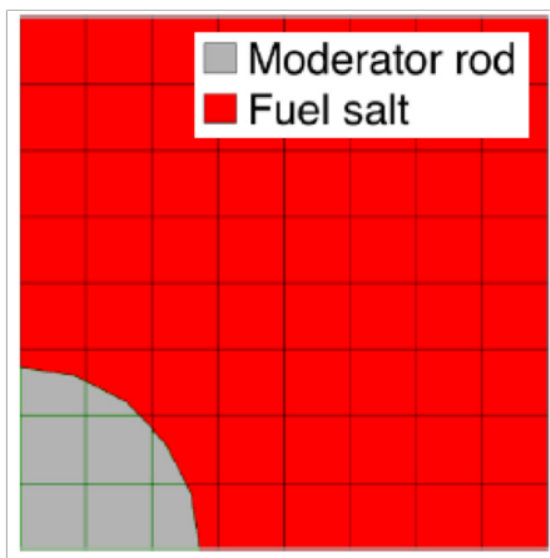

Figure 19. MSR unit cell with fuel salt moderated by $\mathrm{ZrH}$ rods (courtesy of B. Betzler).

\subsubsection{Fast Spectrum MSR Mixture}

An infinite medium representative for a fast-spectrum MSR concept, based on $\mathrm{NaCl}$ as the carrier salt, has been modeled. $\mathrm{PuCl}_{3}-\mathrm{NaCl}$ fuel salt and $\mathrm{UCl}_{3}-\mathrm{NaCl}$ coolant salt are homogenized for this model. The simplification to one homogenized mixture is justified by the fast neutron spectrum. The models are taken from earlier studies at ORNL (Davidson et al. 2018, Betzler et al. 2017d). The fresh fuel composition is shown in Table 9.

Table 9. Fresh fast-spectrum MSR mixture composition

\begin{tabular}{|c|c|c|c|}
\hline Nuclide & Density (atoms/barn-cm) & Nuclide & Density (atoms/barn-cm) \\
\hline${ }^{37} \mathrm{Cl}$ & $9.05723 \mathrm{E}-01$ & ${ }^{242} \mathrm{Pu}$ & $1.61658 \mathrm{E}-04$ \\
\hline${ }^{23} \mathrm{Na}$ & $4.65039 \mathrm{E}-01$ & ${ }^{234} \mathrm{U}$ & $1.92876 \mathrm{E}-06$ \\
\hline${ }^{238} \mathrm{Pu}$ & $1.41219 \mathrm{E}-04$ & ${ }^{235} \mathrm{U}$ & $2.36080 \mathrm{E}-03$ \\
\hline${ }^{239} \mathrm{Pu}$ & $1.75202 \mathrm{E}-01$ & ${ }^{236} \mathrm{U}$ & $3.56821 \mathrm{E}-04$ \\
\hline${ }^{240} \mathrm{Pu}$ & $9.85930 \mathrm{E}-03$ & ${ }^{238} \mathrm{U}$ & $1.92604 \mathrm{E}+00$ \\
\hline${ }^{241} \mathrm{Pu}$ & $4.49670 \mathrm{E}-04$ & & \\
\hline
\end{tabular}

\subsection{Criticality Calculations}

This section presents the results of the KENO-VI calculations with the last three ENDF/B library releases.

\subsubsection{OECD/NEA UAM SFR Benchmark: MET1000 Fuel Assembly}

The eigenvalues between the different KENO-VI calculations of the MET100 fuel assembly are compared in terms of the reactivity difference $\Delta \rho$ provided in $\mathrm{pcm}(1 \mathrm{pcm}=0.00001$, Table 10$)$. In addition to the eigenvalue, the Doppler constant $\mathrm{K}_{\mathrm{D}}$ and the sodium void worth $\Delta \rho_{\mathrm{Na}}$ were calculated. For the Doppler constant, the fuel temperature was doubled. It is calculated as follows (nom: nominal, mod: modified):

$$
K_{D}=\frac{\frac{1}{k_{\text {nom }}}-\frac{1}{k_{\text {mod }}}}{\ln \left(\frac{T_{m o d}}{T_{\text {nom }}}\right)}
$$


For the sodium void worth, all sodium was removed from the model. It is calculated as reactivity difference:

$$
\Delta \rho_{N a}=\frac{1}{k_{\text {nom }}}-\frac{1}{k_{\text {mod }}}
$$

The results of $K_{D}$ (Table 11) and $\Delta \rho_{\mathrm{Na}}$ (Table 12) are provided in pcm. In all tables, the results between the different $\mathrm{ENDF} / \mathrm{B}$ releases are compared in one column (only for $\mathrm{CE}$ results), and within a release, the $\mathrm{MG}$ results are compared to their corresponding $\mathrm{CE}$ reference in the second column.

The eigenvalues vary significantly, depending on the ENDF/B release. ENDF/B-VII.1 leads to a decrease of about $250 \mathrm{pcm}$ compared to ENDF/B-VII.0. This is a result of an update in the preparation of the probability tables (Kim et al. 2018). This update has been found to have a significant impact on the eigenvalues of fast-spectrum systems. When comparing the ENDF/B-VIII.0 and ENDF/B-VII.1 results, a difference of about $350 \mathrm{pcm}$ is observed. Main contributors to these differences are fission, capture, and neutron multiplicity of ${ }^{239} \mathrm{Pu}$ (Figure 10, Figure 11).

The comparisons between the MG and CE results show that the 238- and 252-group libraries that were optimized for thermal systems are not adequate for simulation of this assembly. The energy resolution in the fast energy range is too coarse to adequately capture the resonances of the fast neutron spectrum of this system (Figure 20). A significant improvement can be obtained by the application of a 302-group structure which includes a fine energy group resolution in the fast energy range. For the 252- and 302-group libraries, the MG bias is increased by a factor of $\sim 2$ when switching from ENDF/B-VII.1 to ENDF/B-VIII.0.

The influence of the applied library on the Doppler constant is negligible. All differences are within three statistical standard deviations of the Monte Carlo calculations.

Small differences are observed for the sodium void worth. While the difference from the update from ENDF/B-VII.0 to ENDF/B-VII.1 is negligible, $\Delta \rho_{\mathrm{Na}}$ is increased by about $200 \mathrm{pcm}$ when using ENDF/BVIII.0 data. A MG bias between 150 and $230 \mathrm{pcm}$ is observed for the thermal 238- and 252-group libraries, while the 302-group library shows a bias of less than $100 \mathrm{pcm}$.

Table 10. Calculated MET1000 fuel assembly eigenvalues with $1 \sigma$ statistical error

\begin{tabular}{|c|c|c|c|c|}
\hline \multirow{2}{*}{ Library } & & \multirow{2}{*}{$\mathbf{k}_{\text {inf }}$} & \multicolumn{2}{|c|}{$\Delta \rho(\mathrm{pcm})$} \\
\hline & & & ENDF release & MG vs. CE \\
\hline \multirow{2}{*}{$\begin{array}{l}\text { ENDF/B- } \\
\text { VII.0 }\end{array}$} & $\mathrm{CE}$ & $1.28390(11)$ & \multirow[t]{2}{*}{ (ref) } & (ref) \\
\hline & $238 \mathrm{~g}$ & $1.27148(8)$ & & $-761(9)$ \\
\hline \multirow{3}{*}{$\begin{array}{l}\text { ENDF/B- } \\
\text { VII.1 }\end{array}$} & $\mathrm{CE}$ & $1.27982(12)$ & \multirow[t]{3}{*}{$-248(10)^{*}$} & (ref) \\
\hline & $252 \mathrm{~g}$ & $1.27263(8)$ & & $-441(9)$ \\
\hline & $302 \mathrm{~g}$ & $1.27825(8)$ & & $-96(9)$ \\
\hline \multirow{3}{*}{$\begin{array}{l}\text { ENDF/B- } \\
\text { VIII.0 }\end{array}$} & $\mathrm{CE}$ & $1.28555(11)$ & \multirow[t]{3}{*}{$100(9)$} & (ref) \\
\hline & $252 \mathrm{~g}$ & $1.27096(8)$ & & $-893(9)$ \\
\hline & $302 \mathrm{~g}$ & $1.28194(8)$ & & $-219(9)$ \\
\hline
\end{tabular}

*This difference was significantly influenced by differences in the probability tables between ENDF/B-VII.0 and VII.1. 


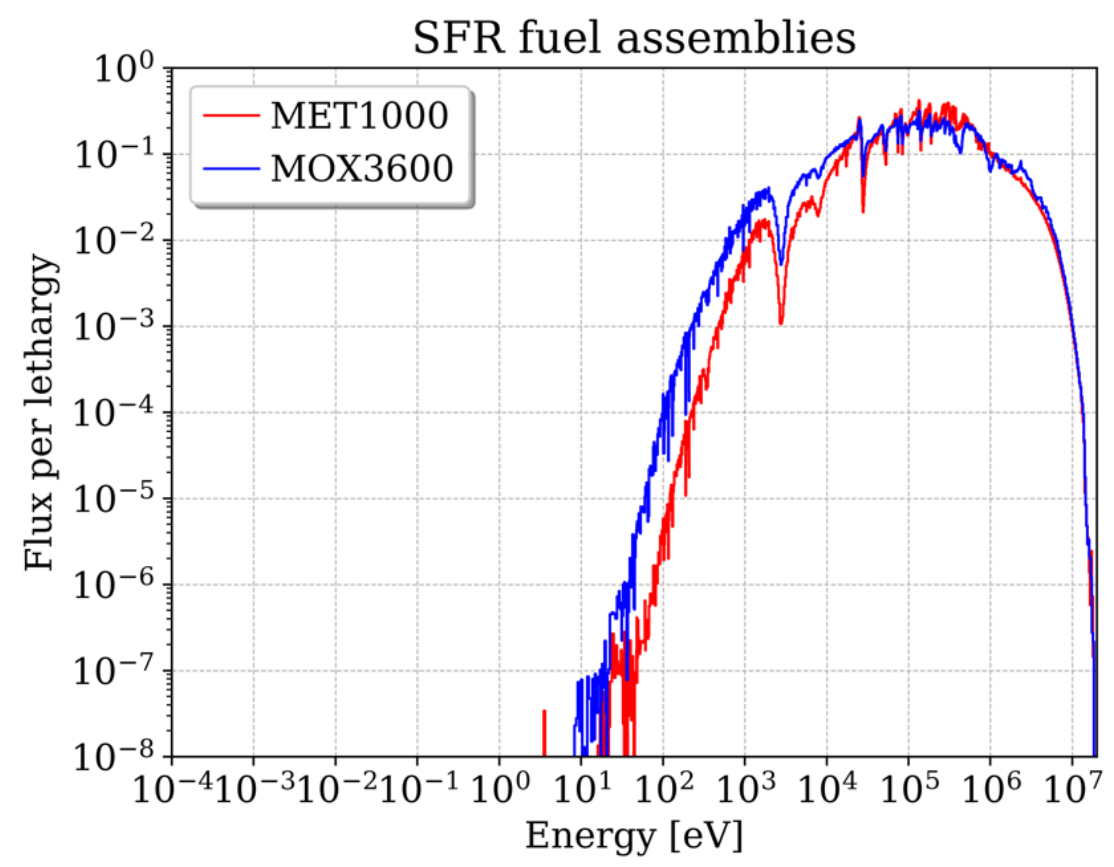

Figure 20. Neutron flux of the SFR fuel assemblies.

Table 11. Calculated MET1000 fuel assembly Doppler constant with $1 \sigma$ statistical error

\begin{tabular}{|c|c|c|c|c|}
\hline \multirow{2}{*}{ Library } & & \multirow{2}{*}{$K_{D}[\mathrm{pcm}]$} & \multicolumn{2}{|c|}{$\Delta K_{D}(\mathrm{pcm})$} \\
\hline & & & ENDF release & MG vs. CE \\
\hline \multirow{2}{*}{$\begin{array}{l}\text { ENDF/B- } \\
\text { VII.0 }\end{array}$} & $\mathrm{CE}$ & $-315(14)$ & (ref) & (ref) \\
\hline & $238 \mathrm{~g}$ & $-355(10)$ & & $-40(18)$ \\
\hline \multirow{3}{*}{$\begin{array}{l}\text { ENDF/B- } \\
\text { VII.1 }\end{array}$} & $\mathrm{CE}$ & $-323(15)$ & $-8(21)$ & (ref) \\
\hline & $252 \mathrm{~g}$ & $-348(10)$ & & $-25(18)$ \\
\hline & $302 \mathrm{~g}$ & $-318(9)$ & & $6(18)$ \\
\hline \multirow{3}{*}{$\begin{array}{l}\text { ENDF/B- } \\
\text { VIII.0 }\end{array}$} & $\mathrm{CE}$ & $-283(14)$ & $32(20)$ & (ref) \\
\hline & $252 \mathrm{~g}$ & $-325(10)$ & & $-43(17)$ \\
\hline & $302 \mathrm{~g}$ & $-301(10)$ & & $-18(17)$ \\
\hline
\end{tabular}

Table 12. Calculated MET1000 fuel assembly sodium void worth with $1 \sigma$ statistical error

\begin{tabular}{|c|c|c|c|c|}
\hline \multirow[b]{2}{*}{ Library } & & \multirow[b]{2}{*}{$\Delta \rho_{N a}(\mathrm{pcm})$} & \multicolumn{2}{|c|}{$\Delta\left(\Delta \rho_{N a}\right)(\mathrm{pcm})$} \\
\hline & & & $\begin{array}{l}\text { ENDF } \\
\text { release }\end{array}$ & MG vs. CE \\
\hline \multirow{2}{*}{$\begin{array}{l}\text { ENDF/B- } \\
\text { VII.0 }\end{array}$} & $\mathrm{CE}$ & $5,843(9)$ & (ref) & (ref) \\
\hline & $238 \mathrm{~g}$ & $5,692(7)$ & & $-151(12)$ \\
\hline \multirow{3}{*}{$\begin{array}{l}\text { ENDF/B- } \\
\text { VII.1 }\end{array}$} & $\mathrm{CE}$ & $5,917(9)$ & $75(29)$ & (ref) \\
\hline & $252 \mathrm{~g}$ & $5,687(7)$ & & $-230(12)$ \\
\hline & $302 \mathrm{~g}$ & $5,830(7)$ & & $-87(12)$ \\
\hline \multirow{3}{*}{$\begin{array}{l}\text { ENDF/B- } \\
\text { VIII.0 }\end{array}$} & $\mathrm{CE}$ & $6,057(9)$ & $214(29)$ & (ref) \\
\hline & $252 \mathrm{~g}$ & $5,900(7)$ & & $-157(12)$ \\
\hline & $302 \mathrm{~g}$ & $6,005(9)$ & & $-52(12)$ \\
\hline
\end{tabular}




\subsubsection{OECD/NEA UAM SFR Benchmark: MOX3600 Fuel Assembly}

The same comparisons performed for the MET1000 fuel assembly were also performed for the MOX3600 fuel assembly (Table 13).

The difference between the ENDF/B-VII.0 and VII.1 calculations is again mainly driven by the update in the probability tables, and the difference to ENDF/B-VIII.0 is caused by differences in the ${ }^{239} \mathrm{Pu}$ cross sections.

The MG biases are similar to the MET1000 biases, showing reasonable agreement of the 302-group results with the CE reference for ENDF/B-VII.1, but a larger difference of about $260 \mathrm{pcm}$ was shown in the case of ENDF/B-VIII.0.

The influence of the applied library on the Doppler constant is again negligible. The sodium void worth is consistent between ENDF/B-VII.0 and VII.1. It is slightly increased by about $140 \mathrm{pcm}$ when using ENDF/B-VIII.0 data. A MG bias is not observed for the sodium void worth for the latest two ENDF/B releases.

Table 13. Calculated MOX3600 fuel assembly eigenvalues with $1 \sigma$ statistical error

\begin{tabular}{|c|c|c|c|c|}
\hline \multirow{2}{*}{\multicolumn{2}{|c|}{ Library }} & \multirow{2}{*}{$\mathbf{k}_{\text {inf }}$} & \multicolumn{2}{|c|}{$\Delta \rho(\mathrm{pcm})$} \\
\hline & & & ENDF release & MG vs. CE \\
\hline \multirow{2}{*}{$\begin{array}{l}\text { ENDF/B- } \\
\text { VII.0 }\end{array}$} & $\mathrm{CE}$ & $1.15159(12)$ & (ref) & (ref) \\
\hline & $238 \mathrm{~g}$ & $1.14490(8)$ & & $-507(11)$ \\
\hline \multirow{3}{*}{$\begin{array}{l}\text { ENDF/B- } \\
\text { VII.1 }\end{array}$} & $\mathrm{CE}$ & $1.14677(11)$ & $-365(12)^{*}$ & (ref) \\
\hline & $252 \mathrm{~g}$ & $1.14440(8)$ & & $-181(11)$ \\
\hline & $302 \mathrm{~g}$ & $1.14632(8)$ & & $-34(11)$ \\
\hline \multirow{3}{*}{$\begin{array}{l}\text { ENDF/B- } \\
\text { VIII.0 }\end{array}$} & $\mathrm{CE}$ & $1.14944(11)$ & $-162(12)$ & (ref) \\
\hline & $252 \mathrm{~g}$ & $1.14434(8)$ & & $-388(11)$ \\
\hline & $302 \mathrm{~g}$ & $1.14596(8)$ & & $-264(11)$ \\
\hline
\end{tabular}

*This difference was significantly influenced by differences in the probability tables between ENDF/B-VII.0 and VII.1.

Table 14. Calculated MOX3600 fuel assembly Doppler coefficient with 1 $\sigma$ statistical error

\begin{tabular}{|c|c|c|c|c|}
\hline \multirow{2}{*}{ Library } & & \multirow{2}{*}{$K_{D}(\mathrm{pcm})$} & \multicolumn{2}{|c|}{$\Delta K_{D}(\mathrm{pcm})$} \\
\hline & & & ENDF release & MG vs. CE \\
\hline \multirow{2}{*}{$\begin{array}{l}\text { ENDF/B- } \\
\text { VII.0 }\end{array}$} & $\mathrm{CE}$ & $-764(27)$ & (ref) & (ref) \\
\hline & $238 \mathrm{~g}$ & $-773(17)$ & & $-10(31)$ \\
\hline \multirow{3}{*}{$\begin{array}{l}\text { ENDF/B- } \\
\text { VII.1 }\end{array}$} & $\mathrm{CE}$ & $-804(26)$ & $-41(37)$ & (ref) \\
\hline & $252 \mathrm{~g}$ & $-776(18)$ & & $29(31)$ \\
\hline & $302 \mathrm{~g}$ & $-785(18)$ & & $20(31)$ \\
\hline \multirow{3}{*}{$\begin{array}{l}\text { ENDF/B- } \\
\text { VIII.0 }\end{array}$} & $\mathrm{CE}$ & $-796(26)$ & $-32(20)$ & (ref) \\
\hline & $252 \mathrm{~g}$ & $-766(19)$ & & $29(31)$ \\
\hline & $302 \mathrm{~g}$ & $-740(18)$ & & $55(30)$ \\
\hline
\end{tabular}

Table 15. Calculated MOX3600 fuel assembly sodium void worth with $1 \sigma$ statistical error

Library $\Delta \rho_{N a}(\mathrm{pcm}) \quad \Delta\left(\Delta \rho_{N a}\right)(\mathrm{pcm})$




\begin{tabular}{|c|c|c|c|c|}
\hline & & & ENDF release & MG vs. CE \\
\hline $\begin{array}{l}\text { ENDF/B- } \\
\text { VII.0 }\end{array}$ & $\begin{array}{l}\mathrm{CE} \\
238 \mathrm{~g}\end{array}$ & $\begin{array}{l}2,922(12) \\
2,828(8)\end{array}$ & (ref) & $\begin{array}{c}\text { (ref) } \\
-94(14)\end{array}$ \\
\hline $\begin{array}{l}\text { ENDF/B- } \\
\text { VII.1 }\end{array}$ & $\begin{array}{l}\mathrm{CE} \\
252 \mathrm{~g} \\
302 \mathrm{~g}\end{array}$ & $\begin{array}{l}2,923(11) \\
2,940(8) \\
2,949(8)\end{array}$ & $1(29)$ & $\begin{array}{c}\text { (ref) } \\
17(14) \\
26(14)\end{array}$ \\
\hline $\begin{array}{l}\text { ENDF/B- } \\
\text { VIII.0 }\end{array}$ & $\begin{array}{l}\mathrm{CE} \\
252 \mathrm{~g} \\
302 \mathrm{~g}\end{array}$ & $\begin{array}{l}3,060(12) \\
3,072(8) \\
3,077(8)\end{array}$ & $138(29)$ & $\begin{array}{c}\text { (ref) } \\
11(14) \\
16(14)\end{array}$ \\
\hline
\end{tabular}

\subsubsection{Prismatic HTGR: HTTR}

The calculated HTTR eigenvalues are compared to the experiment in Table 16. The ENDF/B-VII.0 results largely overestimate the benchmark eigenvalue. Due to an increase in the carbon capture cross section (Figure A-14. ), the ENDF/B-VII.1 results are consistent with the experiment when considering the large experimental error bars. The carbon capture cross section in the thermal energy range in ENDF/B-VII. 1 is identical to that of ENDF/B-VIII.0. However, updates in especially ${ }^{235} \mathrm{U}$ and ${ }^{238} \mathrm{U}$ cross sections (e.g., Figure A-5. to Figure A-10. ) lead to an eigenvalue increase of about $300 \mathrm{pcm}$ for ENDF/B-VIII.0 compared to VII.1, so the eigenvalue is just slightly outside the experimental error bar.

The MG bias of the annular double-het cell model is less than $100 \mathrm{pcm}$ for ENDF/B-VII.1, but it is slightly increased to about $180 \mathrm{pcm}$ for ENDF/B-VIII.0.

The neutron flux in a fuel component of the HTTR is displayed in Figure 21.

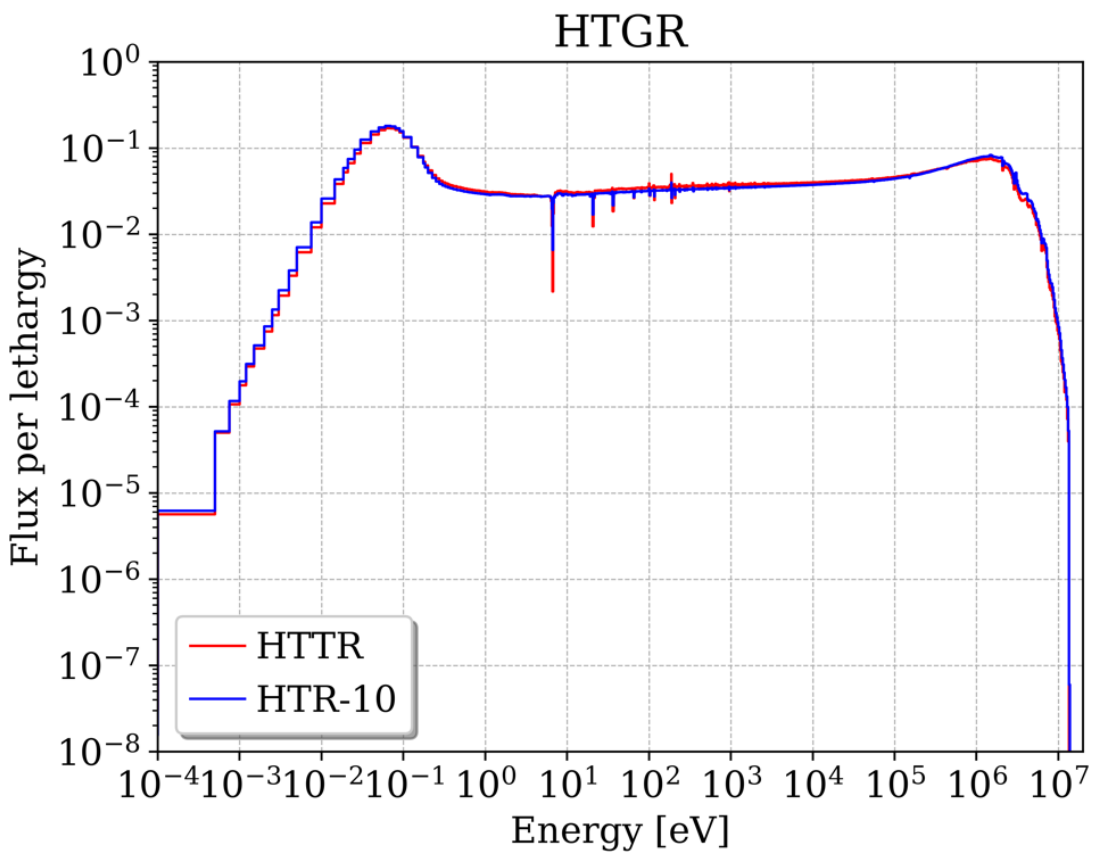

Figure 21. Neutron flux of the HTTR and HTR-10 reactors.

Table 16. Eigenvalue comparisons of the fully loaded HTTR core configuration (DH: double-het)

\section{Library}

$\mathbf{k}_{\text {eff }}$

$\Delta \mathbf{k}(\mathbf{p c m})$ 


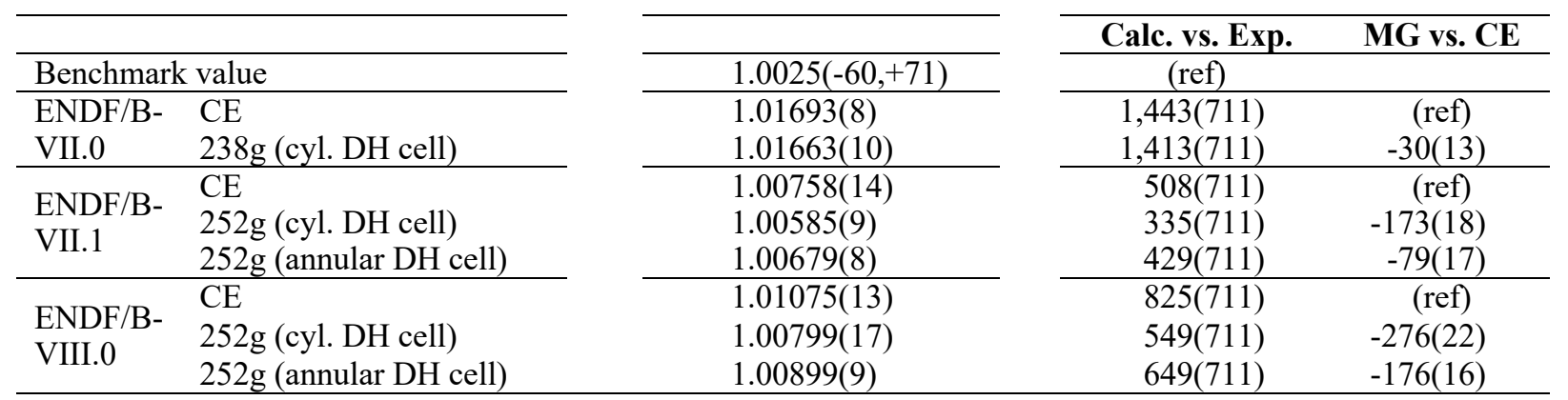

\subsubsection{Pebble-Bed HTGR: HTR-10}

The HTTR and the HTR-10 have similar results (Table 17). A large improvement of the eigenvalue compared to the experiment is observed when moving from ENDF/B-VII.0 to VII.1. The switch to ENDF/B-VIII.0 leads again to an eigenvalue increase of about $300 \mathrm{pcm}$. Therefore, a MG bias of $180 \mathrm{pcm}$ is observed that does not appear for ENDF/B-VII.1. The closest eigenvalue to the experiment is obtained when using ENDF/B-VII.1 data. The neutron flux in one of the HTR-10 fuel pebbles is displayed in Figure 21.

With the release of ENDF/B-VIII.0, three different graphite evaluations are available: graphite as perfect crystal (as in the previous ENDF/B releases), graphite with $10 \%$ porosity, and graphite with $30 \%$ porosity. In addition to the calculations assuming a perfect graphite crystal, the HTR-10 calculations were repeated with $10 \%$ and $30 \%$ porosity. The impact of the graphite porosity in only the reflector regions is small; $30 \%$ porosity led to an eigenvalue decrease of about $140 \mathrm{pcm}$. In contrast, when the porosity is assumed in all graphite structures, a significant difference of about $330 \mathrm{pcm}$ for $10 \%$ porosity and $650 \mathrm{pcm}$ for $30 \%$ porosity was observed (Table 18). These results were obtained at room temperature; the impact of the porosity was less for increased temperatures.

Information about the graphite porosity is not given in the benchmark specifications. Therefore, these calculations provide only a test to estimate the impact of the porosities, but they are not to be considered as guidance for calculations of graphite-moderated systems. In fact, the graphite porosity changes as a function of neutron fluence (Campbell 2016). Therefore, for an adequate consideration of the porosity, it is necessary to have detailed information about the porosity in the included materials.

Table 17. HTR-10 eigenvalue comparison

\begin{tabular}{|c|c|c|c|c|}
\hline \multirow{2}{*}{\multicolumn{2}{|c|}{ Library }} & \multirow{2}{*}{$\mathbf{k}_{\text {eff }}$} & \multicolumn{2}{|c|}{$\Delta \mathrm{k}(\mathrm{pcm})$} \\
\hline & & & Calc. vs. Exp. & MG vs. CE \\
\hline \multicolumn{2}{|c|}{ Benchmark value } & $1.00000(370)$ & (ref) & \\
\hline \multirow{2}{*}{ ENDF/B-VII.0 } & $\mathrm{CE}$ & $1.01375(10)$ & $1,375(371)$ & (ref) \\
\hline & $238 \mathrm{~g}$ & $1.01569(15)$ & $1,569(371)$ & 194(19) \\
\hline \multirow{2}{*}{ ENDF/B-VII.1 } & $\mathrm{CE}$ & $1.00267(10)$ & $267(371)$ & (ref) \\
\hline & $252 \mathrm{~g}$ & $1.00287(10)$ & $287(371)$ & $20(15)$ \\
\hline \multirow{2}{*}{ ENDF/B-VIII.0 } & $\mathrm{CE}$ & $1.00582(8)$ & $582(371)$ & (ref) \\
\hline & $252 \mathrm{~g}$ & $1.00447(10)$ & $447(371)$ & $-135(14)$ \\
\hline
\end{tabular}

Table 18. Calculated HTR-10 KENO-VI CE results using different ENDF/B-VIII.0 graphite evaluations

\begin{tabular}{lllcc}
\hline Applied graphite data & & $\mathbf{k}_{\text {eff }}$ & $\Delta \mathbf{k}(\mathbf{p c m})$ \\
\hline Perfect graphite crystal & & $1.00582(8)$ & (ref)
\end{tabular}




\subsubsection{Graphite-Moderated MSR Unit Cell}

For all MSR cells, only CE results based on different ENDF/B releases were compared. Since the eigenvalues were significantly larger than 1.0, the comparisons were performed in terms of the reactivity differences $\Delta \rho$.

As in the HTGR results, the ENDF/B-VII.1 and VIII.0 calculations resulted in lower eigenvalues than the corresponding ENDF/B-VII.0 calculations due to the increase of the carbon capture cross section Figure A-14. ). Updates in ${ }^{235} \mathrm{U},{ }^{238} \mathrm{U}$ and ${ }^{239} \mathrm{Pu}$ cross sections between ENDF/B-VII.1 and VIII.0 (Figure A-5. to Figure A-13. ) led to slight differences of about $70 \mathrm{pcm}$ for the fresh fuel, and $90 \mathrm{pcm}$ for the depleted fuel. The neutron flux is shown in Figure 22.

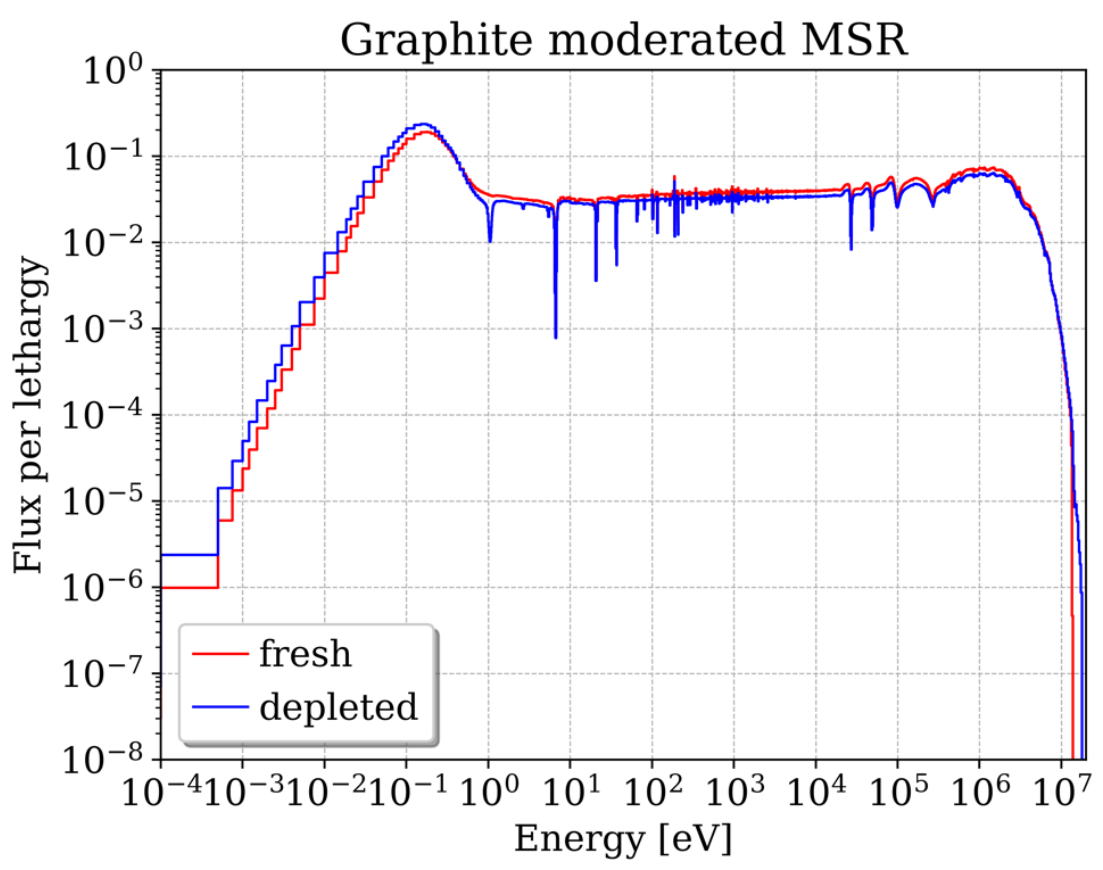

Figure 22. Neutron flux of the graphite-moderated MSR unit cell.

Table 19. Calculated eigenvalues of the graphite-moderated MSR unit cell

\begin{tabular}{|c|c|c|c|c|}
\hline \multirow{2}{*}{ ENDF/B release } & \multicolumn{2}{|c|}{ Fresh } & \multicolumn{2}{|c|}{ Depleted } \\
\hline & $\mathbf{K}_{\text {inf }}$ & $\Delta \rho(\mathrm{pcm})$ & $\mathbf{k}_{\text {inf }}$ & $\Delta \rho(\mathrm{pcm})$ \\
\hline ENDF/B-VII.0 & $1.47776(13)$ & (ref) & $1.05950(18)$ & (ref) \\
\hline
\end{tabular}




\begin{tabular}{|c|c|c|c|c|}
\hline$\overline{\text { ENT }}$ & & & & \\
\hline ENDF/B-VIU 0 & $\frac{1.4 / 210(1 /)}{1.47069(13)}$ & $\frac{-25 /(10)}{-325(8)}$ & $\begin{array}{l}1.05411(10) \\
1.05514(18)\end{array}$ & $\frac{-485(22)}{-390(23)}$ \\
\hline
\end{tabular}

\subsubsection{Zirconium Hydride-Moderated MSR Unit Cell}

The differences between the calculations with the various ENDF/B libraries for the fresh $\mathrm{ZrH}$-moderated unit cell were very small with less than $100 \mathrm{pcm}$. In case of the depleted fuel, larger differences, especially for ENDF/B-VIII.0, were visible due to the introduction of plutonium. The neutron flux is shown in Figure 23.

Table 20. Calculated eigenvalues of the zirconium hydride-moderated MSR unit cell

\begin{tabular}{|c|c|c|c|c|}
\hline \multirow[t]{2}{*}{$\mathrm{ENDF} / \mathrm{B}$ release } & \multicolumn{2}{|c|}{ Fresh } & \multicolumn{2}{|c|}{ Depleted } \\
\hline & Kinf & $\Delta \rho(\mathrm{pcm})$ & $\mathbf{k}_{\text {inf }}$ & $\Delta \rho(\mathrm{pcm})$ \\
\hline ENDF/B-VII.0 & $1.04940(14)$ & (ref) & $1.01365(16)$ & (ref) \\
\hline ENDF/B-VII.1 & $1.04914(14)$ & $-24(18)$ & $1.01495(16)$ & $126(22)$ \\
\hline ENDF/B-VIII.0 & $1.05040(14)$ & $91(18)$ & $1.01666(16)$ & $292(22)$ \\
\hline
\end{tabular}

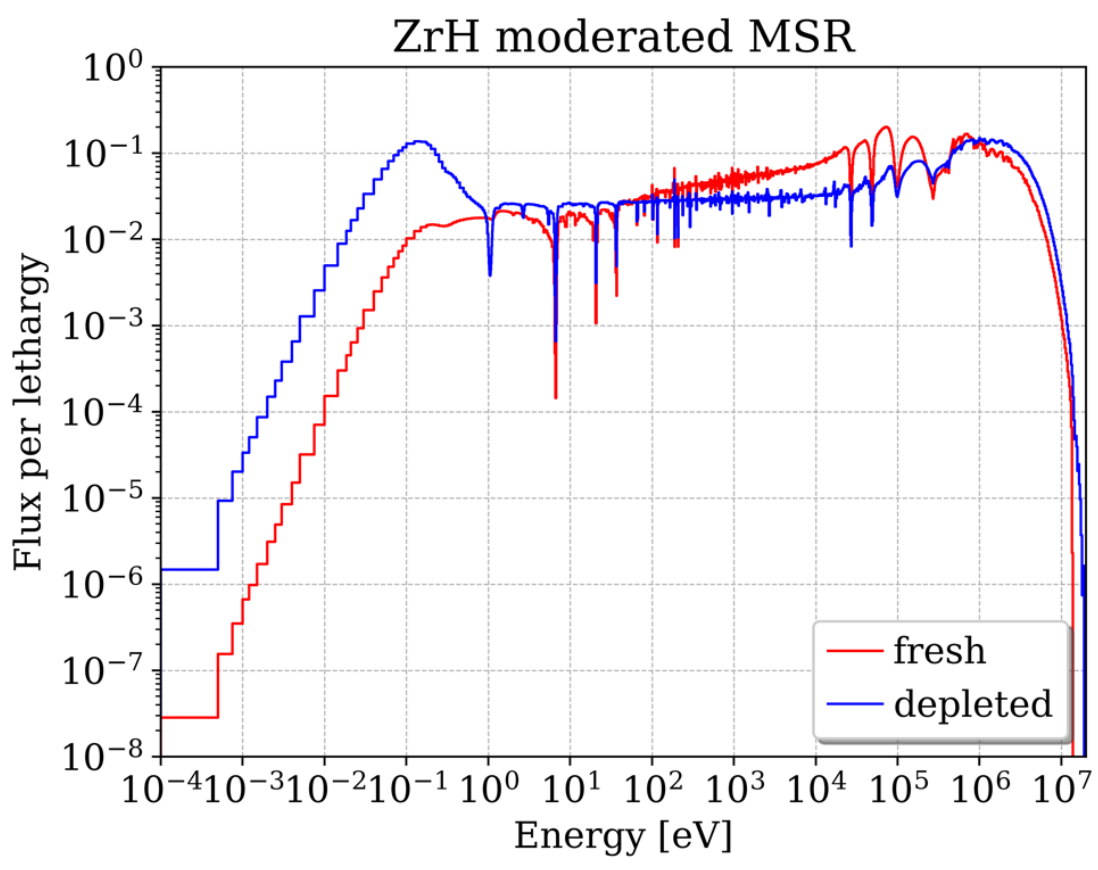

Figure 23. Neutron flux of the ZrH-moderated MSR unit cell.

\subsubsection{Fast Spectrum MSR Mixture}

Since the fresh and depleted fuels of the fast-spectrum MSR mixture contain plutonium, the differences between the ENDF/B-VII.1 and VIII.0 calculations were significant, more than $340 \mathrm{pcm}$. Differences to the ENDF/B-VII.0 calculations were caused by the update in the preparation of the probability tables. The fast neutron flux of this system is shown in Figure 24. 


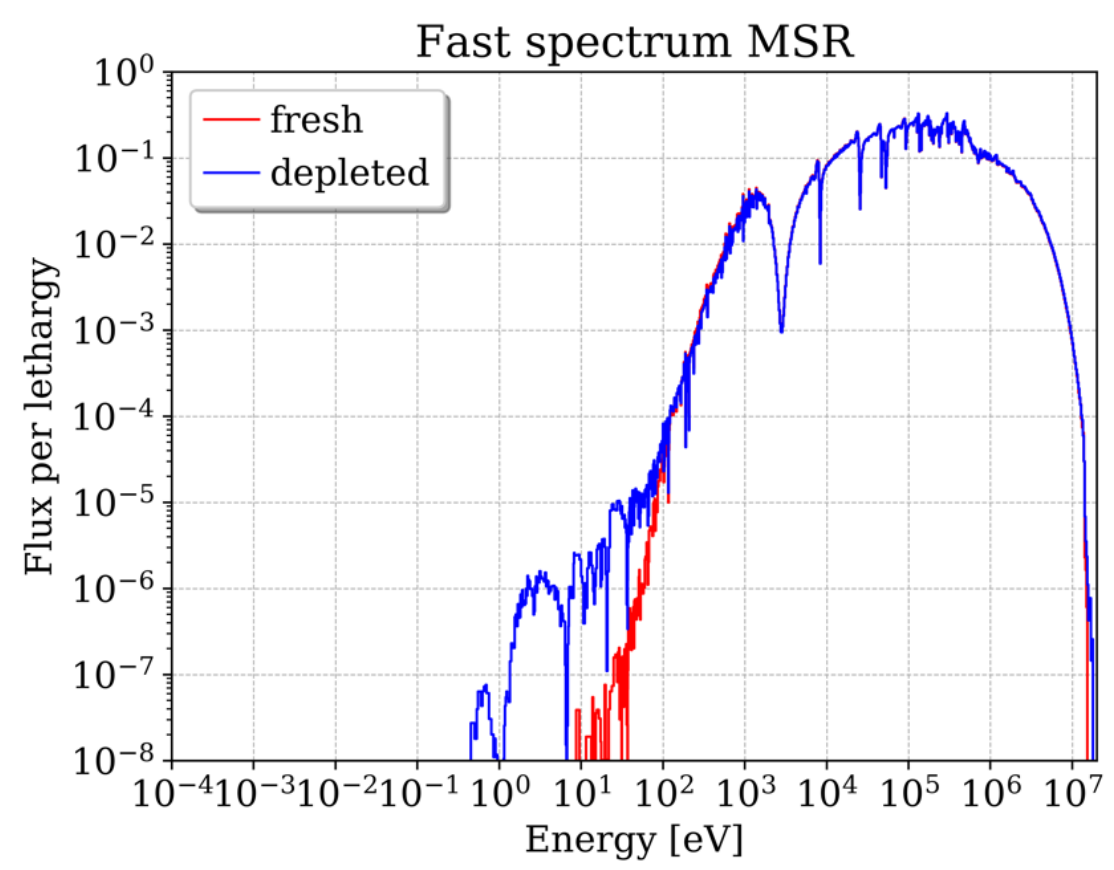

Figure 24. Neutron flux of the fast MSR mixture.

Table 21. Calculated eigenvalues of the fast-spectrum MSR mixture

\begin{tabular}{|c|c|c|c|c|}
\hline \multirow{2}{*}{$\begin{array}{l}\text { ENDF/B } \\
\text { release }\end{array}$} & \multicolumn{2}{|c|}{ Fresh } & \multicolumn{2}{|c|}{ Depleted } \\
\hline & kinf & $\Delta \rho(\mathrm{pcm})$ & Kinf & $\Delta \rho(\mathrm{pcm})$ \\
\hline ENDF/B-VII.0 & $1.09121(11)$ & (ref) & $1.10654(11)$ & (ref) \\
\hline ENDF/B-VII.1 & $1.08784(11)$ & $-284(13)^{*}$ & $1.10258(10)$ & $-325(12)^{*}$ \\
\hline ENDF/B-VIII.0 & $1.09194(11)$ & 61(13) & $1.10809(12)$ & $126(13)$ \\
\hline
\end{tabular}

*This difference was significantly influenced by differences in the probability tables between ENDF/B-VII.0 and VII.1.

\subsection{Uncertainty Quantification}

This section presents the results of the uncertainty analyses with TSUNAMI based on ENDF/B-VII.1 cross section and SCALE 6.2 covariance data. Important cross section uncertainties as a function of energy are displayed in the appendix.

\subsubsection{OECD/NEA UAM SFR Benchmark: MET1000 Fuel Assembly}

The uncertainties of the eigenvalue, Doppler constant, and sodium void worth due to nuclear data have been found to be significantly larger-for some values three times as large-for the MET1000 fuel assembly compared to the uncertainties of common LWR systems (Table 22). The top contributing covariance matrices are mainly the scattering reactions of ${ }^{238} \mathrm{U},{ }^{23} \mathrm{Na}$ and ${ }^{56} \mathrm{Fe}$ (Table 23). For the eigenvalue and the Doppler constant, inelastic scattering of ${ }^{238} \mathrm{U}$ is the main contributor to the uncertainty, and for the sodium void worth, it is ${ }^{23} \mathrm{Na}$ elastic scattering. Inelastic scattering of ${ }^{238} \mathrm{U}$ is the main driver of the eigenvalue uncertainty because of its very large uncertainty of up to $50 \%$ in the fast energy range, i.e. the energy range that is important to the fast spectrum systems (Error! Reference source not found.). 
Table 22. Nominal values and uncertainties due to nuclear data the MET1000 fuel assembly calculated with TSUNAMI-3D-CE (1 $\sigma$ statistical errors in parentheses)

\begin{tabular}{|c|c|c|}
\hline Response & Value & Uncertainty \\
\hline Kinf & $1.2800(1)$ & $1.413(1) \%$ \\
\hline$K_{D}$ & $-338(12) \mathrm{pcm}$ & $6.3(5) \%$ \\
\hline$\Delta \rho_{N a}$ & $5895(9) \mathrm{pcm}$ & $5.47(1) \%$ \\
\hline
\end{tabular}

Table 23. Top five contributing covariance matrices to the uncertainty for the MET1000 fuel assembly calculated with TSUNAMI-3D-CE (1 $\sigma$ statistical errors in parentheses)

\begin{tabular}{|c|c|c|c|c|c|}
\hline \multicolumn{2}{|c|}{ Kinf } & \multicolumn{2}{|c|}{$K_{D}$} & \multicolumn{2}{|c|}{$\Delta \rho_{N a}$} \\
\hline $\begin{array}{c}\text { cov } \\
\text { matrix }\end{array}$ & $\Delta \mathbf{k} / \mathbf{k}$ & $\begin{array}{c}\text { cov } \\
\text { matrix }\end{array}$ & $\Delta K_{D} / K_{D}$ & $\begin{array}{c}\text { cov } \\
\text { matrix }\end{array}$ & $\Delta \rho_{N a} / \rho_{N a}$ \\
\hline${ }^{238} \mathrm{U}$ inel. & $1.1721(3) \%$ & ${ }^{238} \mathrm{U}$ inel. & $4.5(2) \%$ & ${ }^{23} \mathrm{Na}$ el. & $4.601(3)$ \\
\hline${ }^{23} \mathrm{Na}$ el. & $0.3471(1) \%$ & ${ }^{23} \mathrm{Na}$ el. & $2.7(2) \%$ & ${ }^{23} \mathrm{Na}$ inel. & $2.165(1)$ \\
\hline 56 $\mathrm{Fe}$ el. & $0.2798(1) \%$ & ${ }^{239} \mathrm{Pu}$ inel. & $1.89(6) \%$ & ${ }^{238} \mathrm{U}$ inel. & $1.289(2)$ \\
\hline${ }^{238} \mathrm{U} n, \gamma$ & $0.2598(1) \%$ & ${ }^{56} \mathrm{Fe}$ el. & $1.2(3) \%$ & ${ }^{238} \mathrm{U} \mathrm{n}, \gamma$ & $0.950(1)$ \\
\hline${ }^{239} \mathrm{Pu} \mathrm{n}, \gamma$ & $0.2205(1) \%$ & ${ }^{239} \mathrm{Pu} \mathrm{n}, \gamma$ & $1.2(1) \%$ & ${ }^{239} \mathrm{Pu}$ inel. & $0.613(1)$ \\
\hline
\end{tabular}

\subsubsection{OECD/NEA UAM SFR Benchmark: MOX3600 Fuel Assembly}

The uncertainties of the MOX3600 fuel assembly are similar to those observed for the MET1000 assembly. The top contributing covariance matrices are inelastic scattering on ${ }^{238} \mathrm{U}$ for the eigenvalue and the Doppler constant, and ${ }^{23} \mathrm{Na}$ elastic scattering for the sodium void worth. Due to the slightly different neutron spectrum and material composition of oxide fuel compared to metallic fuel, the order of the importance of the other contributing covariance matrices is slightly changed. For example, elastic scattering on ${ }^{16} \mathrm{O}$ is an additional important uncertainty contributor.

Table 24. Nominal values and uncertainties due to nuclear data of the MOX3600 fuel assembly calculated with TSUNAMI-3D-CE (1 $\sigma$ statistical errors in parentheses)

\begin{tabular}{crc}
\hline Response & \multicolumn{1}{c}{ Value } & Uncertainty \\
\hline $\mathbf{k}_{\text {inf }}$ & $1.1467(1)$ & $1.515(1) \%$ \\
$\boldsymbol{K}_{\boldsymbol{D}}$ & $-781(21) \mathrm{pcm}$ & $5.2(3) \%$ \\
$\boldsymbol{\Delta} \boldsymbol{\rho}_{\mathrm{Na}}$ & $2945(10) \mathrm{pcm}$ & $5.57(1) \%$ \\
\hline
\end{tabular}

Table 25. Top five contributing covariance matrices to the uncertainty for the MOX3600 fuel assembly calculated with TSUNAMI-3D-CE (1 $\sigma$ statistical errors in parentheses)

\begin{tabular}{|c|c|c|c|c|c|}
\hline \multicolumn{2}{|c|}{ Kinf } & \multicolumn{2}{|c|}{$K_{D}$} & \multicolumn{2}{|c|}{$\Delta \rho_{N a}$} \\
\hline $\begin{array}{c}\text { cov } \\
\text { matrix }\end{array}$ & $\Delta \mathbf{k} / \mathbf{k}$ & $\begin{array}{c}\text { cov } \\
\text { matrix }\end{array}$ & $\Delta K_{D} / K_{D}$ & $\begin{array}{c}\text { cov } \\
\text { matrix }\end{array}$ & $\Delta \rho_{N a} / \rho_{N a}$ \\
\hline${ }^{238} \mathrm{U}$ inel. & $1.339(3) \%$ & ${ }^{238} \mathrm{U}$ inel. & $4.3(2) \%$ & $23 \mathrm{Na}$ el. & $3.857(3) \%$ \\
\hline${ }^{238} \mathrm{U} n, \gamma$ & $0.326(1) \%$ & ${ }^{16} \mathrm{O}$ el. & $1.1(1) \%$ & ${ }^{23} \mathrm{Na}$ inel & $3.068(2) \%$ \\
\hline${ }^{239} \mathrm{Pu}$ n, $\gamma$ & $0.250(1) \%$ & ${ }^{239} \mathrm{Pu} \mathrm{n}, \gamma$ & $1.0(1) \%$ & ${ }^{238} \mathrm{U}$ inel. & $1.643(4) \%$ \\
\hline${ }^{239} \mathrm{Pu}$ chi & $0.218(1) \%$ & ${ }^{56} \mathrm{Fe}$ inel. & $0.8(1) \%$ & ${ }^{238} \mathrm{U} \mathrm{n}, \gamma$ & $1.145(1) \%$ \\
\hline${ }^{16} \mathrm{O}$ el. & $0.2051(1) \%$ & ${ }^{239} \mathrm{Pu}$ inel. & $0.8(1) \%$ & ${ }^{239} \mathrm{Pu}$ fis. & $0.882(1) \%$ \\
\hline
\end{tabular}




\subsubsection{Prismatic HTGR: HTTR}

The eigenvalue uncertainty of the HTTR was $0.611(1) \%$, so it was in the expected range of a thermal system. As usually observed for thermal systems with fresh ${ }^{235} \mathrm{U}$ enriched fuel, the neutron multiplicity (nubar) of ${ }^{235} \mathrm{U}$ was the main contributor to the uncertainty, followed by radiative neutron capture in ${ }^{235} \mathrm{U}$. Due to the large amount of graphite in this reactor, the carbon capture and elastic scattering reaction also played an important role for the output uncertainty (Table 26).

\subsubsection{Pebble-Bed HTGR: HTR-10}

The eigenvalue uncertainty of the HTR was $0.687(3) \%$, which was similar to the eigenvalue uncertainty of the HTTR. The major contributor was also the neutron multiplicity of ${ }^{235} \mathrm{U}$. The order of the other important covariance matrices was slightly different from the HTTR, as carbon elastic scattering was the second largest contributor to the output uncertainty (Table 26).

Table 26. Top five contributing covariance matrices to the HTTR and HTR-10 eigenvalue uncertainty calculated with TSUNAMI-3D-CE (1 $\sigma$ statistical errors in parentheses)

\begin{tabular}{|c|c|c|c|}
\hline \multicolumn{2}{|c|}{ HTTR } & \multicolumn{2}{|c|}{ HTR-10 } \\
\hline cov matrix & $\Delta \mathrm{k} / \mathbf{k}$ & cov matrix & $\Delta \mathbf{k} / \mathbf{k}$ \\
\hline${ }^{235} \mathrm{U}$ nubar & $0.3668(1) \%$ & ${ }^{235} \mathrm{U}$ nubar & $0.380(1) \%$ \\
\hline${ }^{235} \mathrm{U} \mathrm{n}, \gamma$ & $0.2708(1) \%$ & C el. & $0.343(2) \%$ \\
\hline $\mathrm{C} \mathrm{n}, \mathrm{g}$ & $0.2075(1) \%$ & ${ }^{235} \mathrm{U}$ chi & $0.271(3) \%$ \\
\hline $\mathrm{C}$ el. & $0.1967(5) \%$ & $\mathrm{Cn}, \gamma$ & $0.253(1) \%$ \\
\hline${ }^{238} \mathrm{U} \mathrm{n}, \gamma$ & $0.1843(1) \%$ & ${ }^{235} \mathrm{U} \mathrm{n}, \gamma$ & $0.171(1) \%$ \\
\hline
\end{tabular}

\subsubsection{Graphite-Moderated MSR Unit Cell}

The eigenvalue uncertainty of the graphite-moderated MSR cell was $0.561(1) \%$ for the fresh cell and $0.636(1) \%$ for the depleted cell. The fresh fuel showed similar important contributors to the eigenvalue uncertainty as those presented for the HTTR in

Table 27. For depleted fuel, neutron capture in ${ }^{238} \mathrm{U}$ and ${ }^{239} \mathrm{Pu}$ fission were the most important contributors due to the buildup of plutonium during depletion.

Table 27. Top five contributing covariance matrices to the graphite-moderated MSR eigenvalue uncertainties calculated with TSUNAMI-3D-CE (1 $\sigma$ statistical errors in parentheses)

\begin{tabular}{|c|c|c|c|}
\hline \multicolumn{2}{|c|}{ Fresh } & \multicolumn{2}{|c|}{ Depleted } \\
\hline cov matrix & $\Delta \mathbf{k} / \mathbf{k}$ & cov matrix & $\Delta \mathbf{k} / \mathbf{k}$ \\
\hline${ }^{235} \mathrm{U}$ nubar & $0.3744(1) \%$ & ${ }^{238} \mathrm{U} n, \gamma$ & $0.3470(1) \%$ \\
\hline${ }^{238} \mathrm{U} n, \gamma$ & $0.2631(1) \%$ & ${ }^{239} \mathrm{Pu}$ fis. & $0.2031(1) \%$ \\
\hline${ }^{235} \mathrm{U} n, \gamma$ & $0.1983(1) \%$ & ${ }^{239} \mathrm{Pu}$ fis. $/ \mathrm{n}, \gamma^{*}$ & $0.2001(1) \%$ \\
\hline $\mathrm{C}$ el. & $0.1352(5) \%$ & C el. & $0.1974(1) \%$ \\
\hline${ }^{235} \mathrm{U}$ fis. & $0.1204(1) \%$ & ${ }^{7} \mathrm{Li} \mathrm{n}, \gamma$ & $0.1783(1) \%$ \\
\hline
\end{tabular}

\subsubsection{Zirconium Hydride-Moderated MSR Unit Cell}

The ZrH-moderated MSR unit cell showed an uncertainty of $0.748(2) \%$ for the fresh fuel and $0.661(1) \%$ for the depleted fuel. Top contributors were radiative capture of ${ }^{91} \mathrm{Zr}$ and ${ }^{92} \mathrm{Zr}$, followed by the ${ }^{239} \mathrm{Pu}$ reaction (Table 28). 
Table 28. Top five contributing covariance matrices to the ZrH-moderated MSR eigenvalue uncertainties calculated with TSUNAMI-3D-CE (1 $\sigma$ statistical errors in parentheses)

\begin{tabular}{|c|c|c|c|}
\hline \multicolumn{2}{|c|}{ Fresh } & \multicolumn{2}{|c|}{ Depleted } \\
\hline cov matrix & $\Delta \mathbf{k} / \mathbf{k}$ & cov matrix & $\Delta \mathbf{k} / \mathbf{k}$ \\
\hline${ }^{238} \mathrm{U} \mathrm{n}, \gamma$ & $0.4563(1) \%$ & ${ }^{91} \mathrm{Zr} \mathrm{n,g}$ & $0.2587(1) \%$ \\
\hline${ }^{235} \mathrm{U} \mathrm{n}, \gamma$ & $0.3703(1) \%$ & ${ }^{92} \mathrm{Zr} \mathrm{n,g}$ & $0.2348(1) \%$ \\
\hline${ }^{235} \mathrm{U}$ nubar & $0.2832(1) \%$ & ${ }^{239} \mathrm{Pu}$ fis. & $0.2312(1) \%$ \\
\hline${ }^{238} \mathrm{U}$ inel. & $0.1934(7) \%$ & ${ }^{239} \mathrm{Pu}$ fis./ $\mathrm{n}, \gamma^{*}$ & $0.2088(1) \%$ \\
\hline${ }^{235} \mathrm{U}$ chi & $0.1854(3) \%$ & ${ }^{241} \mathrm{Pu}$ fis. & $0.2013(1) \%$ \\
\hline
\end{tabular}

\subsubsection{Fast-Spectrum MSR Mixture}

The uncertainty of the fast-spectrum MSR mixture was $1.764(3) \%$ for the fresh fuel and $1.853(6) \%$ for the depleted fuel. This was in the same range as the SFR fuel assemblies. Also, the top contributing covariance matrices were identical due to the fast neutron spectrum (Table 29).

Table 29. Top five contributing covariance matrices to the fast-spectrum MSR eigenvalue uncertainties calculated with TSUNAMI-3D-CE (1 $\sigma$ statistical errors in parentheses)

\begin{tabular}{|c|c|c|c|}
\hline \multicolumn{2}{|c|}{ Fresh } & \multicolumn{2}{|c|}{ Depleted } \\
\hline cov matrix & $\Delta \mathbf{k} / \mathbf{k}$ & cov matrix & $\Delta \mathbf{k} / \mathbf{k}$ \\
\hline${ }^{238} \mathrm{U}$ inel. & $1.508(2) \%$ & ${ }^{238} \mathrm{U}$ inel. & $1.583(4) \%$ \\
\hline${ }^{23} \mathrm{Na}$ el. & $0.532(2) \%$ & ${ }^{23} \mathrm{Na}$ el. & $0.602(3) \%$ \\
\hline${ }^{238} \mathrm{U} \mathrm{n}, \gamma$ & $0.429(1) \%$ & ${ }^{238} \mathrm{U} \mathrm{n}, \gamma$ & $0.398(1) \%$ \\
\hline${ }^{23} \mathrm{Na}$ inel. & $0.333(1) \%$ & ${ }^{23} \mathrm{Na}$ inel. & $0.355(1) \%$ \\
\hline${ }^{239} \mathrm{Pu} \mathrm{n}, \gamma$ & $0.291(1) \%$ & ${ }^{239} \mathrm{Pu} \mathrm{n}, \gamma$ & $0.264(1) \%$ \\
\hline
\end{tabular}




\section{IMPACT OF CROSS SECTION LIBRARIES ON PIN POWER DISTRIBUTIONS}

It was desired to assess the impact of the nuclear data libraries on pin power distributions of a reactor. In addition to comparisons between results obtained with the ENDF/B-VII.1 and ENDF/B-VIII.0 libraries, comparisons with experimental measurements were desired. Validated pin power measurements are, however, not readily available for the advanced reactor concepts of interest. A first assessment of the performance of the nuclear data libraries is therefore performed for pin power calculations of an LWR.

The basis for comparison used in this work are the Babcock and Wilcox (B\&W) BAW-1810 (Newman 1984) experiments. The pin power calculations were performed using the Monte Carlo code KENO V.a in combination with the CE versions of the ENDF/B-VII.1 library distributed with SCALE 6.2.3 and the ENDF/B-VIII.0 library intended for release with SCALE 6.3 beta 1. Two sets of comparisons were performed. The first set of comparisons was between the experimental measurements and KENO V.a calculations performed with both ENDF/B-VII.1 and ENDF/B-VIII.0 libraries. A second set of calculations was performed using models in which the innermost fuel composition of the BAW-1810 was replaced with fuel compositions representative of $5 \mathrm{wt} \%$ enriched fuel irradiated to a burnup of $40 \mathrm{GWd} / \mathrm{MTU}$. Since there were no experimental measurements with burned fuel available, a direct comparison of calculations with the two libraries was performed.

Section 3.1 describes the experiments documented in BAW-1810, as well as the experimental methods used to infer the pin powers. Section 3.2 provides a discussion of the analytical methods and modeling approximations used in the KENO V.a and depletion modeling, and Section 3.3 presents the results and conclusions of the study.

\subsection{Experimental Description}

B\&W ran a series of 23 critical experiments in the early 1980 s to test the ability of core physics codes to predict results of $\mathrm{UO}_{2}-\mathrm{Gd} 2 \mathrm{O}_{3}$ cores. These critical experiments are documented in BAW-1810. The 23 cores in BAW-1810 varied the arrangement and composition of the fuel to be similar to cores that were composed of B\&W $15 \times 15$ and Combustion Engineering $16 \times 16$ fuel assemblies. The cores also included soluble boron, discrete $\mathrm{B}_{4} \mathrm{C}$ absorber rods, and $\mathrm{UO}_{2}-\mathrm{Gd}_{2} \mathrm{O}_{3}$ pins, in addition to standard $\mathrm{UO}_{2}$ fuel rods. The first ten cores were composed entirely of $2.46 \mathrm{wt} . \%$ enriched $\mathrm{UO}_{2}$ fuel rods, with the exception of $\mathrm{UO}_{2}$ $\mathrm{Gd}_{2} \mathrm{O}_{3}$ fuel rods, which were composed of 1.944 wt.\% enriched $\mathrm{UO}_{2}$ mixed with 4.02 wt. $\% \mathrm{Gd}_{2} \mathrm{O}_{3}$. Both the 2.46 wt. $\%$ enriched $\mathrm{UO}_{2}$ fuel rods and the $\mathrm{UO}_{2}-\mathrm{Gd}_{2} \mathrm{O}_{3}$ fuel rods were clad in aluminum. The soluble boron concentration was adjusted for each case so that criticality could be achieved at approximately the same water height while adjusting for the amount of fixed absorber rods included in the experimental configuration. Cores 12 through 17 were similar to the first ten cores, except a central region composed of 4.02 wt.\% $\mathrm{UO}_{2}$ fuel clad in stainless steel was used. Cores 18 through 20 were similar to earlier cores, except that water holes equal to four fuel rod locations were included to simulate the guide tube placement of CE $16 \times 16$ fuel assemblies. For all of the configurations modeled as part of this work, in-core detectors were placed in the central water-filled region of the core.

With respect to the validation for reactor physics purposes, pin powers were measured for Cores $1,5,12$, 14,18 , and 20 by placing the reactor on a positive period and exposing the cores to a burnup of approximately $1 \mathrm{~kW}$-minute. Following the irradiations, the fuel rods in the central region of the core were removed, and the fission product gammas were counted. The rods were placed in a holder such that a collimated sodium iodide detector could be used to count the gammas arising from the axially centered oneinch segment of each rod. The decay associated with the time interval between irradiation and counting was corrected by using the "master" fuel rod, which was removed and counted with a replica detector system simultaneously with each rod. The drop off in the number of the counts for the master fuel rod was then factored into the counts associated with each of the experimental rods. Additional corrections to the counting procedure to account for the variations in intrapellet radial power profile, cladding material, and 
thickness discrepancies were accounted for by dissolving a few selected pellets and measuring the activity of the resulting solution. Powers were measured for each of the fuel pins in the east-southeast eighth of the central fuel assembly of the cores, as well as along the diagonal in the southeastern quadrant of the core.

A summary of the of characteristics of each of the cores analyzed here is provided in Table 30 . Figure 25 through Figure 27 provide the radial layout of the analyzed cores with the placement of the fuel rods of various enrichment, the $\mathrm{UO}_{2}-\mathrm{Gd}_{2} \mathrm{O}_{3}$ rods, and in-core detector placement. Figure 25 shows Cores 1 and 5 , Figure 26 shows Cores 12 and 14, and Figure 27 shows Cores 18 and 20. These cores were grouped into figures together because they are identical to one another, except that $20 \mathrm{UO}_{2}-\mathrm{Gd}_{2} \mathrm{O}_{3}$ rods are included in place of pure $\mathrm{UO}_{2}$ rods. As discussed later, an axially reflected model was used, so the water height was not important. However, the water height was $153 \mathrm{~cm}$ for each of the B\&W $15 \times 15$ lattices and $180 \mathrm{~cm}$ for the Combustion Engineering $16 \times 16$ lattices.

Table 30. Characteristics of the analyzed BAW-1810 core

\begin{tabular}{|c|c|c|c|c|c|}
\hline Core & $\begin{array}{c}2.46 \text { wt. } \% \\
\text { Rods }\end{array}$ & $\begin{array}{c}4.02 \text { wt. } \% \\
\text { Rods }\end{array}$ & $\begin{array}{c}\mathrm{UO}_{2-} \\
\mathrm{Gd}_{2} \mathrm{O}_{3} \\
\text { Rods } \\
\end{array}$ & Similar Fuel Design & $\begin{array}{c}\text { Soluble boron } \\
\text { concentration } \\
{[\mathrm{ppm}]}\end{array}$ \\
\hline 1 & 4,808 & 0 & 0 & B\&W $15 \times 15$ & $1,337.9$ \\
\hline 5 & 4,780 & 0 & 20 & $\mathrm{~B} \& \mathrm{~W} 15 \times 15$ & $1,208.0$ \\
\hline 7 & 3,920 & 888 & 0 & $\mathrm{~B} \& \mathrm{~W} 15 \times 15$ & $1,899.3$ \\
\hline 14 & 3,920 & 860 & 20 & B\&W $15 \times 15$ & $1,653.8$ \\
\hline 18 & 3,676 & 944 & 0 & Combustion Engineering $16 \times 16$ & $1,776.8$ \\
\hline 20 & 3,676 & 912 & 20 & Combustion Engineering $16 \times 16$ & $1,499.8$ \\
\hline
\end{tabular}

\subsection{Analytical Methods and Model Approximations}

The calculations were performed using the Monte Carlo code KENO V.a of SCALE 6.2.3 with ENDF/BVII.1 and ENDF/B-VIII.0 CE cross section libraries. Historically, if individual pin powers were a desired output, then unique geometric units would have to be constructed for each of the locations for which results were desired. SCALE versions 6.0 and above have implemented the mesh tally capability, which allows the user to overlay a mesh on the array of fuel pins using the GridGeometry block and enter "cds=yes" in the parameters block of the input to obtain unique fission reaction rates for each pin. The KENO V.a calculations were performed with 10,000 active generations of 300,000 particles per generation to ensure that the statistical uncertainty on the individual pin fission densities was small; 500 generations were skipped so that the fission source could be properly converged before the fission rate tallies were started. The convergence of the fission source was assessed to be acceptable because all three of the Shannon Entropy tests were passed for all of the calculations. Additionally, reflective boundary conditions were used on the top and bottom surfaces of the model. The reflective boundary conditions eliminate axial leakage, thus making the calculated eigenvalue meaningless; however, the radial pin power distribution was unaffected by the approximation. By eliminating axial leakage from the problem, each computational neutron was forced to score more interactions within the body of the problem, decreasing the statistical uncertainty on the tallied fission rates. The tallied fission rates have a reported Monte Carlo uncertainty of about $0.12 \%$. 

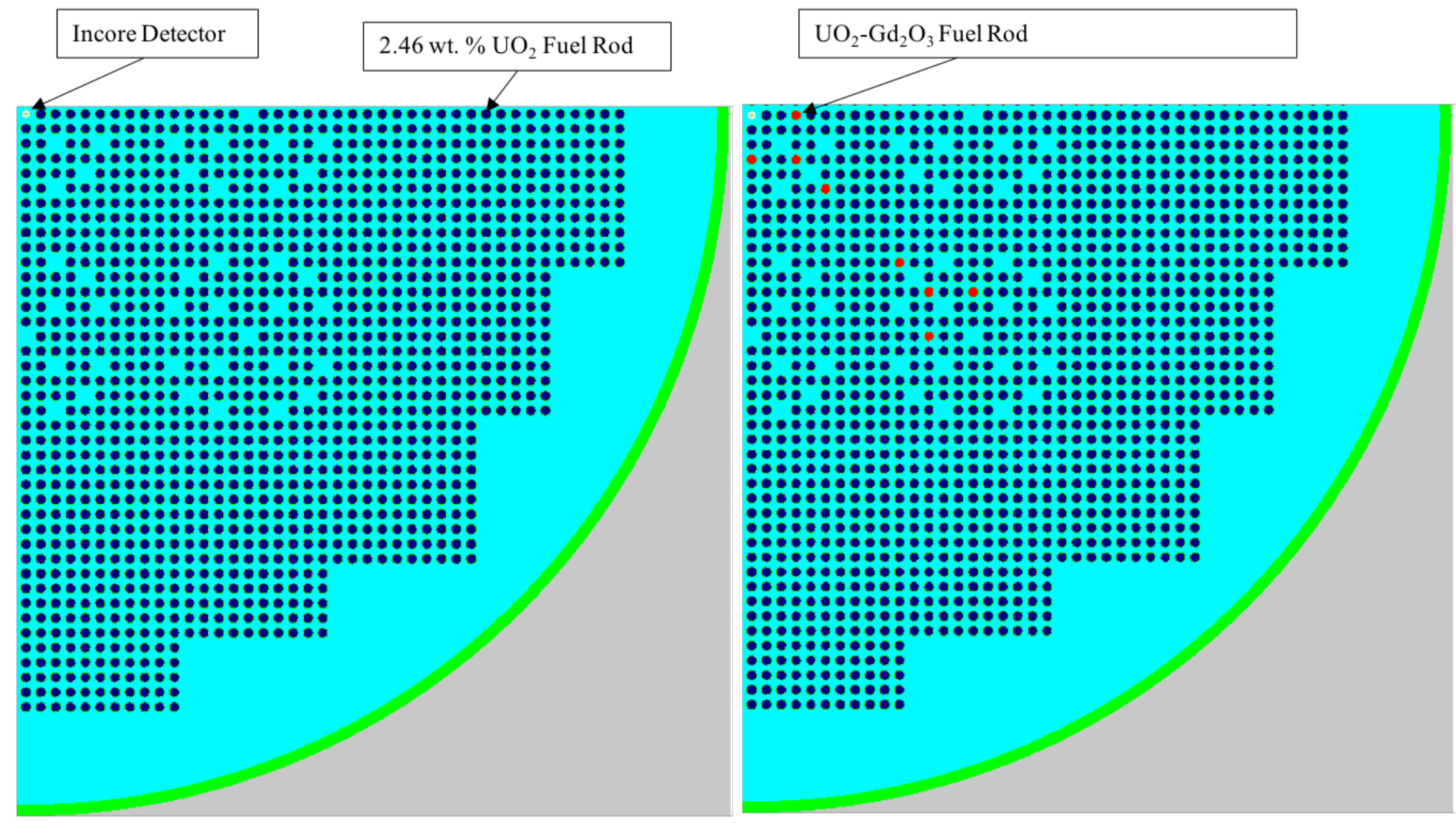

Figure 25. Radial depiction of the quarter core models for Cores 1 and 5. 


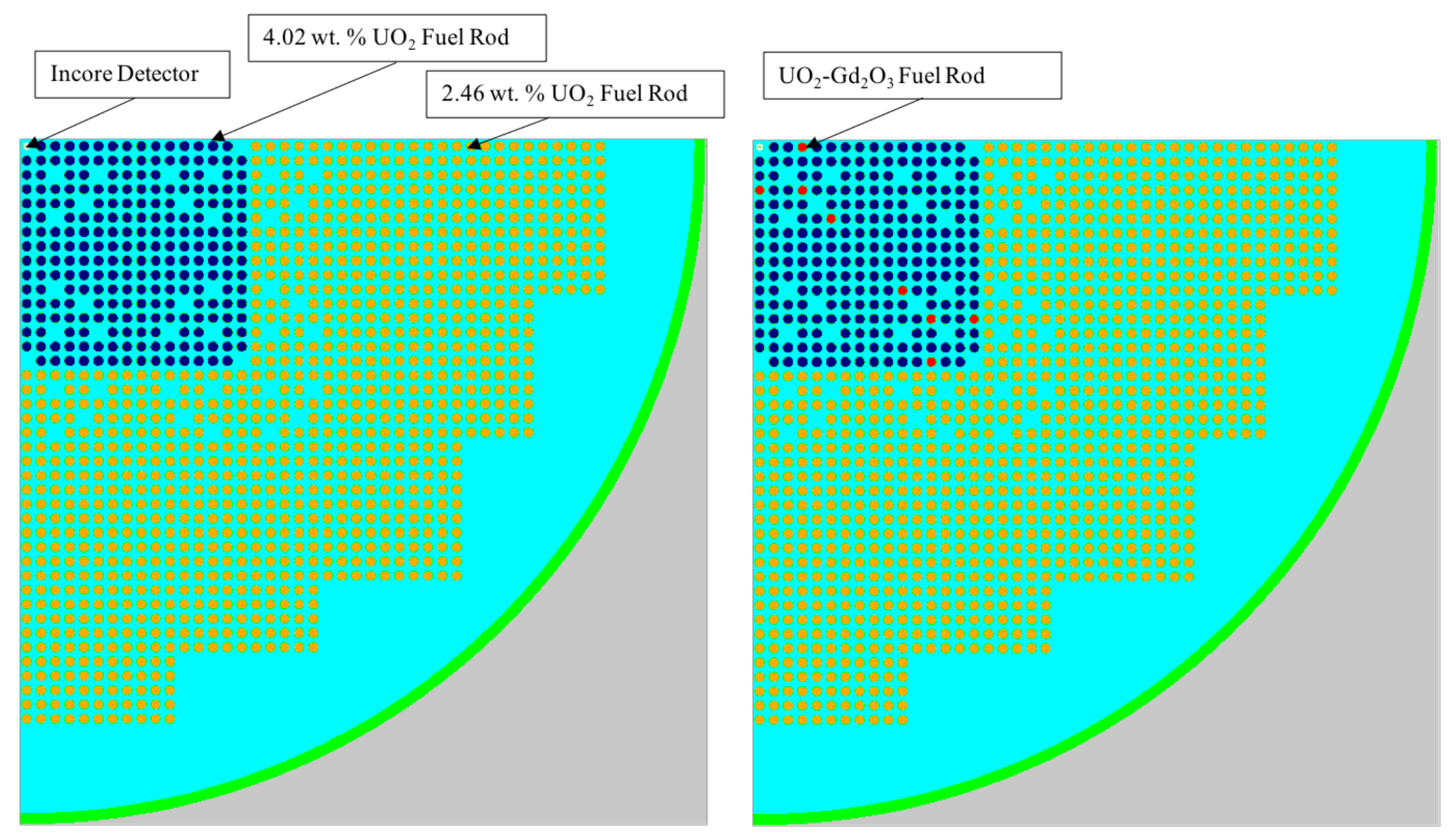

Figure 26. Radial depiction of the quarter core models for Cores 12 and 14. 


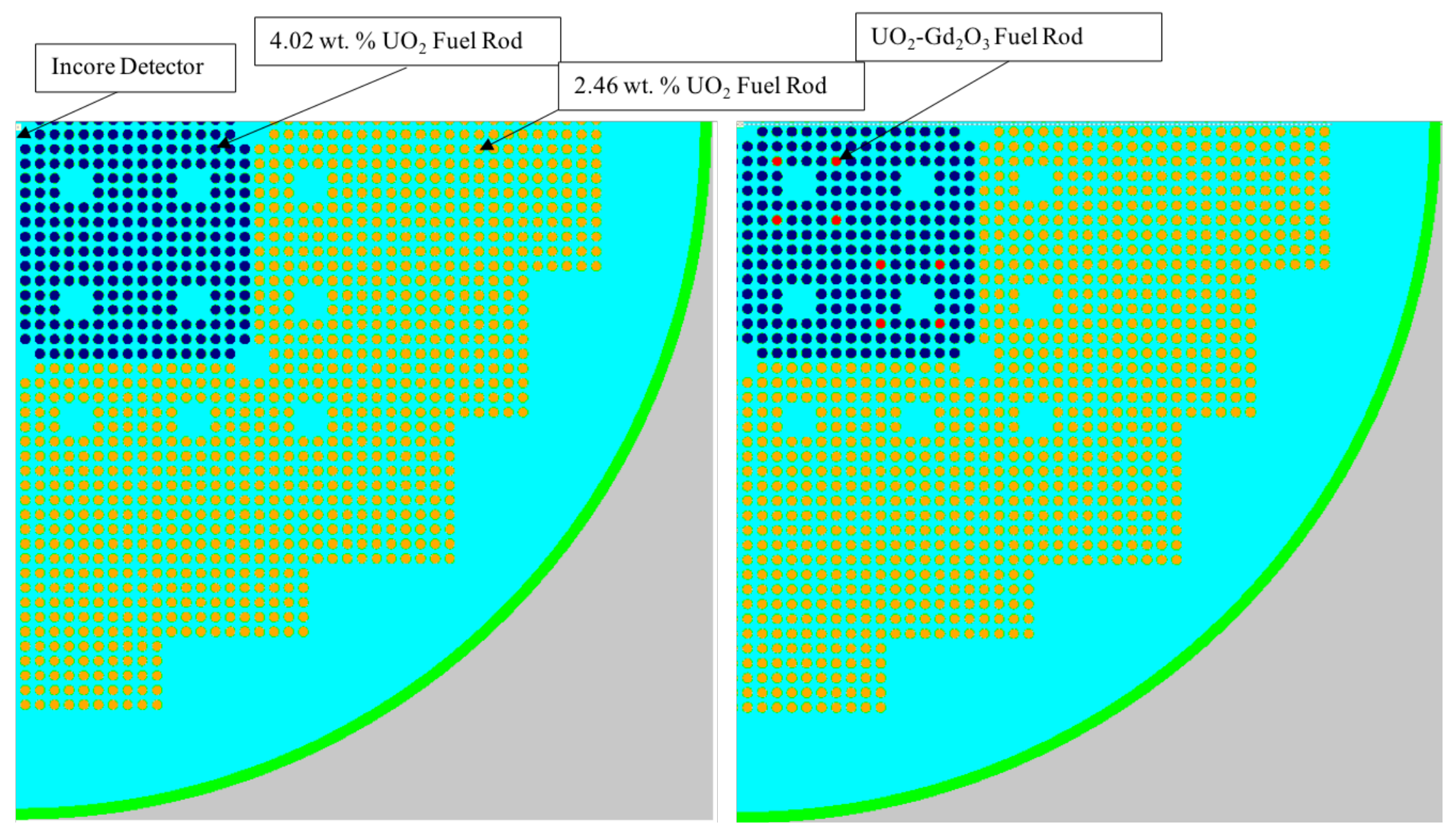

Figure 27. Radial depiction of the quarter core models for Cores 18 and 20. 
Calculations performed without modeling the in-core detector in the center of the problem led to an overprediction of pin powers adjacent to the center of the water hole by approximately $7 \%$ for the $\mathrm{B} \& \mathrm{~W}$ $15 \times 15$ cases and approximately $3.5 \%$ for the Combustion Engineering $16 \times 16$ cases. In order to account for moderator displacement and neutron absorption effect, the detector model used by Palmtag and Stimpson (2017) was used here, as well. For the CE $16 \times 16$ cases, the in-core detector model was placed in the middle of a set of four pins' worth of water, which required dividing the detector into four equal regions. With KENO V.a, a quarter cylinder model cannot be modeled. To work around the geometric limitation of the code and to also preserve the impact of the cylindrical detector model from Palmtag and Stimpson (2017) on the pin powers, a cuboidal model with the same volume was constructed.

Once the calculations were performed, the pin-wise fission rates were extracted from the ".3dmap" output files. The results were then processed into relative pin powers by averaging the values of all of the symmetric values for each of the pins in the calculation. For each of the pins on the major and minor axes, this resulted in averaging four pins together. For all other pins, these values averaged eight values together. The symmetric location averaged fission rates were averaged over the entire central assembly to determine the normalization constant. Each of the fission rates was then divided by the normalization constant to give the calculated value of the relative pin power. The diagonal pin fission density values (Cores 5, 14, and 20) were also divided by the fission density normalization constant from the central assembly to be consistent with the measurement methodology used in in BAW-1810.

To test the impact of the nuclear data changes in nuclides not found in fresh fuel $(\mathrm{Pu}$ isotopes, other actinides, and fission products) on pin power predictions, calculations of models that included a depleted fuel composition substituted for the central fuel composition (navy blue mixture in Figure 25 to Figure 27 were performed. Since there were no experimental values for these problems, only library-to-library comparisons between ENDF/B-VII.1 and ENDF/B-VIII.0 were performed. The burned fuel isotopic compositions were generated using the SCALE 6.2.3 default B\&W $15 \times 15$ reactor library with the point depletion code ORIGAMI. 5.0 wt.\% enriched fuel was depleted up to a burnup of $40 \mathrm{GWd}$ /MTU.

\subsection{Results}

The calculated relative pin powers for this work were compared to the relative pin powers reported in BAW1810. The discussion of the results is most tractably broken into the pin powers from the central assembly and the pin powers along the diagonal of the core. A summary of the central assembly pin powers is provided in Table 31 for ENDF/B-VII.1 and in Table 32 for ENDF/B-VIII.0, and detailed maps of the percentage error, calculated as $\left(\mathrm{P}_{\text {calc }}-\mathrm{P}_{\exp }\right) \times 100 \%$, are presented in Figure 28. Table 31 shows that for the ENDF/B-VII.1 calculations, the root mean square (RMS) error across the central quarter of the assembly ranges from $0.461-0.926 \%$, with the most extreme departures ranging from $-2.18-2.50 \%$. Table 32 shows that for the ENDF/B-VIII.0 calculations, the RMS error is $0.468-0.902 \%$, with the most extreme departures ranging from $-2.08-2.60 \%$. The results of these calculations are consistent across both cross section libraries and are also approximately the same as those given by MPACT (Palmtag and Stimpson 2017). Also, the individual pins with the highest misprediction compared to measurement were in the same locations for both calculations and in the previously generated MPACT values. In most cases, the regions of highest misprediction were directly adjacent to the water hole locations. Since the mispredictions in pin powers occurred in the same locations regardless of the library or transport code used, it is likely that there are experimental errors or errors in the nuclear data that were not addressed by the change between ENDF/VII.1 and ENDF/B-VIII.0.

The diagonal relative pin power mispredictions as a function of the distance from the center of the lattice for Cores 5, 14, and 20 are shown in Figure 29 for the ENDF/B-VII.1 calculations and Figure 30 for the ENDF/B-VIII.0 calculations. The results show that the mispredictions range from about $-2.5-1.2 \%$ for both calculations, and they are similar to the cross section sets in each location analyzed. The pin powers are generally well predicted and consistent between cross section libraries with the MPACT code using ENDFVII. 1 cross sections. It is noticeable that there is a shift in the predictions to an average of about $-1.0 \%$ at 
approximately 20 pitches from the center of the lattice. It is possible that there are modeling approximations made at the periphery of the core that are negatively affecting the results or that the gamma measurement technique biases low for lower power level near the core periphery.

The library-to-library comparisons of the BAW-1810 models in which depleted fuel was inserted in the central portion of the fuel assembly do not reveal significant differences in the pin power distribution. Figure 31 shows the interlibrary differences in the central portion of the lattice, and Figure 32 shows the differences along the diagonal. The peak difference in the central portion of the assembly was $0.49 \%$ across all of the calculations, with the majority of the differences being less than $0.2 \%$. It is noted that while the differences amongst the cross section libraries are not large, they are well outside the Monte Carlo uncertainties $(\sim 0.06 \%)$ and are larger than the interlibrary comparison performed for the fresh fuel calculations in the right column of Figure 28. This indicates that cross section changes for the plutonium isotopes are likely the reason for the majority of the difference in pin power calculations. The differences along the diagonal showed little variability for Core 5 and more variability for Cores 14 and 20. Core 5 was composed of a single fuel composition (outside the Gd rods), while Cores 14 and 20 had two fuel zones. The two zone cores showed increases in the pin powers in fuel pins closest to the center of the core (burned fuel compositions) and slight decreases in pin powers in the fresh fuel regions.

Table 31. Calculated central pin power results for the BAW-1810 cores using the ENDF/B-VII.1 library

\begin{tabular}{cccc}
\hline Core & RMS error & Maximum positive error & Maximum negative error \\
\hline 1 & $0.461 \%$ & $0.79 \%$ & $-1.46 \%$ \\
5 & $0.560 \%$ & $1.33 \%$ & $-1.03 \%$ \\
7 & $0.748 \%$ & $1.47 \%$ & $-2.18 \%$ \\
14 & $0.775 \%$ & $2.12 \%$ & $-1.76 \%$ \\
18 & $0.787 \%$ & $1.74 \%$ & $-1.55 \%$ \\
20 & $0.926 \%$ & $2.50 \%$ & $-1.92 \%$ \\
\hline
\end{tabular}

Table 32. Calculated central pin power results for the BAW-1810 cores using the ENDF/B-VIII.0 library

\begin{tabular}{rccc}
\hline Core & RMS error & Maximum positive error & Maximum negative error \\
\hline 1 & $0.468 \%$ & $0.88 \%$ & $-1.43 \%$ \\
5 & $0.519 \%$ & $1.20 \%$ & $-0.93 \%$ \\
7 & $0.744 \%$ & $1.49 \%$ & $-2.08 \%$ \\
14 & $0.788 \%$ & $2.09 \%$ & $-1.87 \%$ \\
18 & $0.804 \%$ & $1.73 \%$ & $-1.54 \%$ \\
20 & $0.902 \%$ & $2.60 \%$ & $-1.84 \%$ \\
\hline
\end{tabular}




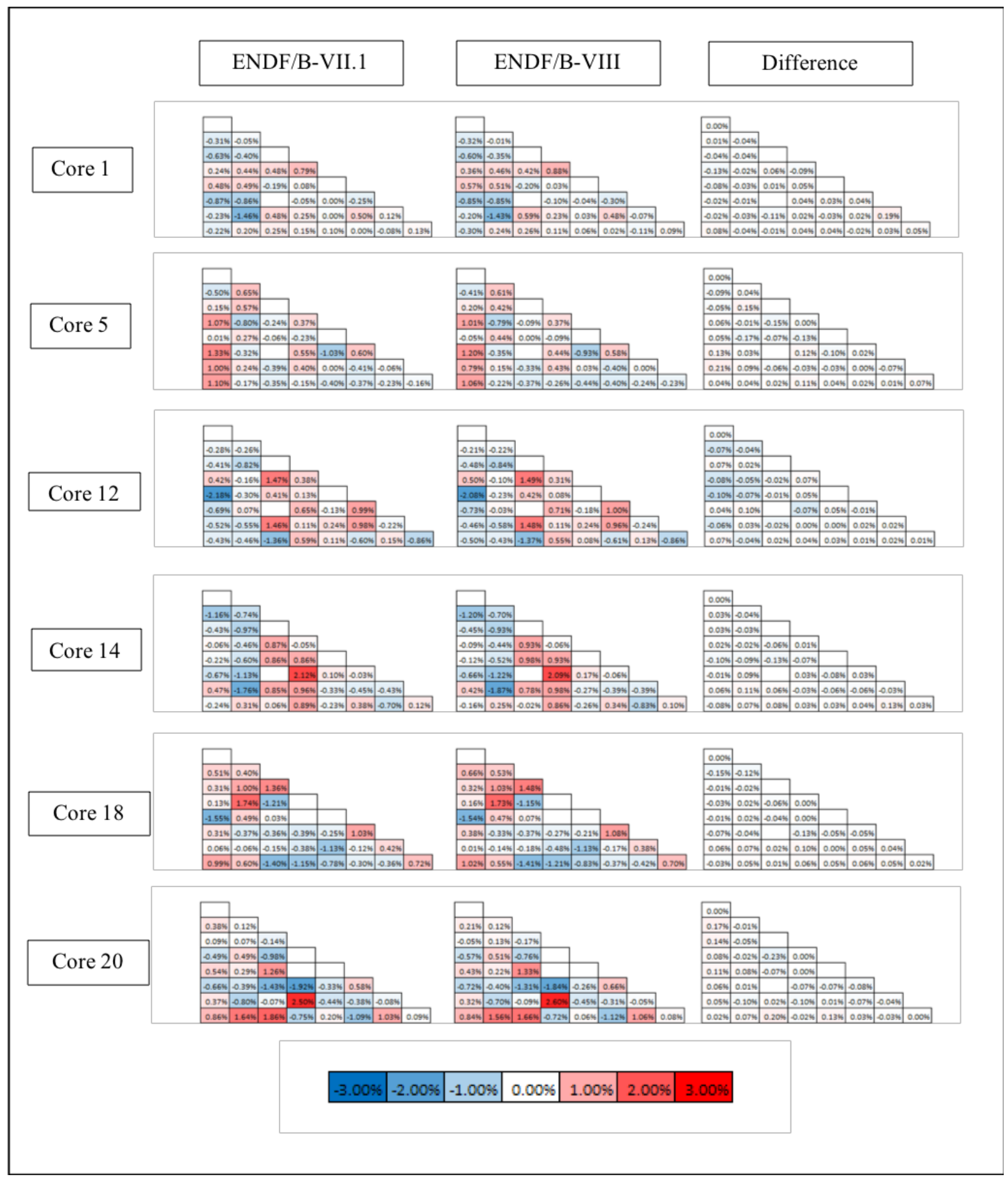

Figure 28. Left two columns: Differences of the calculated central pin powers to the BAW-1810 experimental results with ENDF/B-VII.1 and ENDF/B-VIII.0 nuclear data, respectively. Right column: Differences between the ENDF/B-VII.1 and ENDF/B-VIII pin powers. 


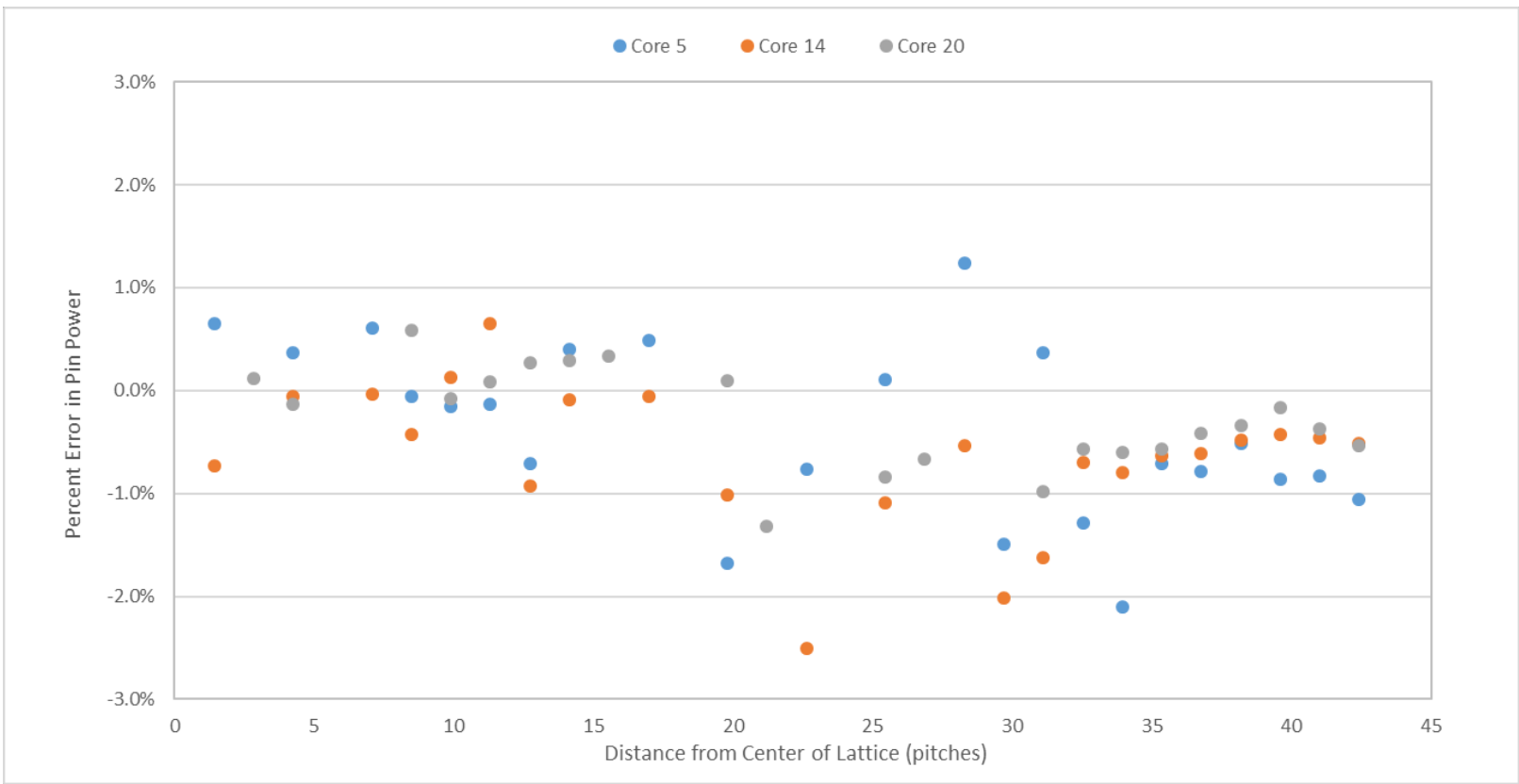

Figure 29. Relative difference of calculated central pin powers using ENDF/B-VII.1 data to the experimental values along the diagonal of BAW-1810 calculated.

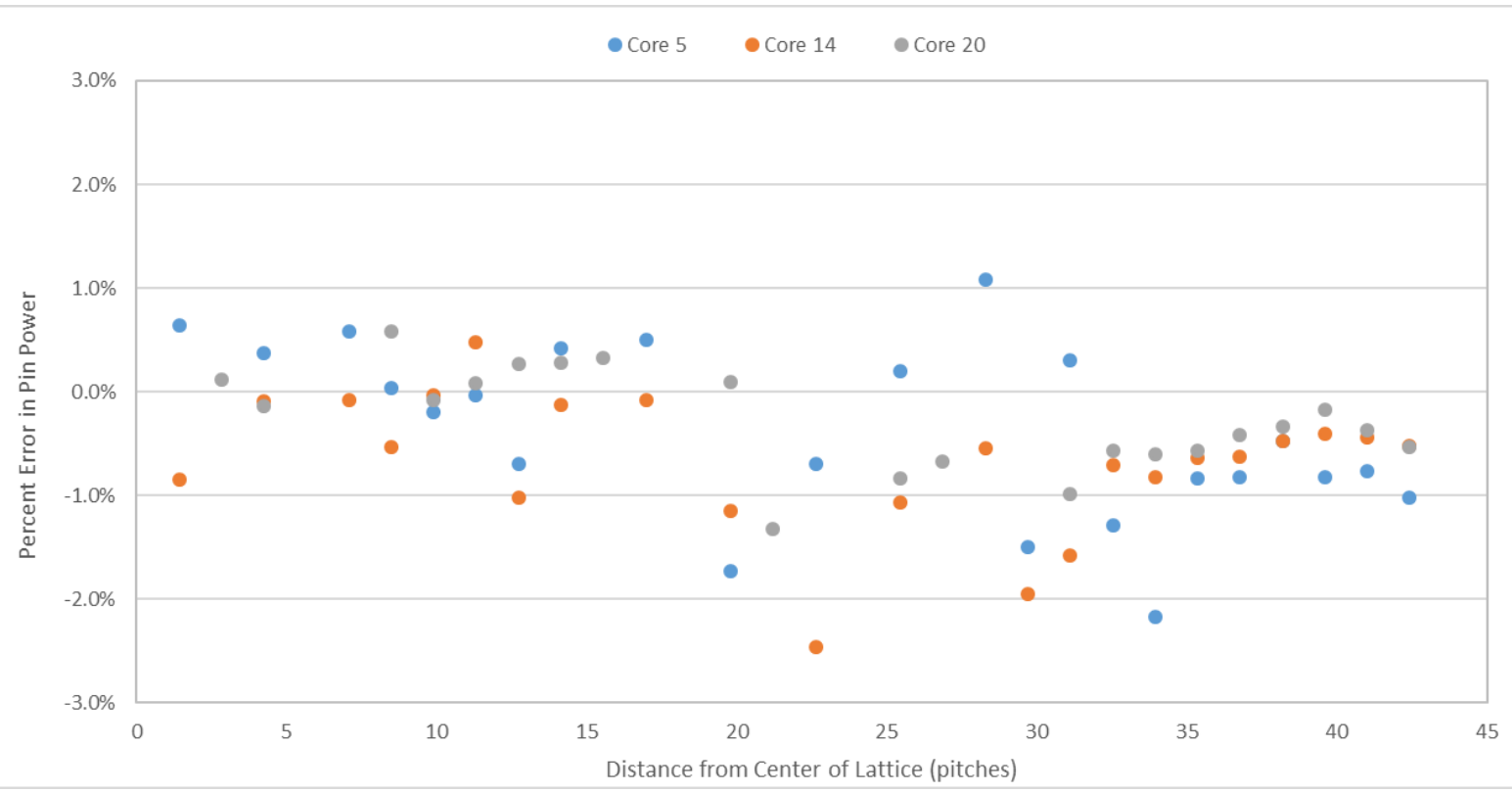

Figure 30. Relative difference of calculated central pin powers using ENDF/B-VIII.0 data to the experimental values along the diagonal of BAW-1810 calculated. 


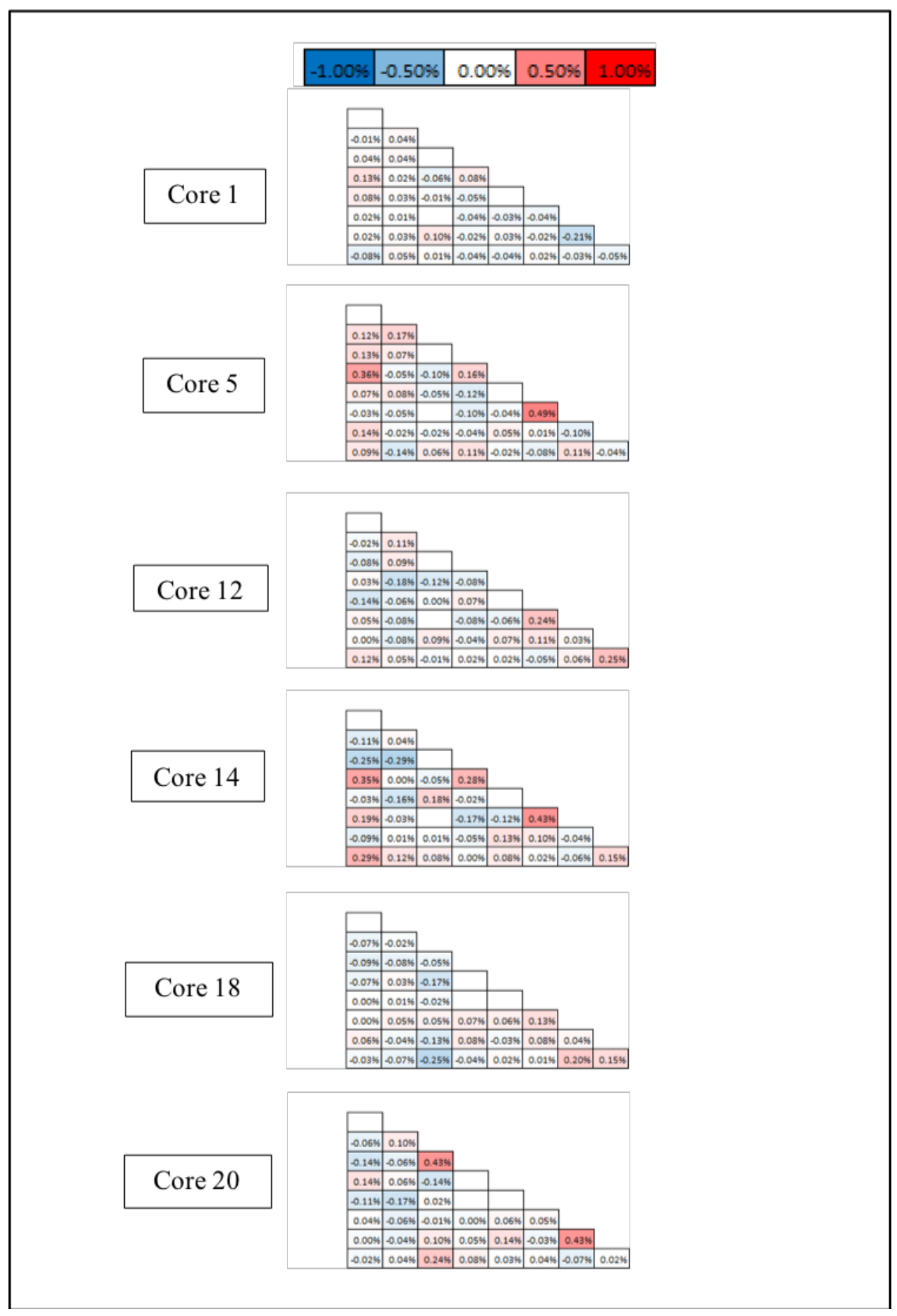

Figure 31. Differences of calculated central pin powers for the BAW-1810 experiments between ENDF/B-VII.1 and ENDF/B-VIII.0 nuclear data for the case with depleted fuel isotopic compositions. 


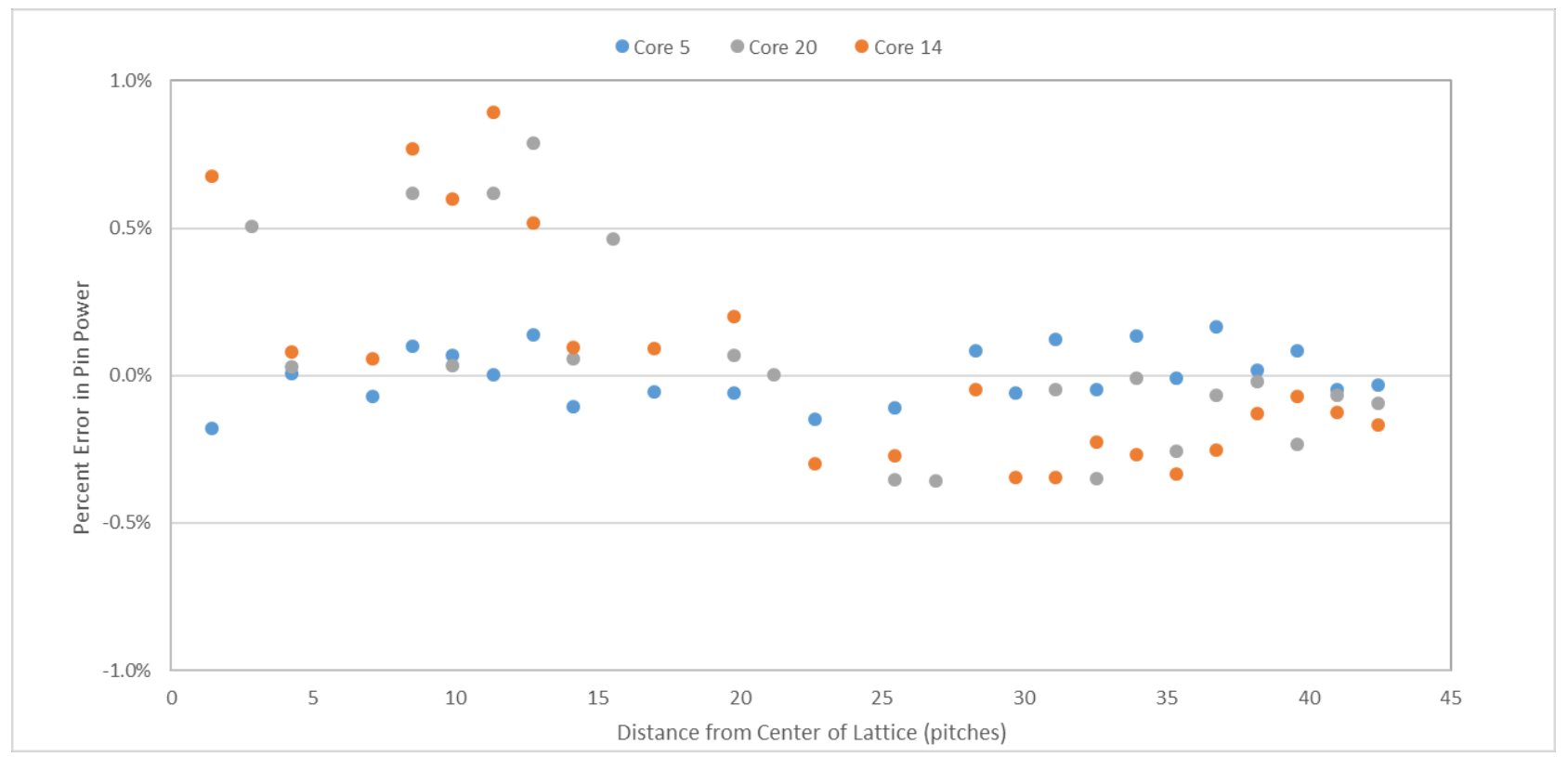

Figure 32. Differences between ENDF/B/VII.1 and ENDF/B-VIII.0 calculated pin powers for the case with depleted fuel isotopic compositions. 



\section{SUMMARY}

Over the last several ENDF/B releases, many updates have been introduced in the nuclear data that can significantly change computational results. These changes can be particularly important for advanced reactor concepts, which are not as thoroughly investigated as those used in LWR systems. Therefore, a performance assessment of the $\mathrm{ENDF} / \mathrm{B}$ libraries relevant to the advanced reactor community was conducted within the framework of the Nuclear Data and Benchmarking Program. The following systems relevant to the advanced reactor community were investigated in this report: sodium cooled fast reactor (SFR) fuel assemblies, graphite moderated high temperature gas-cooled reactors (HTGR), and several molten salt reactor (MSR) models. Criticality calculations were performed with the Monte Carlo code KENO-VI of SCALE 6.2.3 using ENDF/B-VII.0, VII.1 and VIII.0 data. Uncertainty and sensitivity analyses were performed using SCALE's perturbation theory-based TSUNAMI code.

For the investigated SFR fuel assemblies, significant eigenvalue differences of 200-450 pcm were found between calculations using the latest two ENDF/B releases, ENDF/B-VII.1 and VIII.0. These differences were mainly caused by updates of ${ }^{238} \mathrm{U}$ and ${ }^{239} \mathrm{Pu}$ neutron cross sections. Results from the multigroup (MG) calculations further revealed that the group structure of the applied MG library strongly influences the MG bias due to the importance of an appropriate energy resolution of the resonances in higher energy ranges. A difference of several hundred pcm was obtained with the commonly used 252-group library that is optimized for thermal systems. In contrast, significant improvements were obtained with a 302-group library that has been optimized for fast systems.

Nuclear data uncertainty analyses of these SFR systems resulted in eigenvalue uncertainties between 1.4 and $1.8 \%$, which are three to four times higher than corresponding uncertainties in LWR systems. The main contributor to this uncertainty was found to be inelastic scattering on ${ }^{238} \mathrm{U}$, which shows an uncertainty of up to $50 \%$ in the fast energy range. Other important contributors, especially for Doppler and sodium void worth uncertainties, are scattering reactions of ${ }^{56} \mathrm{Fe}$ and ${ }^{23} \mathrm{Na}$ which have so far not appeared in LWR analysis. The impact of uncertainties in the angular scattering data was not considered in these calculations. Angular scattering uncertainty is not available for the majority of nuclides, and the capabilities to determine sensitivities to this data are currently underdeveloped. However, since the scattering reactions play a significant role for fast-spectrum systems, a non-negligible impact may need to be investigated (Hill and Jeong 2017).

For two graphite moderated HTGR benchmarks, only the ENDF/B-VII.1 calculations resulted in consistent eigenvalues with the corresponding experimental measurements. The ENDF/B-VII.0 eigenvalue was larger than the ENDF/B-VII.1 eigenvalue by about $1,000 \mathrm{pcm}$ only due to differences in the carbon capture cross section in the thermal energy range. The ENDF/B-VIII.0 eigenvalue was larger than the ENDF/B-VII.1 eigenvalue by about $300 \mathrm{pcm}$ mainly due to updates in multiple ${ }^{235} \mathrm{U}$ neutron cross sections.

With the release of ENDF/B-VIII.0, three different graphite evaluations are available: graphite as perfect crystal, with $10 \%$ porosity, and with $30 \%$ porosity. ENDF/B releases had so far only included graphite as perfect crystal. It was shown that the choice of the graphite porosity for the individual graphite components can have a major impact on the eigenvalue result: In test calculations of the HTR-10 at room temperature, a maximum eigenvalue difference of about $650 \mathrm{pcm}$ due to the different graphite porosities was observed. It is, however, not possible to make recommendations for the choice of the graphite porosity for neutronics modeling. In fact, the graphite porosity changes as a function of neutron fluence. For an adequate consideration of the porosity, it is consequently necessary to have detailed information about the porosity in the included materials considering the manufacturing and the reactor operation history.

The uncertainty of the HTGR eigenvalues due to nuclear data uncertainties was found between 0.5 and $0.6 \%$, with the top contributor being the neutron multiplicity of ${ }^{235} \mathrm{U}$. A gap in the form of missing 
uncertainties in graphite thermal scattering data, that might have significant impact on HTGR reactors, was identified. New graphite thermal scattering evaluations are being addressed by the Nuclear Data and Benchmarking Program.

For graphite-moderated systems, uncertainties in the thermal scattering data are not available and are consequently not considered. Since graphite is the main structural component in HTGR, the impact of graphite-scattering uncertainties might have a significant impact on uncertainties of important reactor physics parameters. To close this gap, the Nuclear Data and Benchmarking Program has already funded two NEUP projects that are involved in the generation of thermal scattering data for graphite and the generation of thermal scattering sensitivity/uncertainty capabilities.

The fast spectrum molten salt reactor calculations revealed similar comparisons as for the SFR assemblies. The eigenvalue uncertainties were significantly influenced by inelastic scattering on ${ }^{238} \mathrm{U}$, while the impact of angular scattering distributions is unknown. For the graphite and zirconium hydride moderated system, eigenvalue uncertainties of up to $700 \mathrm{pcm}$ were observed, requiring in depth analyses of the cross sections and corresponding uncertainties of the included materials. In general, it was observed that the flux spectra of the various molten salt reactor systems show significant differences, even between a fresh state and a depleted state. The choice of the energy group structure of MG calculations is therefore highly relevant; the applicability of previously used MG libraries needs to be verified.

For an LWR based on Babcock and Wilcox BAW-1810 experiments, pin power calculations with both ENDF/B-VII.1 and VIII.0 data were compared to measurements. Both calculations show good agreement with the measurements. The slight deviations for some pin powers that consistently show up at the same location are most likely the result of measurement errors. A comparison between the ENDF/B-VII.1 and VIII.0 results revealed small differences. Most differences were in the range of about $0.2 \%$.

The similarity of the integral performance of the ENDF/B-VII.1 and ENDF/B-VIII.0 libraries is caused by compensating errors in important differential data. In the CE KENO calculations of a shipping container of high-assay low enriched uranium, the compensating errors between isotopes were demonstrated by systematically swapping the data of individual isotopes between the two ENDF/B libraries. An eigenvalue difference of up to $450 \mathrm{pcm}$ due to the use of ${ }^{235} \mathrm{U}$ and ${ }^{238} \mathrm{U}$ from one library and ${ }^{1} \mathrm{H}$ and ${ }^{16} \mathrm{O}$ from the other library was found. This clearly demonstrates a cross correlation between reaction data sets of different isotopes that should be reported in the evaluations. 


\section{REFERENCES}

E. Bauge et al. 2012. "Coherent Investigation of nuclear data at CEA DAM: Theoretical models, experiments and evaluated data, " The European Physical Journal A 48:113.

B. R. Betzler et al. 2017a. "Molten Salt Reactor and Fuel Cycle Modeling and Simulation with SCALE," Annals of Nuclear Energy 101, pp. 489-503.

B. R. Betzler et al. 2017b. "Assessment of Neutronic and Fuel Cycle Performance of the Transatomic Power Molten Salt Reactor,” ORNL/TM-2017/475, CRADA/NFE-16-06345.

B. R. Betzler et al. 2017c. "Two-Dimensional Neutronic and Fuel Cycle Analysis of the Transatomic Power Molten Salt Reactor,” ORNL/TM-2016/742.

B. R. Betzler et al. 2017d. "Fuel Cycle Analysis of Fast and Thermal Molten Salt Reactors," Proc. GLOBAL International Fuel Cycle Conference, Seoul, Korea, Sep. 24-29.

B. R. Betzler et al. 2018. "Fuel Cycle and Neutronic Performance of a Spectral Shift Molten Salt Reactor Design,” Annals of Nuclear Energy 119, pp. 396-410.

F. Bostelmann et al. 2017. "SCALE Multi-Group Libraries for Sodium-cooled Fast Reactor Systems", Proc. of M\&C 2017, Jeju, Korea, April 16-20, 2017.

F. Bostelmann et al. 2018. "Benchmark for Uncertainty Analysis in Modeling (UAM) for Design, Operation and Safety Analysis of SFRs, Definition of Sub-Exercises" (OECD/NEA UAM-SFR benchmark specifications distributed to authorized participants).

J. B. Briggs et al. 2017. "The International Criticality Safety Benchmark Evaluation Project," Nuclear Science and Engineering 145, Issue 1, pp. 1-10.

D. A. Brown et al. 2018. "ENDF/B-VIII.0: The $8^{\text {th }}$ Major Release of the Nuclear Reaction Data Library with CIELO-project Cross Sections, New Standards and Thermal Scattering Data," Nuclear Data Sheets 148, pp. 1-142.

L. Buiron et al. 2017. "Benchmark for Uncertainty Analysis in Modelling (UAM) for Design, Operation and Safety Analysis of SFRs, Core Definitions," Version 1.5, Rev. 10, February 10 (OECD/NEA UAMSFR benchmark specifications distributed to authorized participants).

A. A. Campbell et al. 2016. "Property Changes of G347A Graphite Due to Neutron Irradiation," Carbon 109, pp. 860-873.

M. B. Chadwick et al. 2006. "ENDF/B-VII.0: Next Generation Evaluated Nuclear Data Library for Nuclear Science and Technology,” Nuclear Data Sheets 107, Issue 12, pp. 2931-3060.

M. B. Chadwick et al. 2011. "ENDF/B-VII.1 Nuclear Data for Science and Technology: Cross Sections, Covariances, Fission Product Yields and Decay Data," Nuclear Data Sheets 112, Issue 12, pp. 2887-2996.

M. B. Chadwick et al. 2018. "CIELO Collaboration Summary Results: International Evaluations of Neutron Reactions on Uranium, Plutonium, Iron, Oxygen, and Hydrogen," Nuclear Data Sheets 148, pp. 189-213. 
E. E. Davidson et al. 2018. "Modeling a Fast Molten Salt Reactor with ORION," Proc. 15 ${ }^{\text {th }}$ NEA Information Exchange Meeting on Actinide and Fission Product Partitioning and Transmutation, Manchester Hall, Manchester, UK.

I. Hill and S. Jeong. 2017. "Status and Analysis of P1 Angular Scattering Sensitivity Data Available Within the Database for ICSBEP (DICE)," Proc. M\&C 2017, April 16-20, Jeju, Korea.

G. Ilas. 2010. "On SCALE Validation for PBR Analysis," PHYSOR 2010 International Conference on Reactor Physics, Pittsburgh, PA.

G. Ilas et al. 2012. "Validation of SCALE for High Temperature Gas-Cooled Reactor Analysis," NUREG/CR-7107, ORNL/TM-2011/161.

International Handbook of Reactor Physics Experiments. 2010. "Evaluation of the Start-up Core Physics Tests at Japan's High Temperature Engineering Test Reactor (Fully-Loaded Core)," HTTR-GCR-RESR001, NEA/NSC/DOC(2006)1, Rev. 1.

International Handbook of Reactor Physics Experiments. 2007. "Evaluation of the Initial Critical Configuration of the HTR-10 Pebble-Bed Reactor," HTR10-GCR-RESR-001, NEA/NSC/DOC(2006)1, Rev. 0.

K. S. Kim et al. 2018a. "The AMPX/SCALE Multigroup Cross Section Processing for Fast Reactor Analysis," Proc. PHYSOR 2018, Cancun, Mexico, April 22-26.

L. W. Newman. 1984. "Urania-Gadolinia: Nuclear Model Development and Critical Experiment Benchmark," BAW-1810, Babcock and Wilcox.

S. Palmtag and S. G. Stimpson. 2017. "MPACT Validation with Critical Experiments," CASL-U-20171388-000, Oak Ridge National Laboratory.

B. T. Rearden et al. 2014. "Modernization Enhancements in SCALE 6.2," Proc. PHYSOR 2014, Kyoto, Japan.

B. T. Rearden, M. A. Jessee, Eds. 2017. "SCALE Code System," ORNL/TM-2005/39, Version 6.2.2, Oak Ridge National Laboratory, Oak Ridge, TN. Available from the Radiation Safety Information Computational Center as CCC-834.

V. Sobes et al. 2018. "Nuclear Data and Benchmarking Program: Nuclear Data and Covariance Assessment, ENDF/B-VIII.0 Covariance Data Development and Testing Report,” ORNL/TM-2018/1037.

E. E. Sunny and G. Ilas. 2010. "SCALE 6 analysis of HTR-10 pebble-bed reactor for initial critical configuration", PHYSOR 2010 International Conference on Reactor Physics, Pittsburgh, PA.

L. P. Swiler et al. 2017. "Treatment of Nuclear Data Covariance Information in Sample Generation," SAND2017-10632. 


\section{APPENDIX A. Cross section plots}

\section{H-1 elastic scattering}

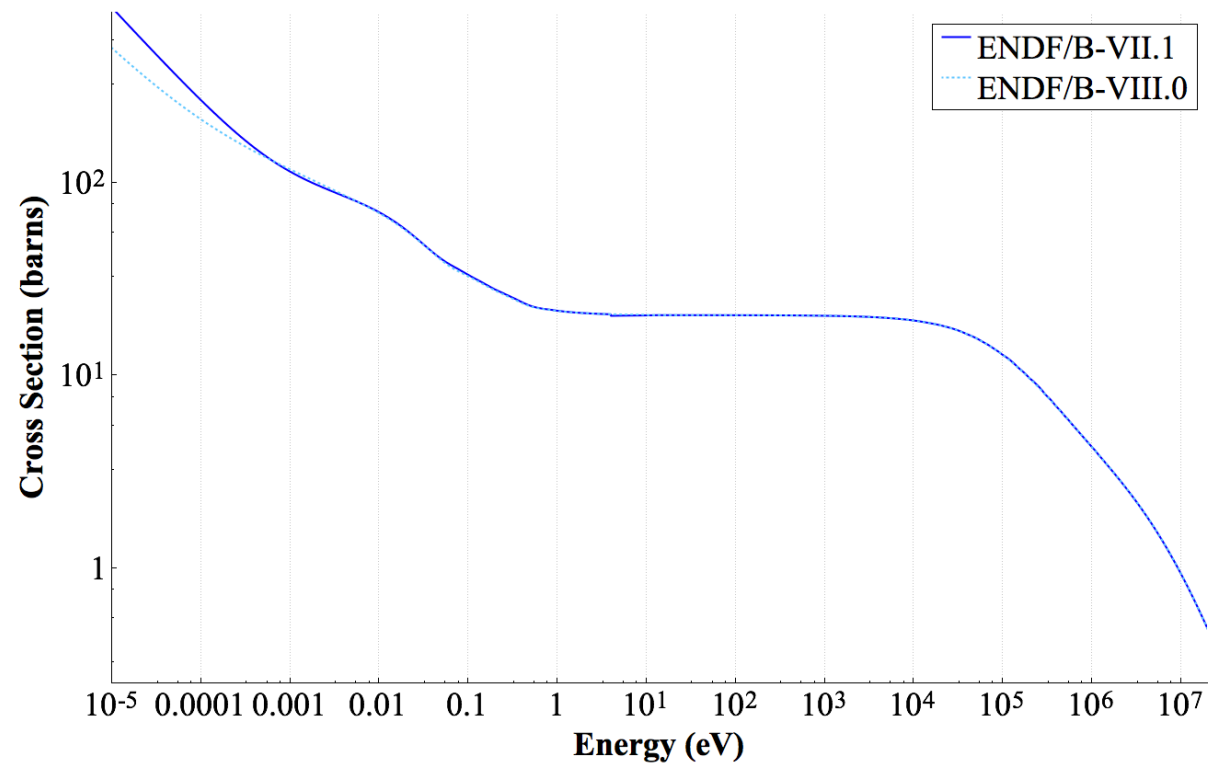

Figure A-1. Elastic scattering of ${ }^{1} \mathrm{H}$ compared between ENDF/B-VII.1 and ENDF/B-VIII.0.

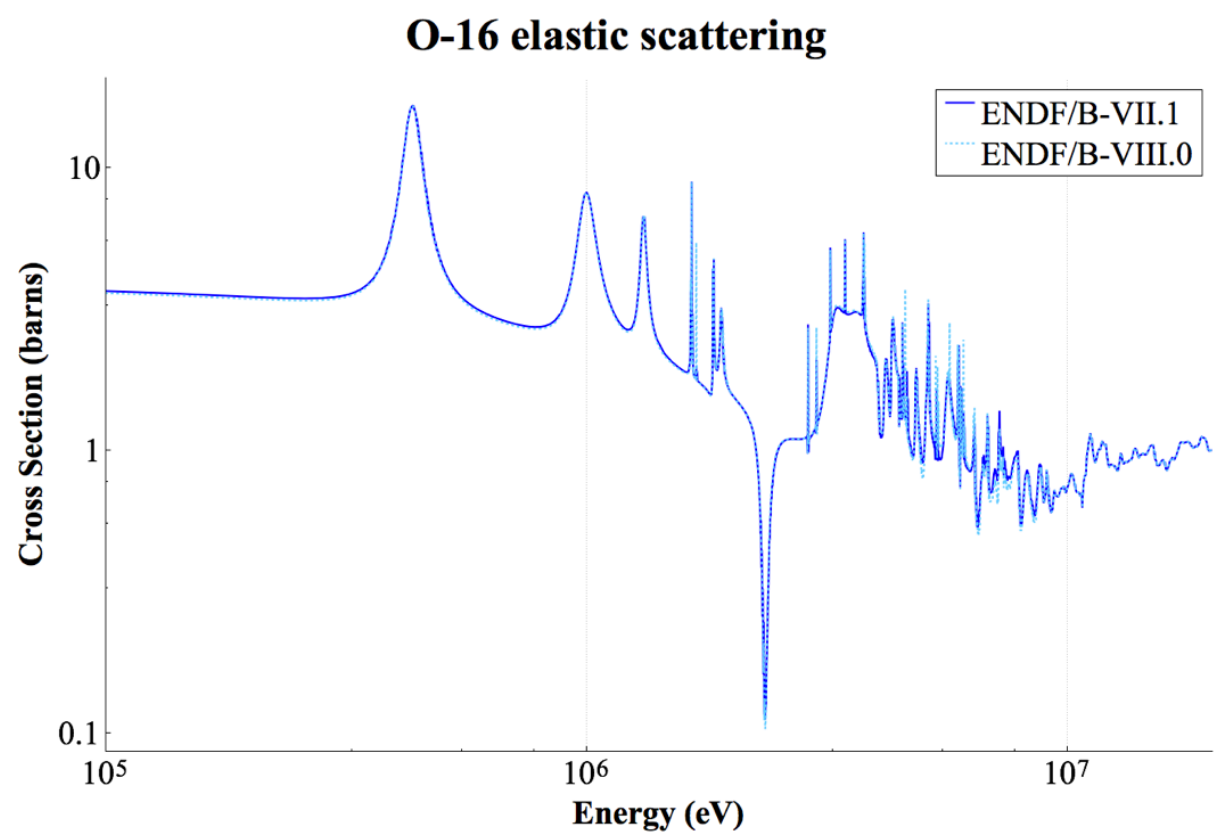

Figure A-2. Elastic scattering of ${ }^{16} \mathrm{O}$ compared between ENDF/B-VII.1 and ENDF/B-VIII.0. 


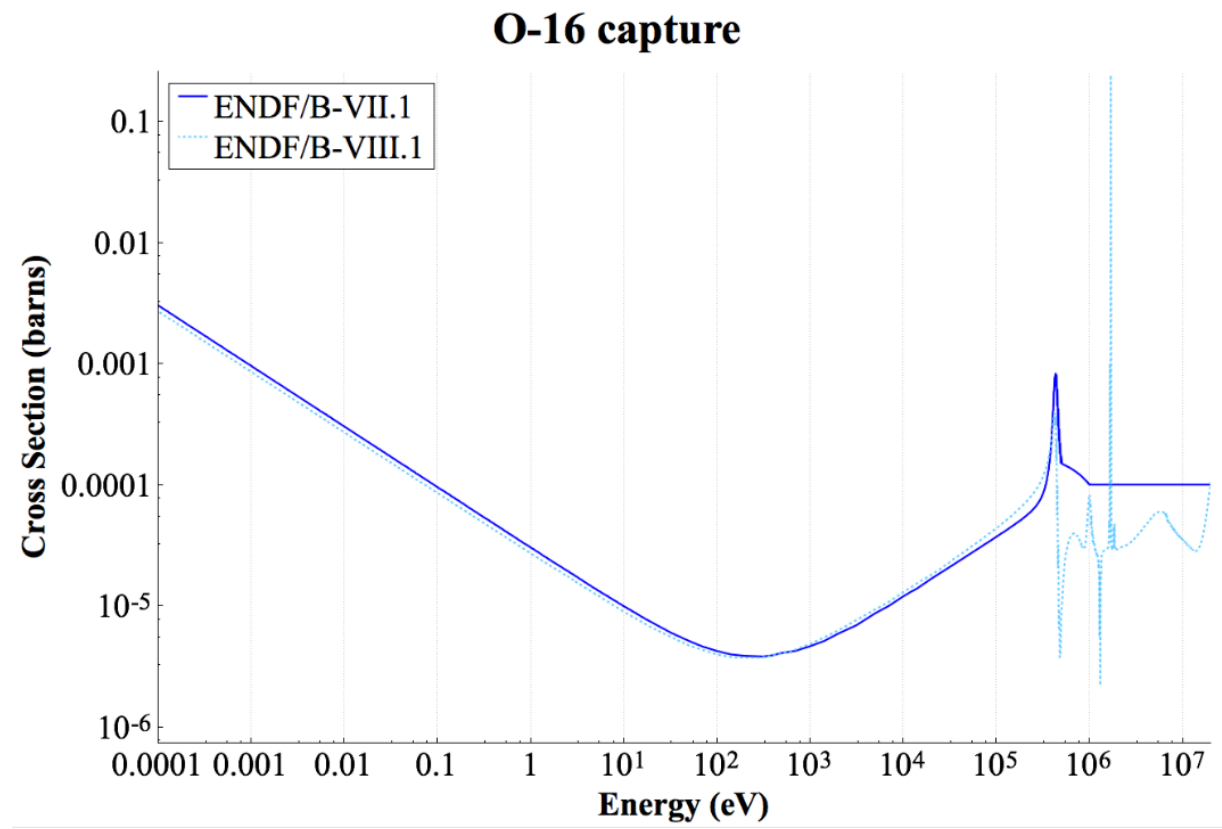

Figure A-3. Radiative capture of ${ }^{16} \mathrm{O}$ compared between ENDF/B-VII.1 and ENDF/B-VIII.0.

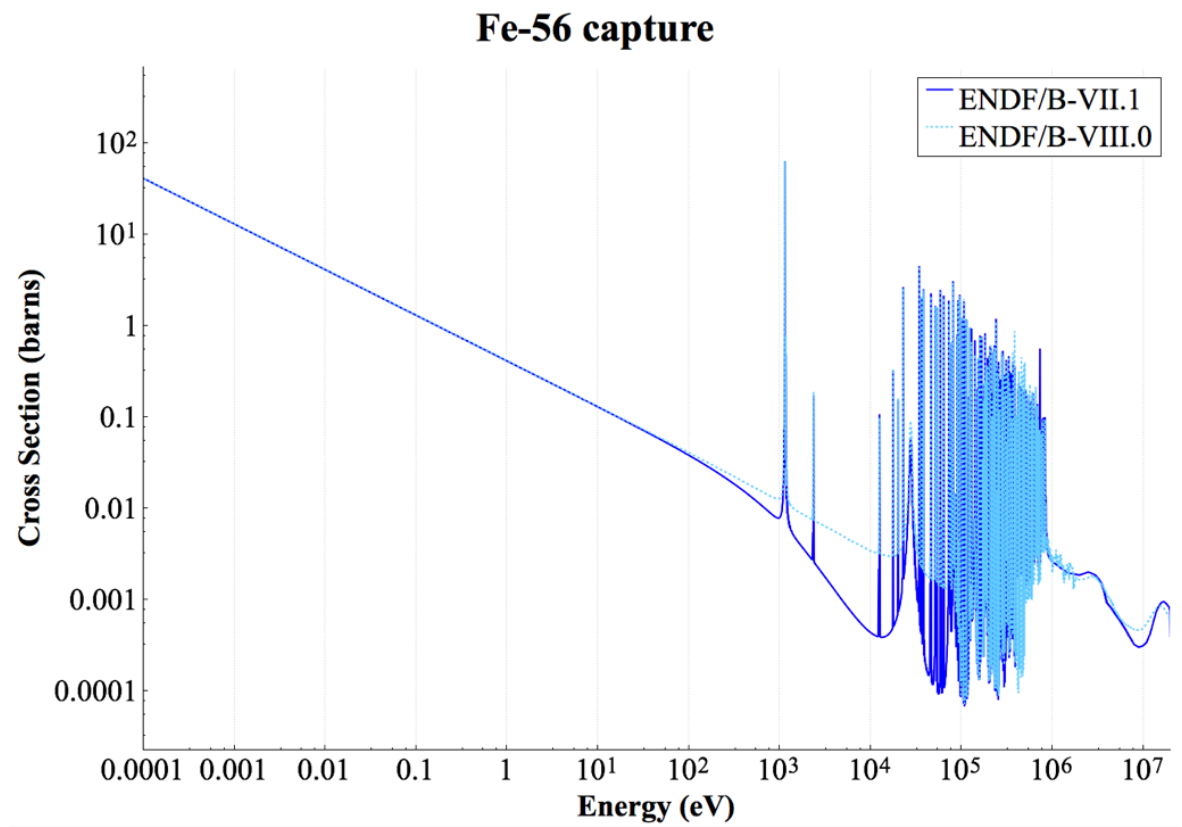

Figure A-4. Radiative capture of ${ }^{56} \mathrm{Fe}$ compared between ENDF/B-VII.1 and ENDF/B-VIII.0. 


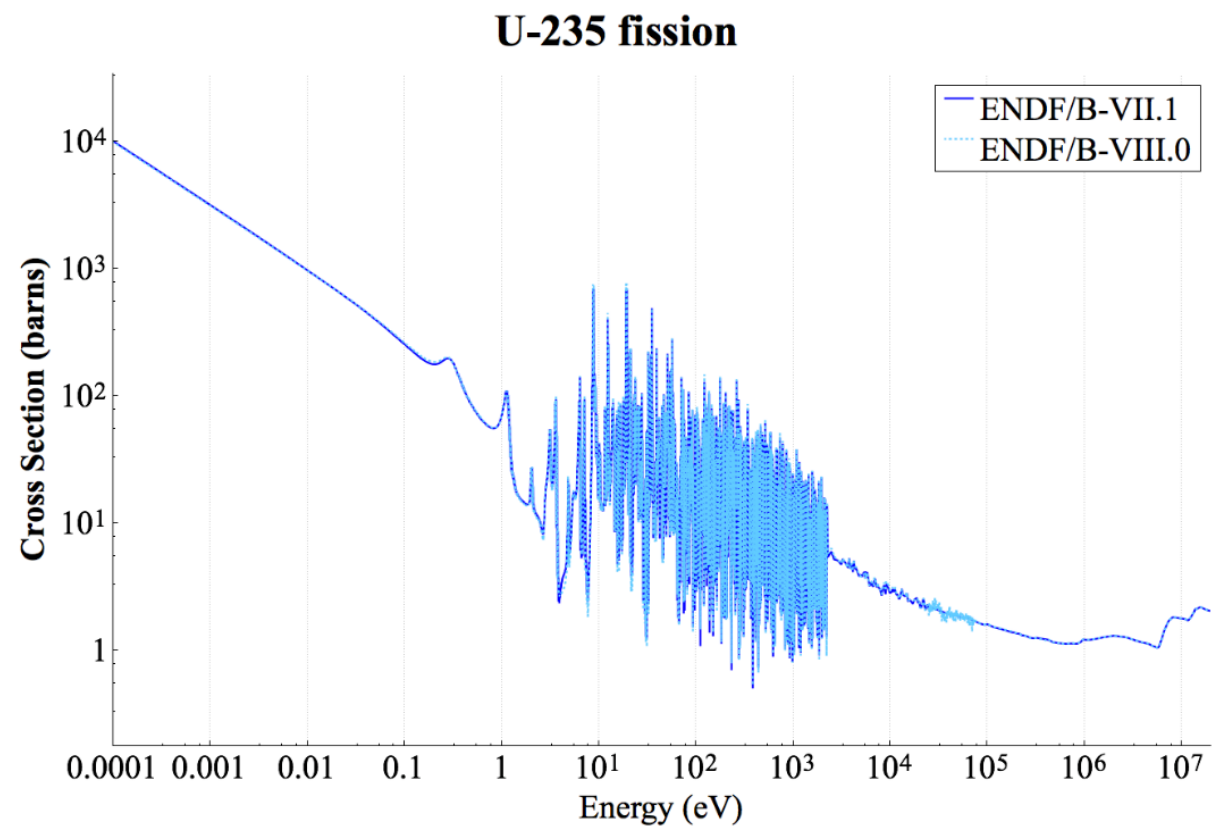

Figure A-5. Fission cross section of ${ }^{235} \mathrm{U}$ compared between ENDF/B-VII.1 and ENDF/B-VIII.0.

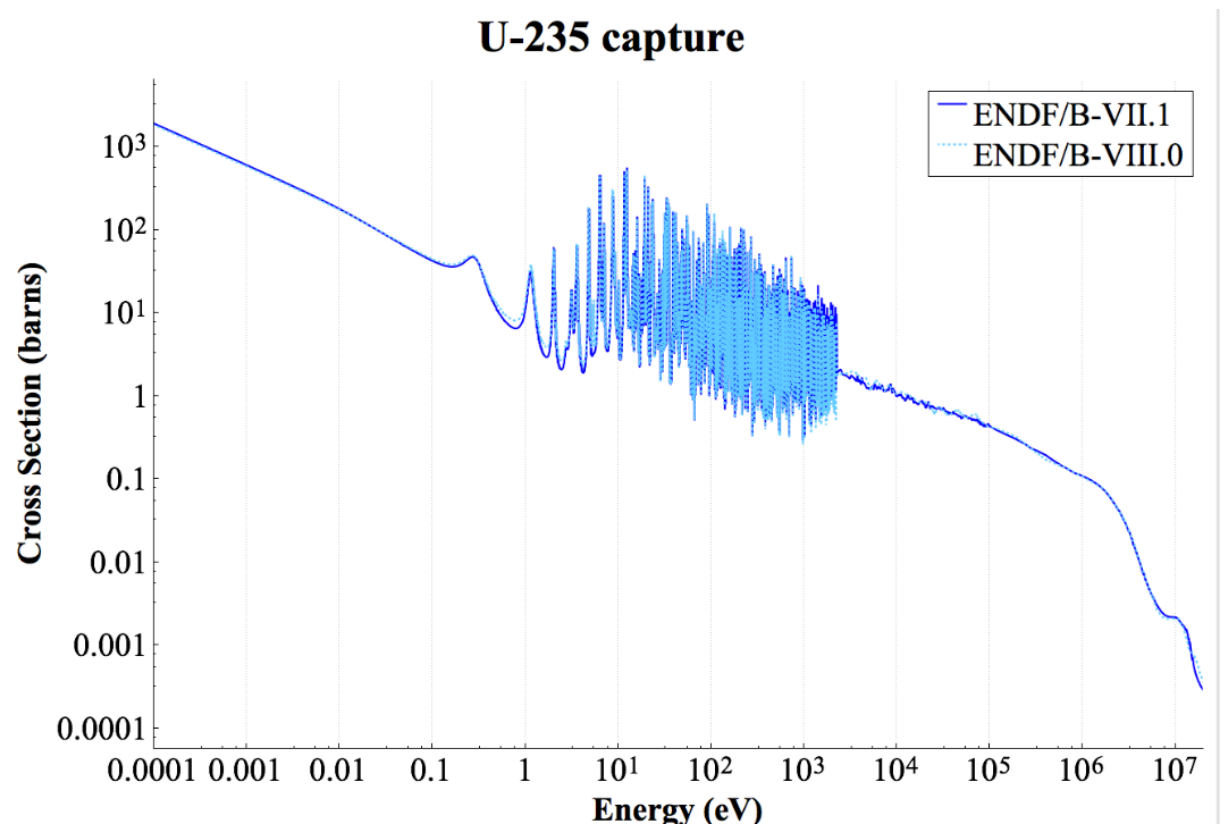

Figure A-6. Radiative capture cross section of ${ }^{235} \mathrm{U}$ compared between ENDF/B-VII.1 and ENDF/B-VIII.0. 


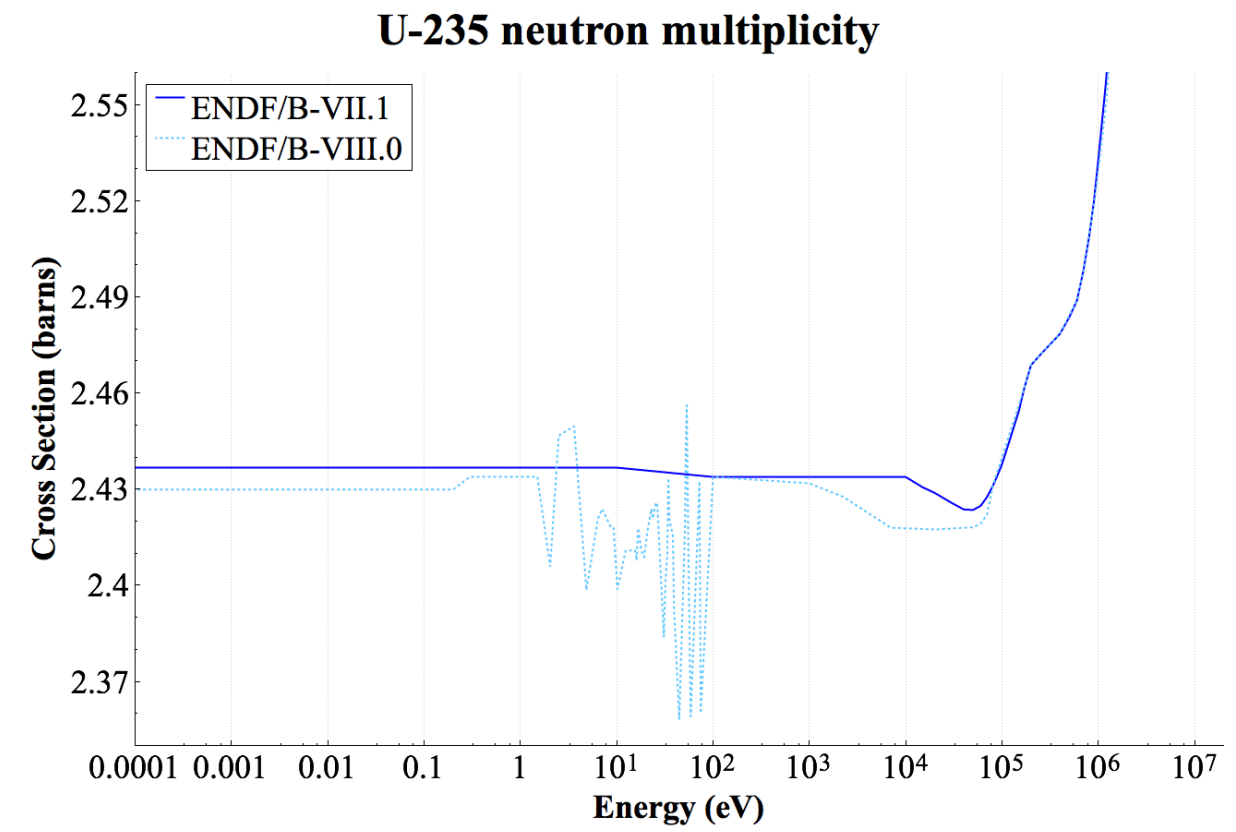

Figure A-7. Neutron multiplicity of ${ }^{235} \mathrm{U}$ compared between ENDF/B-VII.1 and ENDF/B-VIII.0.

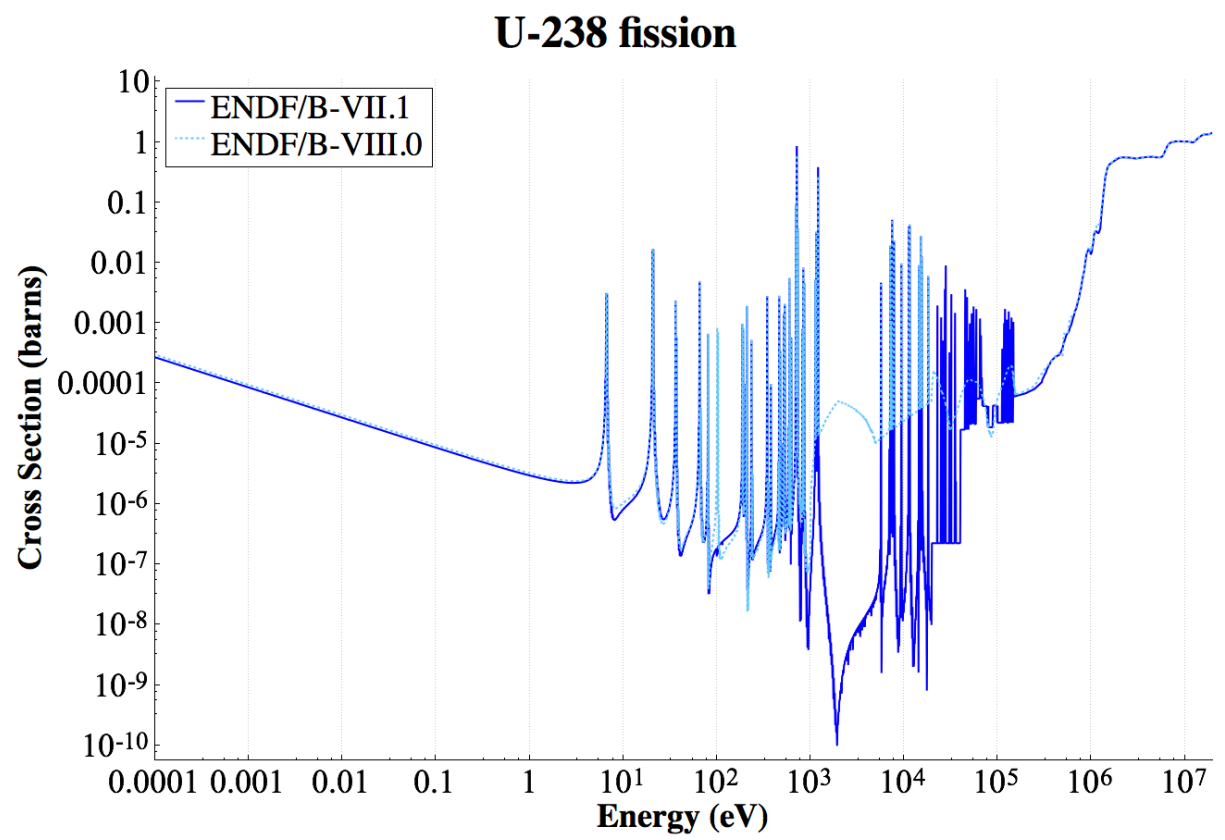

Figure A-8. Fission cross section of ${ }^{238} \mathrm{U}$ compared between ENDF/B-VII.1 and ENDF/B-VIII.0. 


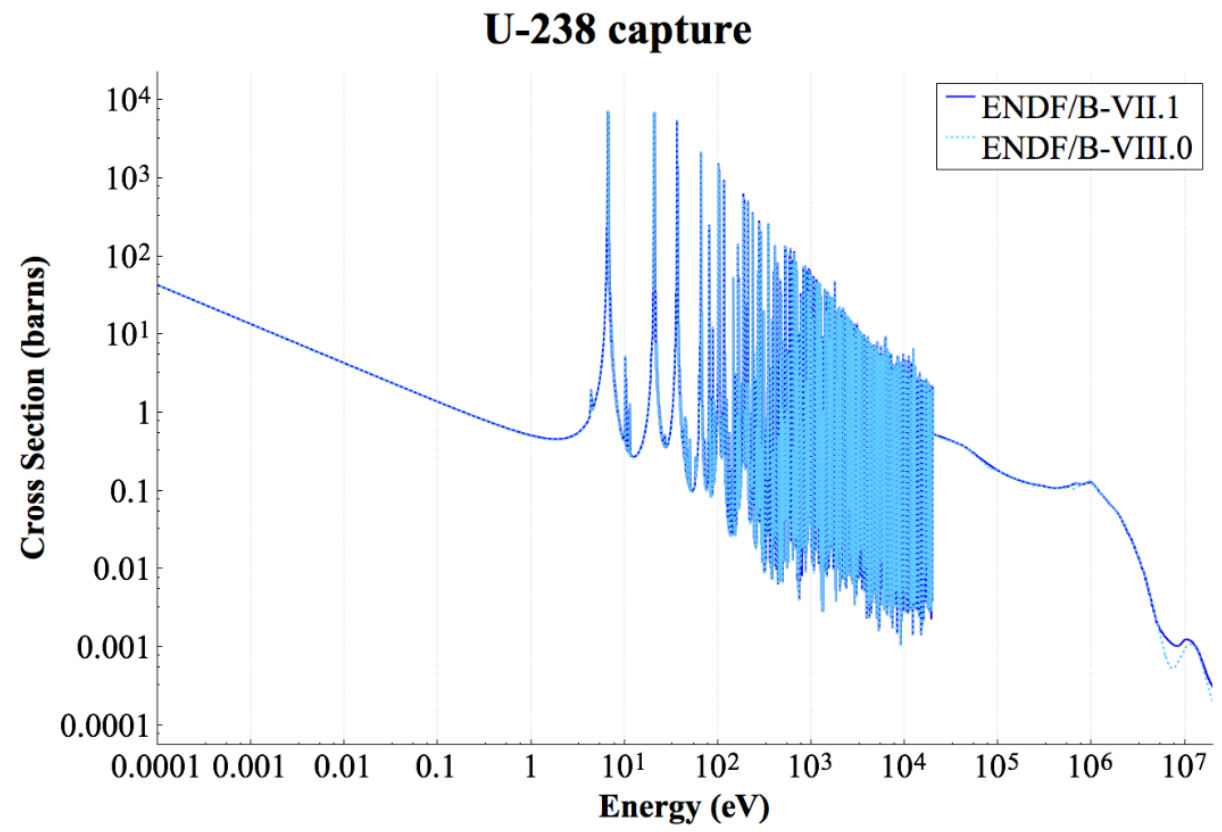

Figure A-9. Radiative capture cross section of ${ }^{238} \mathrm{U}$ compared between ENDF/B-VII.1 and ENDF/B-VIII.0.

\section{U-238 neutron multiplicity}

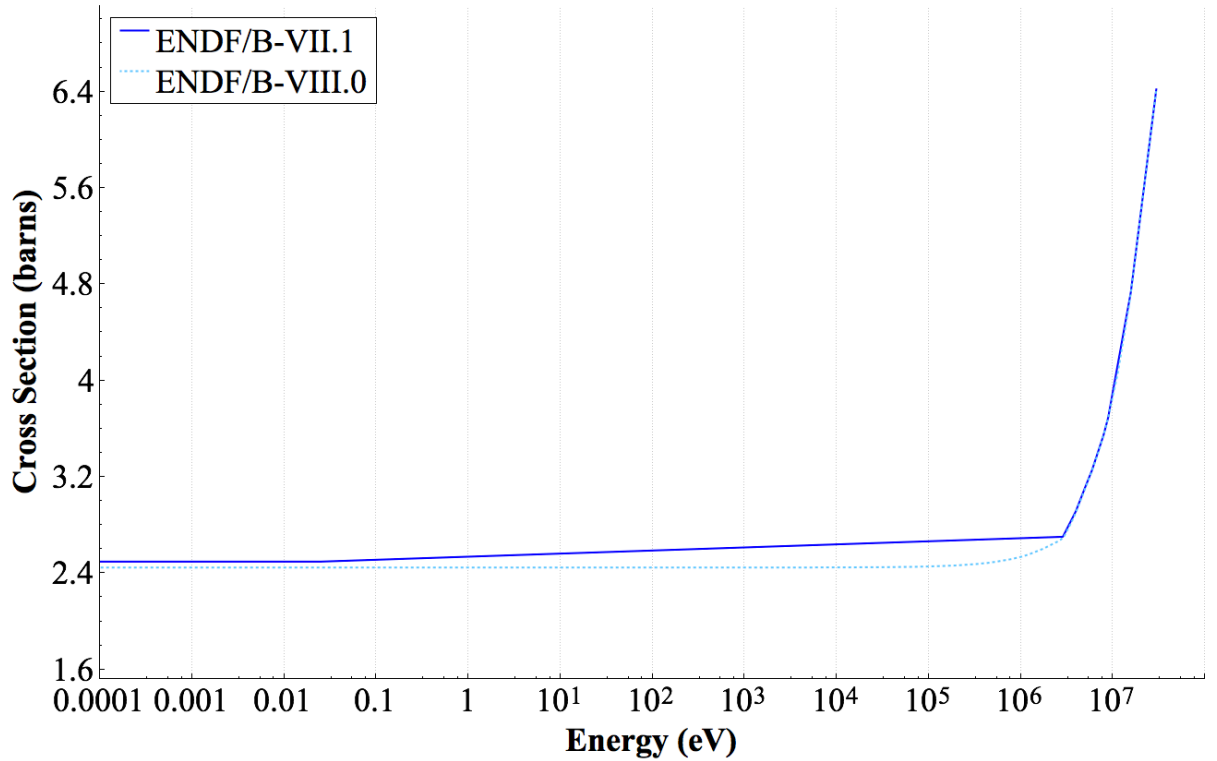

Figure A-10. Neutron multiplicity of ${ }^{238} \mathrm{U}$ compared between ENDF/B-VII.1 and ENDF/B-VIII.0. 


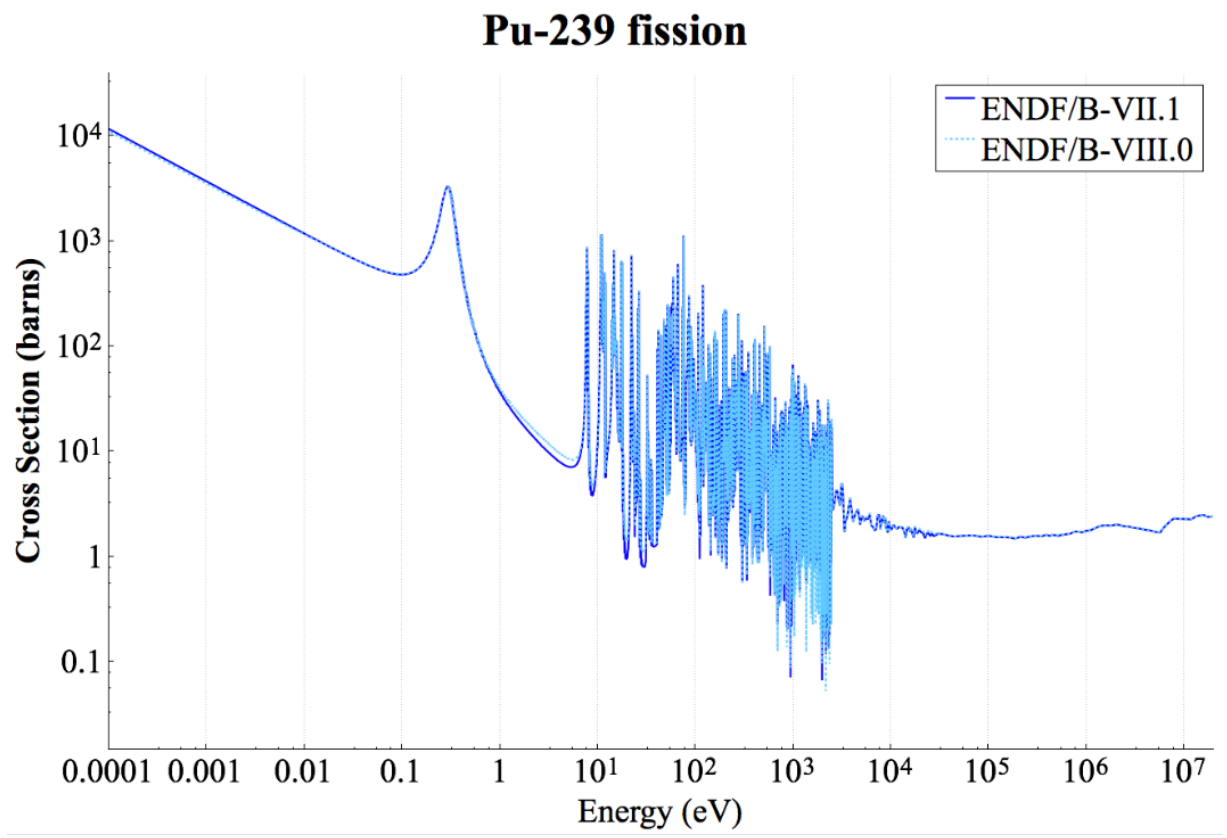

Figure A-11. Fission cross section of ${ }^{239} \mathrm{Pu}$ compared between ENDF/B-VII.1 and ENDF/B-VIII.0.

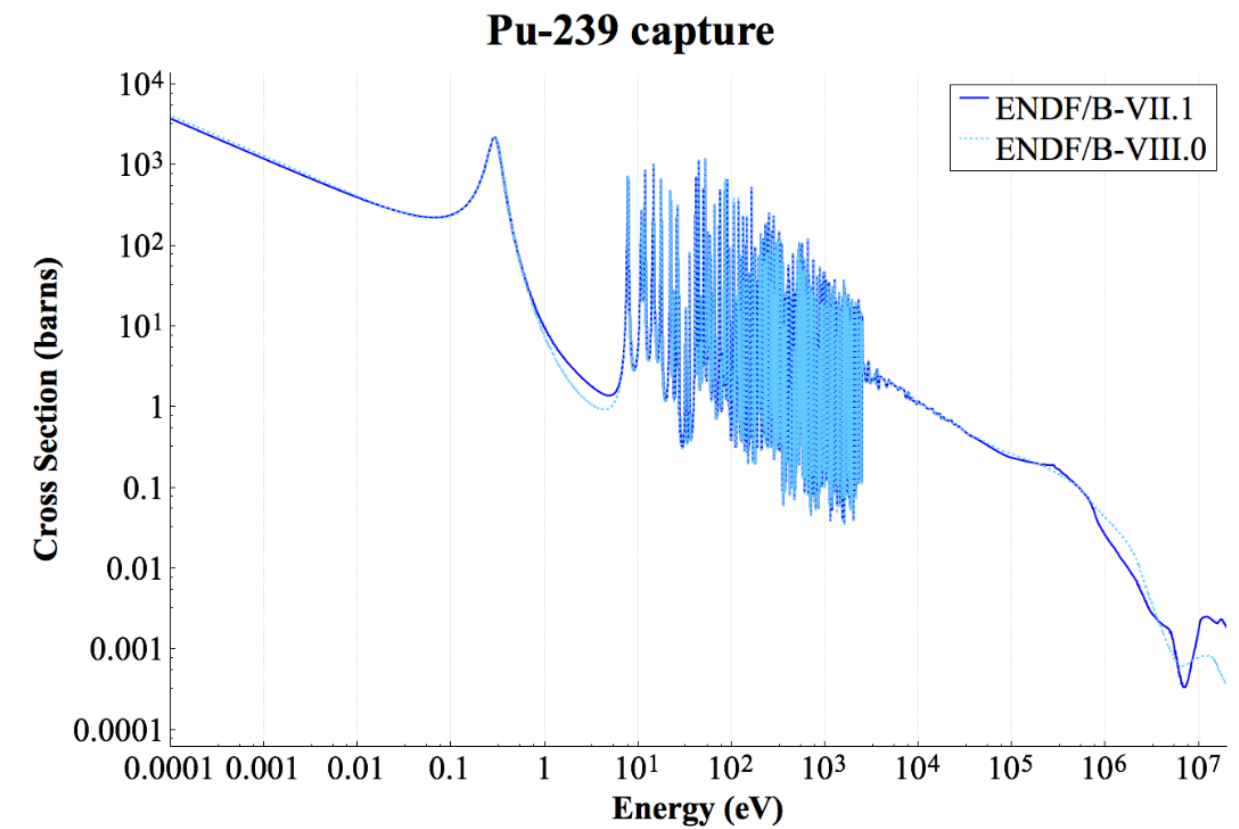

Figure A-12. Radiative capture cross section of ${ }^{239} \mathrm{Pu}$ compared between ENDF/B-VII.1 and ENDF/B-VIII.0. 


\section{Pu-239 neutron multiplicity}

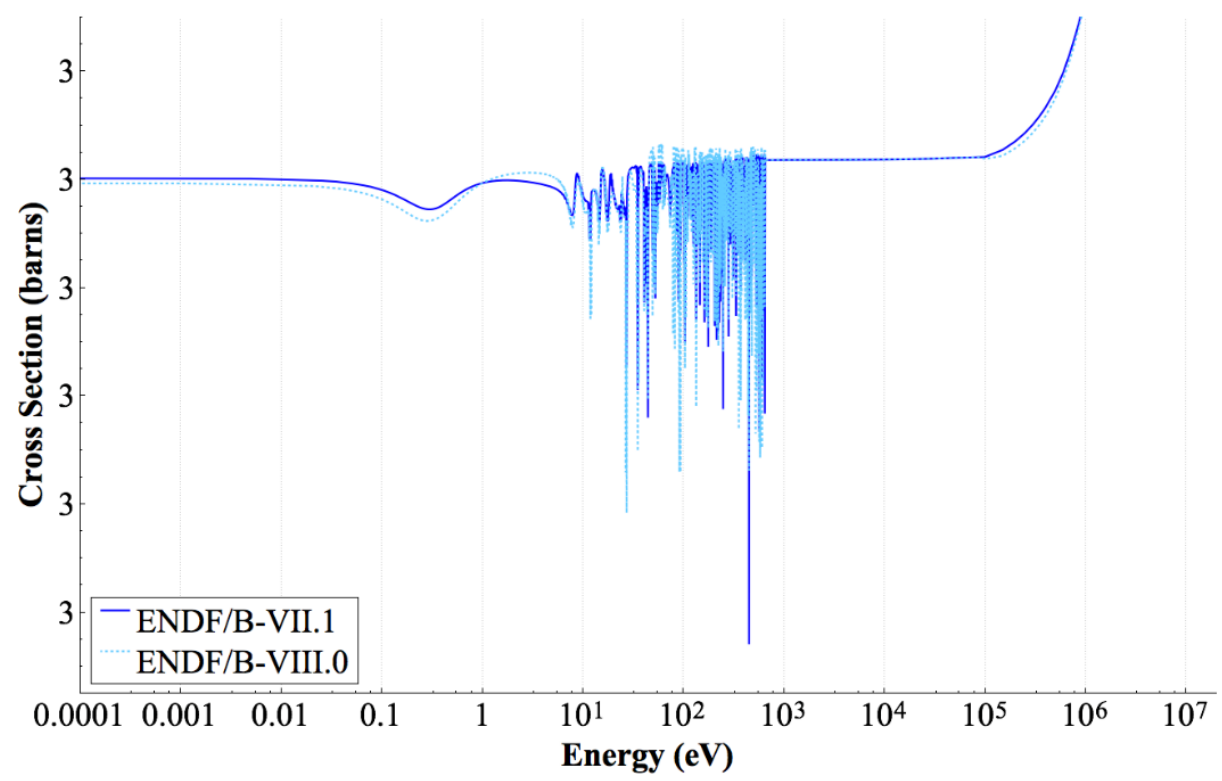

Figure A-13. Neutron multiplicity of ${ }^{239} \mathrm{Pu}$ compared between ENDF/B-VII.1 and ENDF/B-VIII.0.

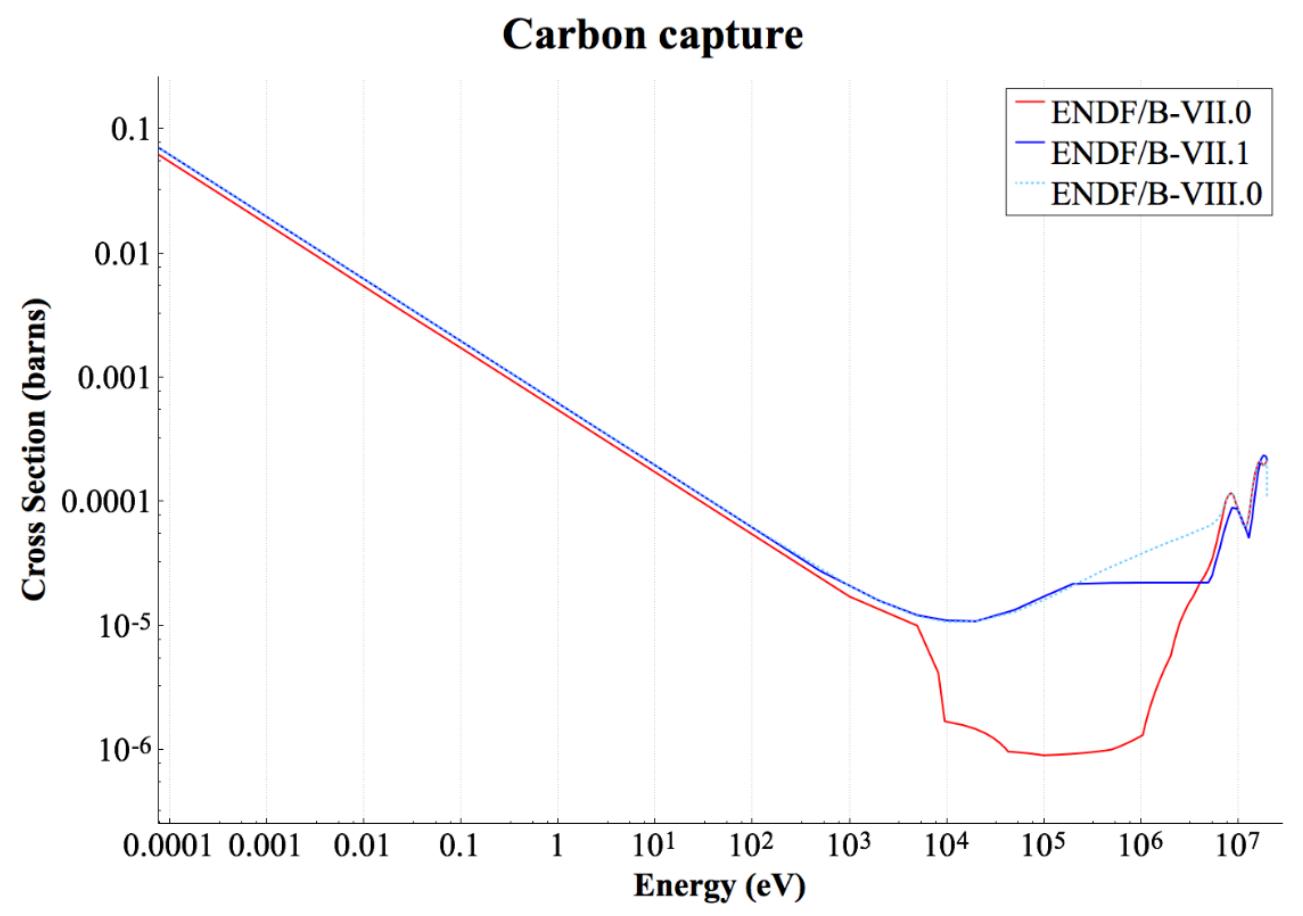

Figure A-14. Carbon capture cross section compared between the ENDF/B releases. 



\section{APPENDIX B. Cross section Uncertainty plots}

Pu-239

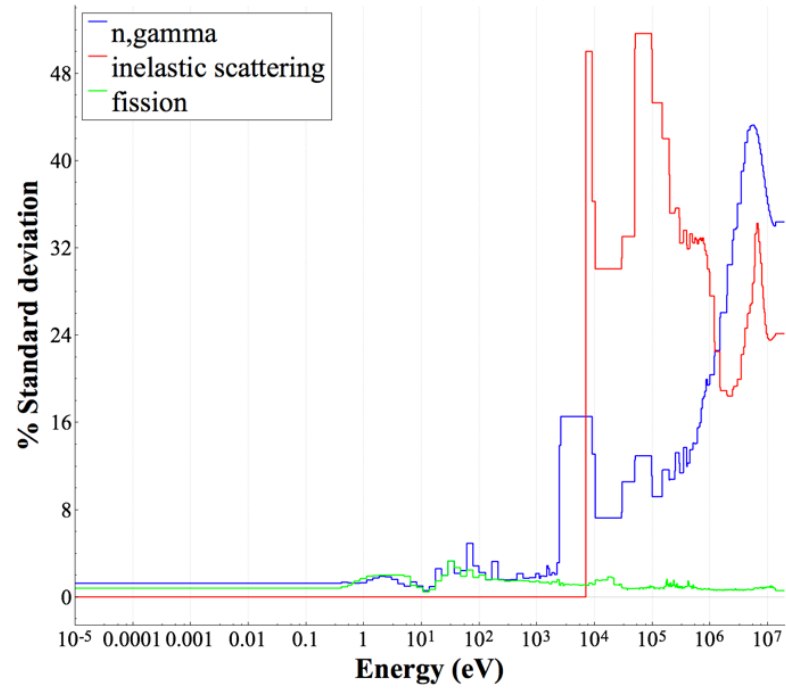

Figure B-1. ${ }^{239} \mathrm{Pu}$ cross section uncertainties.

Na-23

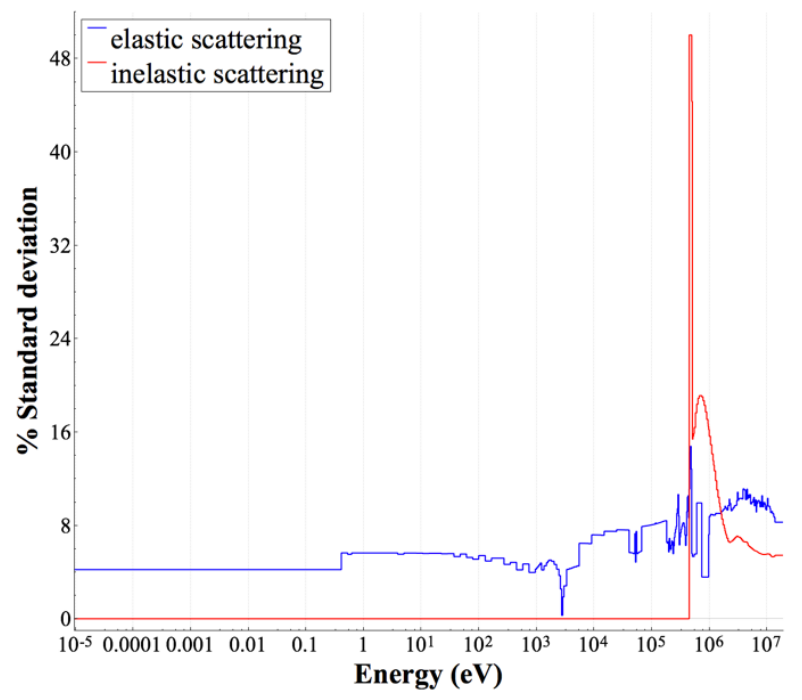

Figure B-3. ${ }^{23} \mathrm{Na}$ cross section uncertainties.
U-238

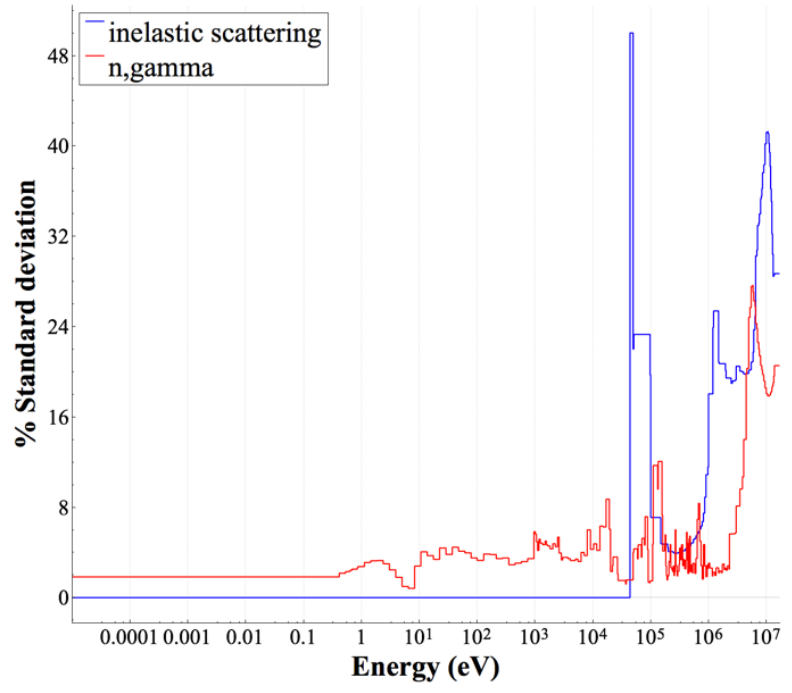

Figure B-2. ${ }^{238} \mathrm{U}$ cross section uncertainties.

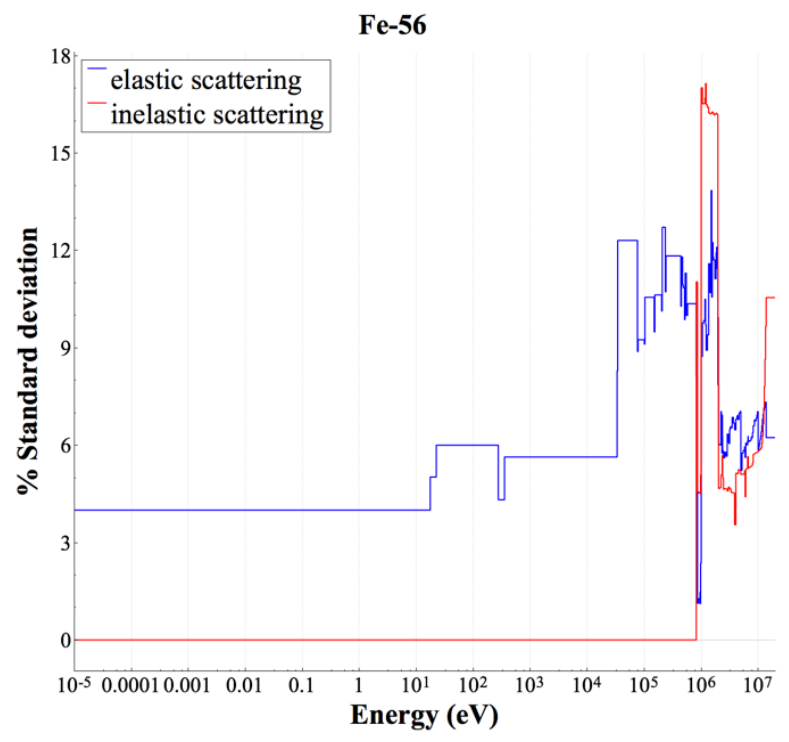

Figure B-4. ${ }^{56} \mathrm{Fe}$ cross section uncertainties. 


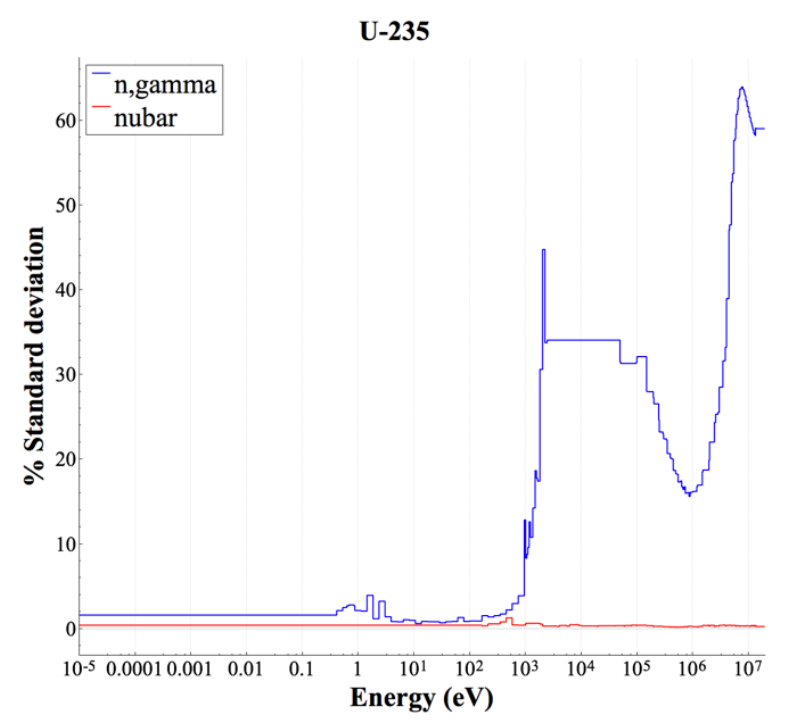

Figure B-5. ${ }^{235} \mathrm{U}$ cross section uncertainties.

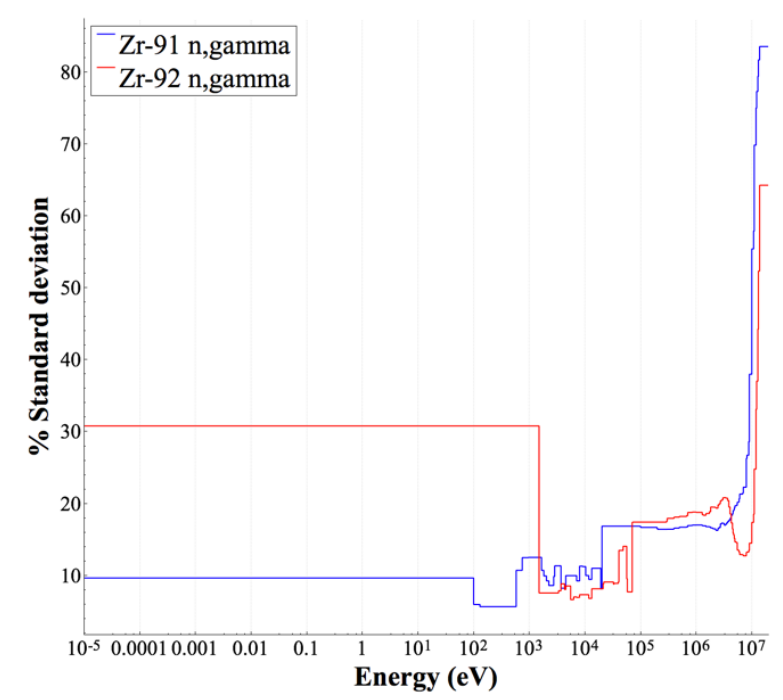

Figure B-6. ${ }^{91} \mathrm{Zr}$ and ${ }^{92} \mathrm{Zr}$ radiative capture uncertainties.

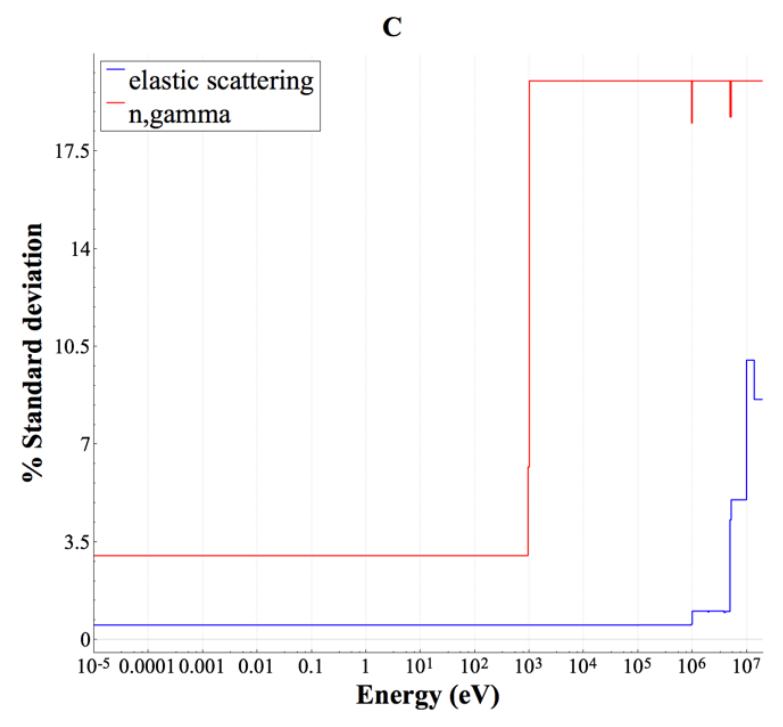

Figure B-7. Carbon cross section uncertainties. 